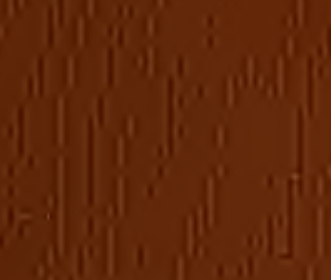




\title{
Monographie der arktischen Acariden.
}

\section{Inaugural-Dissertation}

\author{
Z111 \\ Erlangung (ler Doktorwürde
}

mit Genehmigung der

\begin{abstract}
Mathematisch-Naturwissenschaftlichen Sektion der weitberühmten
Philosophischen Fakultät zu Upsala

zur öfentlichen Beurteilung vorgelegt von

Ivar Trägårdh,
\end{abstract}

Mit 1 Tafel und 133 Figuren im Text.

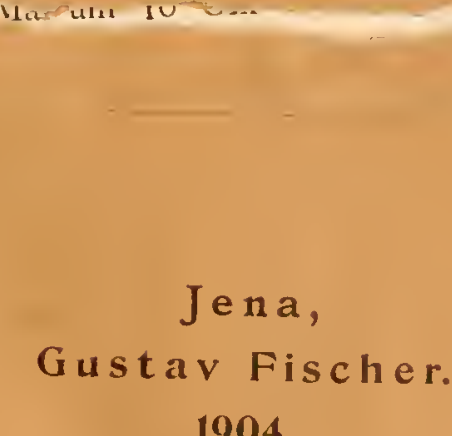

1904. 



\section{Monographie der arktischen Acariden.}

\section{Inaugural-Dissertation}

zur

Erlangung der Doktorwürde

mit Genehmigung der

Mathematisch-Naturwissenschaftlichen Sektion der weitberühmten

Philosophischen Fakultät zu Upsala

zur öffentlichen Beurteilung vorgelegt von

\section{Ivair Trägåroh,}

Mit 1 Tafel und 133 Figuren im Text.

Die Verteidigung wird am 28 Mai um 10 Uhr vormittags im Zoologischen Hörsaale stattfinclen.

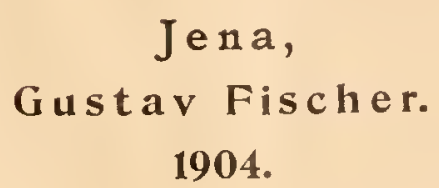





\section{Einleitung.}

Trotzdem die deutsche Expedition in das Nördliche Eismeer im Jahre I898, deren Sammlungen der Fauna arctica zu Grunde liegen, kein Acaridenmaterial heimgebracht hat, übernahm ich die Zusammenstellung der arktischen A cariden, da ich schon vorher beabsichtigt hatte, eine solche herauszugeben.

Die folgende Zusammenstellung ist aber nicht bloß eine Aufzählung der arktischen Acariden, sondern auch eine kritische Revision derselben, die, soweit als möglich, auf Untersuchungen der 'Typen basiert. Schon als ich im Jahre 1900 die von der schwedischen Expedition nach der Bären-Insel im Jahre I899 gesammelten Acariden bearbeitete ${ }^{1}$ ) und dabei durch die Güte des damaligen Intendanten der entomologischen Abteilung des Naturhistorischen Reichsmuseums zu Stockholm, Herrn Prof. Dr. Chr. Aurivillius, einen Teil der Typen der von Thorell ${ }^{2}$ ) aus Grönland, Spitzbergen und der Bären-Insel und von L. KocH ${ }^{3}$ ) aus Sibirien und Novaja-Semlja beschriebenen Acariden zur Vergleichung heranziehen konnte, stellte es sich heraus, daß eine Revision sehr notwendig sei. Das zeigte sich unter anderem auch in der geringen Berücksichtigung, welche die in den Arbeiten THORELL's und L. KocH's beschriebenen Arten in der späteren Litteratur erfuhren, was natürlich darauf beruhte, daß die Beschreibungen und die Abbildungen, wo solche überhaupt vorhanden waren, nicht genügten, um die Tiere mit Sicherheit zu identifizieren und ihre Beziehungen zu anderen Arten zu erkennen.

Ich hielt es daher für notwendig, die Revision über diese sämtlichen Typen auszudehnen; eine vorläufige Mitteilung über das Resultat derselben wurde im Zoologischen Anzeiger ) gegeben. Einige Teile der Revision, nämlich die Revision der Bdella- und der Nothrus-Arten, sind inzwischen schon in anderen Arbeiten ${ }^{5}$ ) ausführlich und unter Benutzung eines beträchtlichen Vergleichsmateriales veröffentlicht worden. Es fehlte mir jedoch ein gutes Material von mehreren Arten, die in den beiden oben erwähnten Sammlungen nur durch ein einziges und oft noch halb ausgetrocknetes Exemplar oder auch gar nicht vertreten waren. Dieser Mangel wurde aber größtenteils beseitigt durch die Güte des Herrn Dr. F. MitneRT, welcher mir

1) Beiträge zur Fauna der Bären-Insel. 5. Die Acariden. Bihang t. Kongl. Sv. Vet.-Akad. Handl., Bd. XXVI, Afd. IV, No. 7. 2) Om Arachnider frăn Spetsbergen och Beeren-Eiland, Öfvers. Kongl. Sv. Vet.-Akad. Handl., 1871, No.6, und Om några Arachnider fri̊n Grönland, ebenda, I872, No. 2.

3) Arachniden aus Sibiıien und Novaja-Semlja. Kongl. Sv. Vet.-Akad. Handl., Bd. XVI, No. 5.

4) Bd. XXV, No. 660 vom 30. Dezember 1901, p. 56-62.

5) Zur Kenntnis der litoralen Arlen der Gattung Bdella. LATk. Bih. t. Kongl. Sv. Vet.-Akad. Handl., Bd. XXVII, Afd. IV, No. 9. - Beiträge zur Kenntnis der schwedischen Acaridenfauna. I. Lappländische Trombidiiden umd Oribatiden. Ebenda, Bd. XXVIII, Afd. 1V, No. 5. 
die im Museum in Kopenhagen befindliche große Sammlung von grönländischen Acariden zur Bearbeitung überließ. Es war mir dadurch möglich, mehrere Arten, die sich vorher jedem Versuch einer Identifizierung entzogen hatten, wiederzuerkennen. Außerdem kann ich aus dieser Sammlung eine ganze Reihe von Arten, welche für die Fauna neu sind, anführen.

Als Resultat der ganzen Revision möchte ich schon hier bezeichnen, daß einerseits die Zahl der wirklich vorhandenen guten Arten unter den bis jetzt aus der Arktis beschriebenen Acariden in einem fast unerwartet hohen Grade reduziert worden ist, andererseits eine ziemlich beträchtliche Anzahl von faunistisch neuen Arten gefunden ist. Diese letzteren sind zum Teil schon aus Europa bekannt oder stehen europäischen Arten sehr nahe. Die Anzahl der endemischen Arten ist somit sehr beträchtlich vermindert worden, dagegen ist die nahe Beziehung zwischen der arktischen und der paläarktischen Acaridenfauna sehr deutlich hervorgetreten.

Das Material zu der vorliegenden Zusammenstellung stammt größtenteils aus dem Nat u r historischen Reichsmuseum zu Stockholm und ist von den folgenden schwedischen Expeditionen heimgebracht worden:

Im Jahre I86I nach der Bären-Insel, von A. E. HoLmGreN,

" " I 868 nach Spitzbergen, von O. Malmgren,

" " " I87 I nach Grönland, von Th. Fries, J. Lindahl, C. Nyström,

" " I 875 nach Sibirien und Novaja-Semlja, von A. E. Nordenskiöld,

" $\quad$ I878-80 von der "Vega"-Expedition in Sibirien und auf der Beringsinsel, von A. E. Nordenskiöld und IV. Stuxberg,

" " 1899 nach der Bären-Insel, von J. G. Andersson und G. Swenander,

" " I 899 nach Jan Mayen und Ostgrönland unter Fülırung von A. G. NAthorst, gesammelt von lic. phil. J. Arwidsson,

" " 1900 nach Lappland, von IVAR TRÄGiRDH,

" " I903 nach Lappland, von lVAR TRÄGÅRDH.

Der übrige Teil des mir zu Gebote stehenden Materiales stammt aus dem Kopenhagener M use um und ist an folgenden Orten gesammelt worden:

Im Jahre 1877 bei Jacobshavn (Westgrönland), von PFAFF,

" " I 885 bei Sermilik und Karsiliak (W.-G.), von Sören Hansen,

" " $\quad 1889$ bei Tasiusak, Arsuk, lpiutat, Nekamiut u. a. Orten (W.-G.),

" " $\quad 1890$ bei Godthaab (W.-G.), von BrummerstedT,

" " 1890 bei Ritenbenk u. a. Orten (W.-G.), von W. Lundbeck,

" " IS9I bei Fredrikshavn (W.-G.), von P. Petersen,

" " I89I bei Cape Steward, Jamesons Land und Rödeö (O.-G.), von Ryder's Expedition,

" " $\quad 1892$ bei Heklahavn auf Island, von Deichmann,

" " 1897 bei Agpiletak, von C. KRUSE.

Außerdem habe ich aus lsland zwei Acaridenpräparate von Prof. FERD. Richters in Frankfurt a. MI. bekommen.

Bei der Bearlseitung habe ich mich besonders darum bemüht, den Unterschied zwischen den arktischen Formen und den zu derselben Art gehörenden oder ihnen am nächsten stehenden paläarktischen so klar wie möglich zu fixieren. Dieses Bestreben hat mich veranlaßt, auch ziemlich unbedeutende Variationen, die ich aber konstant bei den arkischen Formen gefunden habe, mit besonderen Namen zu belegen. Denn wenn 
man sich nur damit begnügt, mehr vorübergehend zu bemerken, daß die Exemplare einer Art aus einer gewissen Lokalität in dieser oder jener Hinsicht von der Hauptform abweichen, so wird diese Angabe leicht von späteren Autoren übersehen. Wenn man aber diese abweichende Form mit einem besonderen Namen bezeichnet, wird sie natürlich leichter in der Litteratur bemerkt, und man wird auf diese Weise mit der Zeit einen Ueberblick über das Variationsvermögen der einzelnen Arten bekommen, was man betreffs der Acariden zur Zeit gar nicht hat. In einigen Fällen ist es mir aus Mangel an Vergleichsmaterial nicht gelungen, zu entscheiden, ob die arktischen Formen von paläarktischen spezifisch verschieden sind oder nicht. Als Beispiel können Rhagidia gelida, Ammonia brevirostris u. a. angeführt werden. Solche Formen habe ich aber so ausführlich beschrieben und abgebildet, daß jeder, der Material von den als eventuelle Synonyme angegebenen paläarktischen Formen hat, leicht meine Arbeit in dieser Hinsicht ergänzen und berichtigen kann. Meistens habe ich auch in den Fällen, wo ich arktische Formen mit paläarktischen identifiziert habe, diese abgebildet, so daß jedermann sich von der Richtigkeit meiner Identifizierungen überzeugen kann, ohne die betreffenden arktischen Formen zu untersuchen.

Sämtliche Figuren, mit einer Ausnahme (Fig. 85), sind mit Hilfe von ABBE's Zeichenapparat von mir selbst gezeichnet.

Betreffs der Angabe der Fundorte ist zu bemerken, daß ich nicht, wenn z. B. eine Art an vielen Orten in Sibirien gefunden ist, alle diese Fundorte anführe, sobald sie schon in der Litteratur vorhanden sind. Wenn die Fundorte aber, was für das grönländische Material gilt, neu sind, habe ich sie sämtlich erwähnt und, wenn möglich, sowohl den Sammler wie die Jahreszahl angegeben. Betreffs der Synonymieangaben ist zu bemerken, daß meistens nur solche Synonyme aufgenommen sind, die in dem Text behandelt werden.

Die pflanzenparasitischen Phytoptiden sind in dieser Arbeit nicht behandelt, da mir kein Material von ihnen zur Verfügung stand und ich mich außerdem nicht mit dieser Familie beschäftigt habe. Sie sind in arktischen Gegenden nur aus Grönland durch eine Arbeit von Rostrup I) bekannt.

Bei der Abgrenzung des in Betracht zu ziehenden Gebietes habe ich die pflanzengeographische Grenze, die die Nordgrenze des Baumwuchses bezeichnet, angenommen. Isolierte Gebiete, die sich oberhalb dieser Grenze befinden, wie z. B. Lappland, sind aber nicht mitherangezogen, sondern nur vergleichungsweise berührt, denn wenn sie auch einige Arten, die bis jetzt nur in arktischen Gebieten gefunden sind, wie Oribata lucens und 0 . cuspidata var. bivulai, beherbergen, so zeigt sich doch im allgemeinen ihre Acaridenfauna durch ihren Reichtum an Formen von der rein arktischen zu verschieden, um hier behandelt zu werden.

Die Nordgrenze des Baumwuchses ist natürlich eine mit Rücksicht auf die Acariden vollsommen willkürlich gewällte und künstliche Grenze, da diese Tiere zufolge der Anspruchslosigkeit der für ihr Gedeihen notwendigen Existenzbedingungen von der Zusammensetzung der Pflanzenwelt, insoweit diese von dem Vorhandensein oder der Abwesenheit von Bäumen abhängt, ganz unabhängig sind.

Es hat sich aber als unmöglich erwiesen, auf der Basis unserer jetzigen Kenntnisse von der Verbreitung der Acariden in den zu der Arktis gehörenden Gebieten eine natürliche Abgrenzung des Gebietes aufzustellen. Ich bin der Meinung, daß sich eine solche für die Acariden überhaupt nicht ziehen läßt. Da aber die auf Acariden hin untersuchten nördlichen Lokalitäten sämtlich in Gebieten liegen, die aus allgemeinen ptlanzengeographischen Gesichtspunkten als arktisch bezeichnet werden müssen, so ist die Frage, ob und in diesem Fall wo die natürliche Grenze der arktischen Acaridenfauna verläuft, für uns von keiner aktuellen Bedeutung.

1) Sophie Rostrup, Gronlandske Phytoptider, Vidensk. Meddel. Naturh. Foren, Kjobenhavn, 1900, p. 241 .-249. 


\section{Historisches.}

Der erste, welcher Acariden aus arlitischen Gebieten beschrieben hat, ist O. FABRicius, der I770 in seiner „Fauna Groenlandica" 9 Arten und eine Varietät für Grönland angiebt, die er ohne Ausnahıne mit skandinavischen, von LiNNÉ ${ }^{1}$ ) und MÜLLER ${ }^{2}$ ) beschriebenen Arten identifiziert. Es sind dies folgende Arten: Acarus siro, A. siro var. farinae, A. cadrverum, A. holosericens, A. aquaticus, A. muscorum, A. gymnopterorum, A. coleoptratorum, A. longicornis und A. littoralis.

Da es aber in den meisten Fällen unmöglich ist, mit irgend welchem Grade von Sicherheit zu ermitteln, welche Species sich unter diesen Namen verbergen, und noch dazu ein Teil der LINNÉschen Namen sicherlich Kollektivnamen sind, isı es klar, daß man kein Gewicht auf die von Fabricius vorgenommenen Identifizierungen legen kann.

Einige Verfasser, wie Thorell ${ }^{3}$ ) und Trouessart ${ }^{4}$ ), die Gelegenheit hatten, kleinere Kollektionen von arktischen, speciell grönländischen Acariden zu untersuchen, haben auch in einzelnen Fällen gezeigt, daß FABRICIUS sich geirrt hat.

Die bis dahin zusammengebrachten Sammlungen waren aber zu klein, um Identifizierungen mit wirklichem Erfolg möglich zu machen. Erst die jetzt von mir untersuchten Kopenhagener Sammlungen legen einen festen Grund für Identifizierungsversuche. Es ist mir auch gelungen, die meisten der von Fabricıus erwähnten Arten zu deuten, und ich teile der Uebersichtlichkeit halber schon hier diese Identifizierungen mit, anstatt sie unter den betreffenden Arten zu behandeln.

Acarus siro ist, wie schon von THORELl hervorgehoben wurde, mit Sarcoptes scabiei (GeER) identisch. Man könnte allerdings auch an S. scubicicrustosuc FürST. denken, die in Norwegen, Deutschland und Frankreich gefunden ist und die sog. norwegische Krätze verursacht. Die von Fabricıus gegebene Diagnose paßst freilich gar nicht auf eine Surcoptes-Art: „Acarus lateribus sublobatis, pedibus quatuor posticis longissimis, femoribus capiteque ferrugineis, abdomine setoso", sondern vielmehr auf ein Vogelsarcoptide; was er aber über ihre Biologie mitteilt, deutet mit Bestimmtheit auf eine Sarcoptes-Art.

Die von Fabricius erwähnte Varietät, die er jedoch zusammen mit seinem Mehlvorrat importiert zu haben glaubt, identifiziert Thorell mit Aleurobius farinae (GEER). Es kann aber auch Tyroglyphus siro sein, den ich aus Grönland besitze, denn beide Arten kommen ebenso häufig in Melıl vor. Es ist aber wenigstens vom tiergeographischen Standpunkte zienlich gleichgültig, welche von den Arten Fabricius gemeint hat, denn beide Arten sind kosmopolitisch.

Acarus cadaverum, welcher in folgender Weise charaliterisiert wird: „Acarus albus ovatus, setis raris, pedibus posticis brevissimis" und auf getrockneten Fischen gefunden ist, steht nach Fabricius der vorigen Art sehr nahe (praecedenti affinis). Trouessart rechnet sie daher der Gattung Tyroylyphus oder Rhyzoglyphus zu. Da in den Kopenhagener Sammlungen keine an solchen Orten gefundenen Acariden sich befinden, ist es unmöglich, über diese Art ins Klare zu kommen. Man könnte möglicherweise an Urosejus acuminatus denken, der von der "La Manche"-Expedition auf Spitzbergen auf einem Renntiercranium gefunden wurde. Es ist aber, wie Trouessart ${ }^{5}$ ) hervorhebt, die Möglichkeit nicht ausgeschlossen, daß diese

1) Systema Naturae, Editio decima, 1758.

2) Zoologiae Danicae Prodromus, 1776.

3) 1. c. p. $148-149$.

4) Revision des Acariens arctipues. Soc. Nat. d. Sciences nat. et math de Cherbourg, Tome XXIX, I892-95, p. I8.4.

5) Note sur les Acariens recueillis au Spitzberg pendant le voyige de la Manche. Archive Missions Scientifiques, ISy3, Tome V, p. 255-263. 
Art später in das Cranium hineingelangt ist. Sie ist sonst nie in den arlatischen Gebieten beobachtet. Für meinen eigenen Teil bin ich sehr geneigt, die FABricius'sche Art als eine Kollektivart anzusehen, die verschiedene kleine Gamasidenlarven und -nymphen ${ }^{1}$ ) einschließt. Denn ich bin der Ansicht, wenn es wirklich eine Rhyzoglyplıus- oder eine Tyroglyphus-Art wäre, so hätte man gewiß nicht schon im Jahre I770, als die Acaridenkunde noch so im Argen lag, diese kleine Art von Aleurobius farinae unterscheiden können, sondern einfach mit dieser identifiziert.

Acarus holosericeus, dessen Diagnose lautet: „Acarus abdomine cordiformi tomentoso, pedibus primis longioribus", wird von Trouessart ${ }^{2}$ ) mit Trombidium holosericeum identifiziert. Diese Bestimmung ist ohne Zweifel unrichtig, denn ich wage zu behaupten, daß diese Art sich gar nicht auf Grönland wie überhaupt nicht in arktischen Gebieten findet. Sie kommt nämlich in den Kopenhagener Sammlungen gar nicht vor. Die Gattung Trombidium wird auf Grönland statt dessen unter anderen von einer ziemlich großen Art vertreten, auf die die Diagnose viel besser als auf holosericeum paßt, nämlich T. bicolor, die ich von mehreren Stellen besitze. Diese Art ist diejenige von den Trombidium.Arten, welche die relativ längsten Vorderbeine besitzt, was gut zu "pedibus primis longioribus" in der Diagnose paßt. Es kann somit kein Zweifel darüber bestehen, daß Fabricius unter dem Namen A. holosericeus Trombidium bicolor beschrieben hat.

Acurus muscorum ist durch die Diagnose: "Acarus abdomine rufo, pedibus posticis longissimis filiformibus" leicht kenntlich. Es kann nur Erythraeus phrelangioides var. gracilipes sein, welcher auf Grönland ungemein häufig vorkommt. Daß diese Art auch zu FABrıcıus' Zeiten häufig war, beweist der Umstand, daß die Grönländer nach ihm dem Tierchen einen besonderen Namen „Merkub-lioma“ gegeben hatten.

Acarus aquaticus. Diese Art dürfte wohl mit der einzigen bis jetzt in arktischen Gegenden gefundenen Hydrachnide, Lebertia falricii THOR, identisch sein.

Acarus littoralis. "A. fusco-rufus, pedibus sanguineis". In einer vorigen Arbeit ${ }^{3}$ ) habe ich gezeigt, daß diese Identifizierung von FABRıcıus richtig ist und daß die Art der Gattung Edella angehört. Ich verweise auf die in dieser Arbeit gelieferte ausführliche Darstellung und will hier nur erwähnen, daß die Art von TROUESSART unrichtigerweise mit Erythraeus miniatus var. muripes identifiziert wird. Diese letztere Art habe ich nicht in der Kopenhagener Sammlung gefunden, während dagegen B. littornlis von zahlreichen Lokalitäten vorhanden ist.

Acarus longicornis. „A. abdomine oblongo rubro, antennis apice bisetis", ist, wie schon von THORELL hervorgehoben wurde, eine andere Bdell $t$-Art als die, welche von $\mathrm{C}$. KocH und anderen Autoren mit dem Namen longicornis (L.) bezeichnet ist. ThORELL spricht die Vermutung aus, daß sie mit seiner B. arctiea identisch sei. Diese letztere ist aber, wie ich in meiner oben zitierten Abhandlung gezeigt habe, mit B. littoralis (L.) identisch. Die Diagnose, ,antennis apice bisetis" paßt ja außerdem gar nicht auf B. arctica, dagegen stimmt sie sehr gut sowohl mit derjenigen von $B$. decipiens Thor. als auch mit $B$. groentandica und Ammonir brevirostris L. Koch, die in den mir zur Verfügung stehenden Sammlungen aus Grönland vorhanden sind. In der ausführlicheren Beschreibung von A. longicormis findet sich glücklicher Weise eine Angabe der Länge, die uns deutlich sagt, welche von diesen Arten gemeint ist. A. longicornis mißst nämlich $1 / 3$ lin. in der Länge, was ungefähr $0,7 \mathrm{~mm}$ entspricht. Dieses Maß schließt $B$. deciniens THor. aus, welche ungefähr 1,5 mm lang ist, und weist deutlich auf Ammonia brevirostris L. KocH, die ungefähr o,5 mm mißt, und auf $B$. groenlandica, die ungefähr $0,7 \mathrm{~mm}$ lang ist. Letztere, die auf Grönland allgemeiner vorzukommen

1) Diese kommen nämlich häufig auf modernden Substanzen vor.

2) 1. c. Revision etc., p. 199.

3) 1. c. Z. Kenntn. etc., p. 5 . 
scheint, identifiziere ich aus Gründen, die ich bei der Beschreibung dieser Art näher auseinandersetzen werde, mit $A$. longicornis.

Acarus coleoptratorum. Es wäre einfach unmöglich, aus der kurzen Diagnose: „Acarus rufus, ano albicante" zu ermitteln, welche Art FABRıcıus mit diesem Namen gemeint hätte, wenn sich nicht außerdem eine kleine Notiz „Hanc non in coleoptratis, sed in ape alpina reperi“ vorfände. Da in den Kopenhagener Sammlungen Exemplare von Parasitus bomborum Oud. sind, die auf „hŭmle“ (= Apis sp.) gefunden wurden, so wird man mit großer Sicherheit annehmen können, daß A. coleoptratorum FABR. mit dieser Art identisch ist. Die von $\mathrm{KRAMER}^{1}$ ) gemachte Identifizierung mit Gamasus colcoptratorum ist völlig unrichtig und ebenso die von Trouessart ${ }^{2}$ ) gemachte Identifizierung mit Gamasus fucorum (DE GEER).

Acarus gymmopterorum, „A. abdomine rubro, lateribus punctis binis coccineis", wird von TrouEsSART mit der Larve von Trombidium gymnopterorum identifiziert. Der Fundort, eine Fliege, Musca scybalaria, giebt eine, wenn auch schwache, Andeutung, denn mehrere Acariden sind auf grönländischen Fliegen gefunden worden, wie z. B. Zercon triangularis auf einer Anthomyi-Art und Trombidiiden- und GamasidenLarven. Die Farbenangabe in der Diagnose spricht jedoch zu Gunsten der Trombidiiden-Larven. Welcher von den aus Grönland bekannten Tromlidium- oder Erythraeus-Arten sie zugerechnet werden muß, ist aber natürlich unmöglich zu ermitteln. Daß es jedenfalls nicht die Larve von Trombidium gymmopterorum sein kann, geht daraus hervor, daß diese Art nicht auf Grönland vorkommt.

Aus Fauna Groenlandica schöpfen die späteren Autoren, die Acariden aus arktischen Gebieten erwähnen, und alle werden von ihnen mit den FABricius'schen Arten olıne weiteres identifiziert. So giebt MoHR ${ }^{3}$ ) für Island folgende Arten an: A. siro, calluverum, longicomis, litloralis, muscurum und uquaticus. A. longicornis und littoralis sollen auf den Steinen am Ufer sehr allgemein vorkommen. A. muscarum wurde auf Fliegen gefunden. A. aquaticus ist rot und findet sich in stagnierendem Wasser. Wenn es schon bei den FABRICIUsschen Arten eine heikle Sache war, ins klare zu kommen, so ist es natürlich noch schwieriger, zu kontrollieren, ob MoHR's Identifizierungen richtig sind ${ }^{4}$ ). Denn die Acaridenfauna von Island ist viel ungenügender bekannt als diejenige von Grönland. Acarus siro und littoralis sind jedoch zweifelsohne dieselben wie die FABricius'schen Arten, denn Bdella littoralis findet sich unter den von DeICHnANN I892 bei HeklaHavn gemachten Sammlungen. $I 824^{5}$ ) werden dieselben Arten ohne irgend welche Notizen für Island angegeben.

I850-5 I $^{6}$ ) wurden von P. S. Sutherland auf der Cornwallis-Insel 2 Acariden gefunden, die von A. White unter den Namen Ixodes Uriue n. sp. und Bilella podurophila n. sp. beschrieben wurden. ThorelL hebt hervor, daß letztere nicht mit seiner $B$. decimiens identisch sein kann, weil bei ihr die Femoralglieder der Beine sehr verdickt sein sollen („much thickened“). Nach meiner Ansicht spricht jedoch die Diagnose ziemlich deutlich für die Annahme, daß diese Arten identisch sind. Man kennt nämlich gegenwärtig die Verbreitung der Bdelliden in arktischen Gebieten so gut, daß man mit Sicherheit behaupten kann, daß nur folgende 5 Arten dort vorkommen: Bidella littoralis (L.), B. longirostris (HERM), B. decipiens THOR., B. groenandica n. sp. und Ammonia brevirostris L. KocH. Von diesen werden B. littoralis und B. groenlandica ausge-

I) VAN HöFFEN, Die Flora und Fauna Grönlands. Die Identifizierung dủrfte von Kramer selbst vorgenommen sein. In einer Fußnote steht freilich, daß die FABRıcius'schen Arten von THORELL und TrouessaRT in der erwähnten Weise identifiziert worden sind; diese Autoren erwähnen aber nicht A. coleoptratorum.

2) 1. c. Revision etc., p. 200.

3) N. MoHR, Forsig til en Islandsk Naturbistorie, Kjøbenhavn I786, p. IO4.

4) Ich habe daher auch diese Angaben in den tabellarischen Uebersichten der geographischen Verbreitung meistens nicht berücksichtigt.

5) Geographische Beschreibung von Island von TH. GLiEniann, Altona I824, p. I64

6) P. S. SutherLand, Jounal of a voyage in Baffin's Bay and Barrow Strails in the years I850-I85I, Vol. II, London I852. Appendix \%. CCIX-CCX, fig. 9, Io. 
schlossen durch die Angaben in der Diagnose, daß das I. Glied der Palpen 3 mal so lang wie die übrigen zusammengenommen ist, und daß am Terminalglied 2 Borsten vorhanden sind. Ammonia brevirostris kann es nicht sein, denn es wird angegeben, daß „the beak is nearly half the length of the rest of the body", und dies paßt gar nicht auf die Gattung Ammonia (Cyta). Es bleiben somit nur B. decipiens und B. longirostris übrig, die mit B. podurophila identifiziert werden können, und von diesen wird B. longirostris dadurch ausgeschlossen, daß bei B. ppdurophila "the first joint is nearly three times as long als the two other joints taken together", unter der Annahme, die mir völlig berechtigt scheint, daß keine anderen Bdelliden in diesen Teilen der Arktis vorkommen.

Ixodes uriae wäre wegen der schlechten Diagnose unmöglich zu identifizieren, wenn sich nicht in den Kopenhagener Sammlungen eine Ixodide, Ixodes putus, befände, die auf Uria brünnichi gefunden wurde. Da diese Art die einzige ist, die in arktischen Gegenden allgemein verbreitet ist, dürfte eine Identifizierung mit I. uriae berechtigt sein.

Es dauert darauf bis I87I, ehe wir neue Kenntnis von der arktischen Acaridenfauna bekommen, und erst jetzt beginnt die eigentliche arktische Acaridenforschung. In diesem Jahre beschrieb nämlich THORELL ${ }^{1}$ ) die von Holmgren auf der Bären-Insel im Jahre I868 und von MaLMGREN auf Spitzbergen I86I gesammelten Acariden. Es waren dies folgende 8 Arten: Oribata notata, Evemaeus lineatus, Nothrus borealis, Hermannia reticulata, Bdella arctica, Bdella decipiens, Rhagidia (n. g.) gelida, Penthalaeus insulanus.

Im Jahre $1872^{2}$ ) beschrieb Thorell ferner die von J. Lindahl, A. E. Nordenskiöld, T. Fries und C. Nyström auf Grönland gesammelten Acariden. Folgende Arten werden von ihm für Grönland angegeben: Bdella arctica, Trombidium hyperboreum, Trombidium inc. sp., Larve, Rhyncholophus inc. spec., Larve, Hygrobates Fabricii und Dermanyssus ambulans. Er versucht dabei, auch einige von den Fabricius'schen Arten zu identifizieren. In Bezug auf diese Identifizierungen verweise ich auf das schon oben Gesagte.

In den Jahren 1875-76 wurden von Herrn Kapitän FeILdeN und Herrn HART auf der Reise mit "Discovery" und "Alerte" in der Baffins-Bucht zwischen $78^{\circ}$ und $83^{\circ} \mathrm{n}$. Br. mehrere Acariden eingesammelt. Diese wurden von MurRAY ${ }^{3}$ ) vorläufig bestimmt und benannt. M. starb aber, ehe er das Material ausführlich bearbeitet hatte, und die von ihm gegebenen Namen sind somit nomina nuda. Es sind dies folgende: Orbita lucasii Nic., O. triangularis n. sp. Murray (nomen nudum) und O. sp., Damaeus sp. „near geniculatus Kocн“", Scirus sp., Biella calandroides Murray (nomen nudum), Bdella sp., Hydrachua sp., Eyalis? sp.

Im Jahre I879 wurde unsere Kenntnis der arktischen Acariden sehr erweitert, indem L. KocH ${ }^{4}$ ) die im Jahre 1875 von der schwedischen Expedition nach Sibirien und Novaja Semlja unter Führung von A. E. Nordenshiöld und A. Stuxberg gesammelten Acariden beschrieb. Er zählt 42 Arten auf, von denen 35 für die Wissenschaft neu sein sollen. Es sind dies folgende Arten: Oribatidae: Mermannia reticulata THoR., Eremaeus lineatus Thor., Nothrus borealis Thor., N. nigrofemoratus n. sp., N. scaber n. sp., N. punctatus n. sp., Oribata notata Thor., O. reticulata n. sp., O. lucens n. sp., O. crassipes n. sp., O. nitens n. sp., Oppiu sphaerica n. sp., O. oblonga n. sp. - Parasitidae (Gamcsidae): Gamasus coleoptratorum L., G. emarginatus Koch, G. armatus n. sp., G. tenellus n. sp., G. borealis n. sp., G. ovalis n. sp., Sejus excisus n. sp., S. semitectus n. sp. - Trombirlidae: Rhyncholophus sucidus n. sp., R. signatus n. sp., R. imperialis Kосн, R. albicomus n. sp., R. tonsus n. sp., Actinedu setosu n. sp., Smaris plana n. sp., Tetranychus borealis n. sp., Rhagidia gelosa THor., Penthalaeus borealis n. sp., P. crassives n. sp., Bdella decipiens Thor., B. arctica Thor., B. pallipes n. sp., B. brevirostris n. sp., B. mollissima n. sp., B. grandis n. sp., Torynophora serrata CAmBRidge, Claviceps trimaculatus n. sp., C. bimaculatus n. sp., C. rugosus n. sp.

1) 1. c.

2) 1. c.

3) NARES. Narrative of a voyage to the Polar sea. London I 878 . Stockholm is 879

4) Arachniden aus Sibirien und Novaja Semlja. Kongl. Svenska Vet. Akad. Handl., Bd. XVI, p. II2-136, Taf. III-VII, 
I882 brachte die österreichische Expedition ${ }^{1}$ ) auf ,Pola ${ }^{66}$ von Jan Mayen 2 Acariden mit, Bdella arctica THOR. und Ixodes:sulcatus KOCH.

Im folgenden Jalrre, I883, beschreiben P. Kramer und C. Neumann die Acariden der, Vega“-Expedition "). Es werden folgende Arten aufgezählt: Trombidium amatum n. sp., T. laevicapillatum, T.? Larve, Bryobia speciosa C. L. KосH, Erythraeus parietinus Kосн, Scyplius hamatus n. sp., Nesea arctica n. sp., Bdella borealis n. sp., B. villosa n. sp., Ixodes borealis n. sp., I. fimbriatus n. sp., Oribata setosa KocH, Damaeus geniculatus KocH, Gamasus musculi, G. arcticus n. sp., G. coleoptratorum KосH, Laelaps pachypus KocH, L. hilaris KocH, L. nanus? MÉGN., L. pectinifer? MÉGN.

I 894 beschreibt E. TrouessarT ${ }^{3}$ ) aus Island eine Bdella-Art, die er als neu bezeichnet und $B$. sanguinea nennt, und in demselben Jahre bearbeitet er die auf Jan Mayen und Spitzbergen von der Expedition mit "La Manche" ${ }^{(4)}$ ) heimgebrachten Acariden. Sein Verzeichnis zählt folgende Arten auf: Bdella arctica ThOR., Urosejus acuminatus (Koch) BERLESE, Laelaps sp.? (Nymphe), Notaspis lucorum (Koch) Michael, Halacarus borealis n. sp., H. poucheti n. sp. und $H$. reticulatus n. sp.

I895 giebt TrouessarT ${ }^{5}$ ) eine Revision der arktischen Acariden. Da er aber lieine Typen untersucht hat und von nur sehr wenigen Arten Material besaß, ist es vielmehr eine Liste der arktischen Acariden als eine Revision derselben. Sein Versuch, die Fabricius'schen Arten zu deuten, ist deshalb nicht glücklich ausgefallen, wie ich schon oben auseinandergesetzt habe, und von den zahlreichen Irrtümern L. KocH's hat er nur einige, wie z. B. daß die 3 Claviceps-Arten L. KocH's Oribatiden-Nymphen sind, korrigieren können. Er spricht jedoch die richtige Vermutung aus, daß die von KocH angegebene Zahl der arktischen Acariden der Wirklichkeit nicht entspreche, sondern zu hoch wäre.

Im Jahre 1897 erscheinen nicht minder als drei Beiträge zu unserer Kenntnis der arktischen Acaridenfauna. A. C. Oudenans ${ }^{6}$ ) und F. Koenike beschreiben die von der ,Willem-Barents" ${ }^{6}$-Expedition I88I -82 auf Novaja Semlja und bei Vardöe und Hammerfest in Norwegen gefundenen Acariden. Sie zählen folgende Arten auf: Bdella villosa Kramer, Trombidium armatum KraM., T. laevicapillatum Kran. und Lebertia oudemansi n. sp.

A. D. MichaEL ${ }^{7}$ ) beschreibt einige Acariden aus dem Franz Joseph-Archipel: Erythraeus harmsworthi n. sp., Thargidia gelosa Thor., Oribata setosa (C. L. Koch), O. Fisheri n. sp. und Glyciphagus domesticus (DE GEer).

P. KRAMER ${ }^{8}$ ) beschreibt einige Acariden aus Grönland, nämlich: Rhyncholophus gracitipes n. sp., R. phalangioides (DE GEER), Bdolla urcticu Thor., Leiosoma globipes n. sp., IHcrmannia carinata n. sp., eine Oribatiden-Larve und Halacarus sp., Larve.

I899 beschreibt der amerikanische Arachnidologe N. BAnks ${ }^{9}$ ) einige Acariden aus den CommanderInseln. 5 von diesen werden als für die Wissenschaft neu bezeichnet: Rhyncholophus elongatus n. sp., Bdella frigida n. sp., Oribatella borenlis, Oppia arctiru und Hermumia quadriseriata. Die übrigen werden mit KRAMER und Neumann'schen Arten identifiziert: Trombidium armatum, Bdella villosa, IIolostasmis arcticus und Ixodes lorealis.

1900 gab TRÄGARDH ${ }^{1}$ ) ein Verzeichnis der von J. G. ANDERSSON im Jahre I899 auf der Bären-Insel gesammelten Acariden. Dieses Verzeichnis enthält folgende Arten: Oribata notata THor., Srutovertex lineatus

I) v. Wohlgemuth, Die österreichische Polarstation Jan-Mlayen, I882-1883: Beobachtungsergebnisse, Bd. III, p. $55 \cdots 56$.

2) Acariden während der Vega-Expedition eingesammelt. Vega-Exp. Vetensk. Jakttagelser, Bd. IIl, Stockholm I 883.

3) Note sur une grande espèce de Bdelle maritime originaire d'Island. Journ. de l'Anat. et de la Phy's., I894, T. XXX, p. 117.

4) Note sur les Acariens recueillis au Spitzberg pendant le voyage de la Manche. Nouv. Arch. des Missions scientifiques et littéraires, T. V, p. 255, Paris 1894.

5) Revision des Acariens arctirues. Soc. Nat. d. Sciences nat. et math. de Cherbourg, T. XXIX, I $892-1895$, p. I81-206.

6) Acari collected during the Willem-Barents-Expedition of I88I and I882. Tijdschrift voor Entomologie, Bd. XL, 1897 , p. $238-242$.

7) Report on the Acari collected by Mr. H. FISHER, Naturalist of the JACkSON-HARMSworth Polar Expedition at Cape Flora, Northbrook Island, Franz Joseph Archipelago, in 1896. The Journal of the Linnean Society, Vol. XXVI, No. I68, p. 355-357,PI.XXI, 1897. 8) Grönländische Milben. Bibliotheca Zoologica, Heft 20, Lieferung 3, I897.

9) Reports upon the Insects, Spiders, Mites, and Myriajous collected by Dr. L. STEjnegger and Mlr. G. E. H. BarretTHamilon on the Commander Islands. Extr. from the Fur Seals and Fur Seal Islands of the north Pacific Ocean, Part IV, p. 347-346, PI. A, Fig. 2-6. 
(Thor.), S. lineatus var. Hermannia reticulate Thor., Hermamia scabre (L. Koch), Nothrus sp., Buclln arcticu ThOr., B. sanguinea TrT., Ammonia brevirostris L. KосH, Notophallus insulamus (Thor.), Rhagidia gelida ThOR., Penthalaeus arcticus n. sp., Bryobiu serrata Cambridge. Ich revidierte dabei auch einen Teil der Thorell'schen und L. Koch'schen Arten, hielt aber gegen Michael die Artberechtigung von Oribata notata THor. aufrecht, zeigte weiter, daß Ercmaeus lineatus THOR. mit Scutovertex corrugatus Mich. und Claviceps rugosus L. Koch, Ammonia brevirostris L. Koch mit A. mollissima L. KocH und Penthalneus insulanus THOR. mit Tetranychus borealis L. Kосн identisch ist und der Gattung Notophallus angehört, daß Penthalaeus crassipes L. KoCH und P. borealis L. KocH Nymphenstadien von Rhagidia gelide THOR. sind, und daß Torynophora sermata CAMBR. eine Bryobia-Art ist.

In demselben Jahre beschreibt N. Banks²) eine Holostaspis-Art aus Alaska.

Igo r revidierte ich sämtliche litorale $\mathrm{Bdelliden}$ und zeigte dabei, daß $B$. sanguinea TrT., B. Basteri Johnst., B. arctica Thor., B. grandis L. Koch und $B$. villosı Kramer u. Neumann miteinander identisch sind und $B$. littoralis (L.) benannt werden sollen, und daß $B$. decipiens Thor. mit B. borealis $K$. u. N. identisch und höchstens nur eine Varietät von $B$. vulgaris ist.

I 902 revidierte ich ${ }^{3}$ ) in Zusammenhang mit der Beschreibung einer Anzahl Trombidiiden und Oribatiden aus dem nördlichen Lappland noch einen Teil der arktischen Acariden und zeigte: daß Rhyncholophus sucidus L. KOCH mit Ottonia spinifera SIG. THOR. identisch ist und der Gattung Trombidium angehört, daß Bryobia scrrata (CAmвr.) L. Koch mit B. praetiosa C. L. Koch, Nothrus muntatus L. Koch mit Hermannia carinata KRAM. und mit N. peltifer C. L. Koch, Nothrus borealis Thor. mit N. horridus (Heru.) Mich. identisch ist, und suchte Notaspis crassipes (L. KOCH) als eine selbständige Art gegen MrCHAEL aufrecht zu halten, der sie mit $N$. exilis Nic. identifiziert.

In selben Jahre beschreibt V. KuLCzynski ${ }^{4}$ ) einige Acariden, die von A. Birula 1899 auf Spitzbergen gesammelt waren. Er hielt ebenfalls Oribata notata THor. als eigene Art aufrecht und unterscheidet wie ich ${ }^{5}$ ) Oppia sphaerica L. Kocy als eine Varietät von Notaspis bipilis (Herm.), faßt aber im Gegensatz zu mir ${ }^{5}$ ) Nolhus borealis Thor. als eine Varietät von $N$. horvilus (HERu.) auf. Weiterhin beschreibt er Oribata lucens L. KocH und eine neue Art, Oribata birulai n. sp.

\section{Systematischer Teil.}

\section{Familie Oribatidae.}

Bestimmungstabelle der arktischen Subfamiliender Familie Oribatidae.

| Abdomen mit Flügelanhängen versehen

Subfamilie Oribatinae p. I2

I Abdomen ohne Flügelanhänge

2. Cephalothorax mit Lamellen versehen

Subfamilie Notıspidinae p. I9

I Cephalothorax ohne Lamellen

3.

| Beine schmal, länger als der Körper

I Beine kurz und dick

Subfamilie Damaeinae p. 25

Subfamilie Nothrmae p. 25

I) 1. $\mathrm{c}$.

2) Papers from the Harriman Alaska Expedition. XI. Entomological Results (5) Pl. XXIX. Proceedings of the Washington Academy of Sciences, VoI. II, I900, p. 485

3) 1. c.

4) Zoologische Ergebnisse der russischen Expedition nach Spitzbergen. Ann. du Musée zoologique de l'Acad. Impériale des Sciences de St. Pétersbourg, I902, T. VII, No. 3, p. 347-354, Tab. VII, Fig. I7-25.

5) Revision der von ThORELl aus Grönland, Spitzbergen und der Bären-Insel und von L. Koch aus Sibirien und Novaja Semlja beschriebenen Acariden. Zool. Anzeiger, Bd. XXV, No. 660, 30. Dezember 190I, p. $56-62$. Vorl. Mitteilung. 
Subfamilie Oribatinae.

Von den beiden zu dieser Subfamilie gehörenden Gattungen Oribata Latr. und Pelops C. L. Koch ist nur die erste in den arktischen Gebieten vertreten.!

\section{Bestimmungstabelle der Gattung Oribata LATR.}

f Eine Translamelle vorhanden

I Keine Translamelle vorhanden.

2. Notogaster deutlich punktiert.

I Notogaster nicht punktiert

3. Notogaster mit kraterförmigen Gebilden

I Notogaster ohne kraterförmige Gebilde

( Notogaster mit langen Haaren versehen, Länge 0,6

4. I Notogaster mit kurzen Haaren versehen, Länge 0,9

5. $\left\{\begin{array}{l}\text { Notogaster fein punktiert } \\ \text { Notogaster nicht punktiert }\end{array}\right.$

6. Lamellen sehr groß, horizontal.

I Lamellen normal.

7. Pseudostigmalorgane kurz, kolbenförmig, nach vorn gerichtet

I I seudostigmalorgane lang, nach hinten gebogen.

7. 0 . reticulata p. I8

\section{Oribata motata THOR.}

Textfig. $I-4$.

1871 Oribata notata, Тнок, l. с. p. 695.

1879 " "Тнок, L. Косн, l. c. p. 114, tab. 4, fig. 1, 1 a.

1879 Claviceps bimaculatus, L. Ǩnch (Nymphe, siehe Trägi̊di, 1900. p. 5).

1883 Oribata setosa (C. L. Koch), Kramer \& Neumann, 1. c. p. 528.

$1897 " \quad$ (C. L. Косн), Нichael, l. c. p. 357.

$1900 \quad " \quad$ notata, Trägídi, l. с. p. 4, fig. 1.

1901 Notaspis trimuculatus (C. L. Косн) var. notreta Thor., TrägindH, l. c. p. 5-9.

$1902 " \quad " \quad$ (C. L. Koch) Kulczinski, 1. c. p. 13, tab. 7, fig. 19.

Diese Form wurde I87I von THORELL aus Spitzbergen beschrieben und später von L. Koch für Sibirien und Novaja Semlja konstatiert. Michael, welcher Exemplare derselben aus Franz Joseph-Land ge-

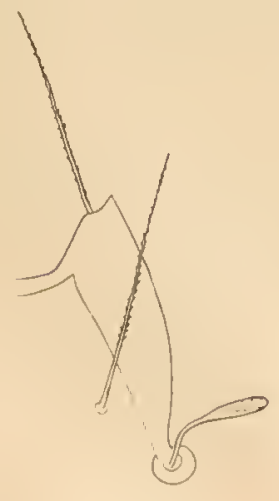

Fig. 1.

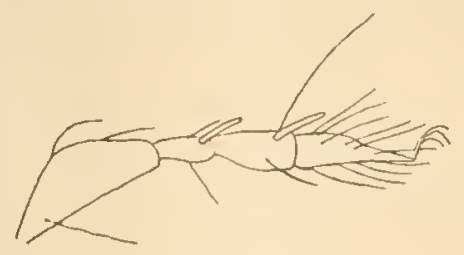

Fig. 2

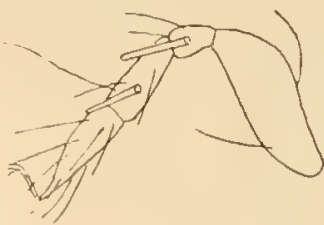

Fig. 3.

Fig. I. Oribata notata THOR. Rechte Cephalothorakallamelle. Vergr. 4I3:1 Fig. 2. " " $"$ 1. rechtes Bein. Vergr. 150: I. Fig. 3. " " " " linkes Bein. Vergr. 150:1.

Fig. 4. " $"$ 4. rechtes Bein. Vergr. 206: I.

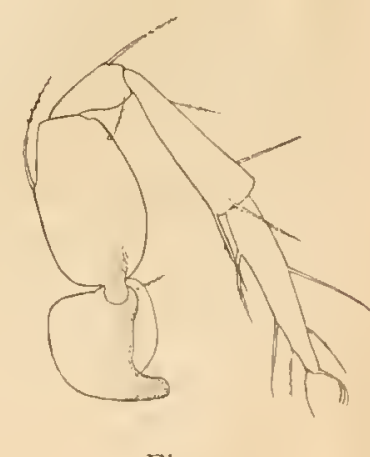

Fig. 4 .

sehen hat, identifiziert sie mit O. setosı C. L. KocH, die er in England fand. In einer früheren Arbeit (97) habe ich trotzdem vorläufig die Art aufrecht erhalten, obwohl MicuAEL für 0 . setosa eine große Variabilität 
in Bezug auf das Merkmal, das ich beim Unterscheiden der beiden Formen benutzte, nämlich den Bau der Cephalothorakallamellen, angiebt. Ich stützte mich dabei auf die Tatsache, daß alle Individuen des reichen arktischen Materiales, das mir zur Verfügung stand, betreffs der Cephalothorakallamellen keine Variation aufweisen, sondern ohne Ausnahme sehr stumpfe Lamellenspitzen haben. Es schien mir dies für die Auffassung zu sprechen, daß man es, wenn nicht mit einer selbständigen, von 0 . setosa verschiedenen Art, so doch mit einer besonderen Lokalvarietät derselben zu tun hatte. In einer vorläufigen Mitteilung über diese Revision führte ich sie als Varietät von O. trimaculata (= setosa) auf. Später habe ich bei der Bearbeitung des von NATHORST im Jahre 1899 aus Jan Mayen und Ostonrönland heimgebrachten Materiales und der großen im Naturhistorischen Museum zu Kopenhagen befindlichen Sammlungen von grönländischen Acariden Gelegenheit gehabt, zu konstatieren, daß auch die von diesen Gebieten stammenden Exemplare im Bau der Cephalothorakallamellen keine Variation zeigen, sondern sehr stumpfe Spitzen haben.

Dieser Befund stützt die Auffassung, daß man $O$. notata als eine von $O$. setosa verschiedene, wenn auch derselben sehr nahestehende Form betrachten muß. Ich hätte sie daher unbedenklich als eine Varietät von letzterer aufgeführt, da ja die von MichaEL vorgenommene Identifizierung der arktischen Form ${ }^{1}$ ) mit seiner $O$. setosn die sonstige (d. h. mit Ausnahme von den Cephalothorakallamellen) Uebereinstimmung von beiden Formen beweist. Neuerdings ist aber von Kulczynski die Identität von 0 . setosa C. L. Koch und $O$. setosu Michael bestritten und es scheint mir, ehe dies konstatiert ist, angemessener, die arktische Form nicht an die englische anzuknüpfen, trotzdem ich noch einmal ihre große Uebereinstimmung hervorhebe. KulCZYNSKi führt sie als eine selbständige Art auf.

Die von Kramer und Neumann O. setosa C. L. Koch benannte Art aus Jinretlen, wovon mir keine Exemplare zur Verfügung standen, stelle ich wegen der Lokalität unbedenklich zu O. notatı THOR.

Die Länge ist ungefähr $0,60 \mathrm{~mm}$, die Breite ungefähr 0,38 . Der Cephalothorax, die Tectopedia und die Lamellen wie bei O. setosa MicH., mit Ausnahme davon, daß letztere sehr stumpfe Spitzen haben (Textfig. I) und daß das Rostrum nur in eine kaum merkbare Spitze ansgezogen ist und 2 kleine laterale Zähne hat.

Bei einer erneuten Untersuchung des Notogasters fand ich, daß die Chitindecke gleich wie bei der unten zu beschreibenden 0 . oblonga L. KocH sog. kraterförmige Gebilde hat, die auch in derselben Weise wie bei dieser Art placiert sind (s. Textfig. I I p. I5). In meiner vorigen Abbildung ${ }^{2}$ ) über die Placierung der Haare sind 2 Haare übersehen worden. KulczYnski's Abbildung ${ }^{3}$ ) zeigt die richtige Placierung derselben.

Schließjlich ist zu bemerken, daß die 2 ersten Beinpaare (Textfig. 2 und 3) auf der Tibia und dem Genu an den äußeren distalen Enden sehr kräftige Borsten besitzen. Solche sind von Michael nicht abgebildet worden.

Fundorte: KulczYnskı hebt hervor, daß die Art ausschließlich arktisch sei. Indessen giebt

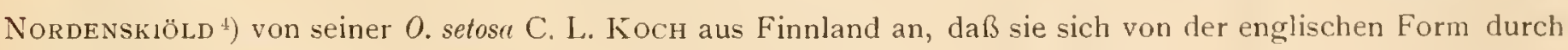
stumpfere Lamellenspitzen unterscheidet, und es ist daher nicht unmöglich, daß diese finnländische Form mit O. notata Thor. identisch ist. Cap Flora, Northbrooh-Insel, Franz Joseph-Archipel (96); Sibirien, Novaja

1) Da alle Exemplare von den verschiedenen arktischen Lokalitäten, die ich untersucht habe, stumpfe Lamellenspitzen zeigen, nehme ich an, daß die Exemplare aus dem Franz Joseph-Archipel auch stumpfe Spitzen haben. In diesem Zusammenhang möchle ich ein Mißverständnis von KulCzynski besprechen. Er sagt p. 318: Notaspis (Oribata) trimaculata. Trägardhii quae cum O. setosu Berlesei conveniri dicitur, probabiliter eadem est atque $N$. picipes (C. L. KocH) nostra". In Wirklichkeit habe ich mich gar nicht über N. trimaculata ( $=\operatorname{sesosa~C.~L.~KOCH)~geäußert,~sondern~gesagt,~daß~THORELL's~und~L.~Koch's~Typen~von~O.~notata~und~das~von~mir~}$ als O. notala hestimmte Exemplar von der Bären-Insel mit der von BERLESE abgebildeten O. setosa C. L. Kocir ïbereinstimmten. Ich dachte dabei besonders an den Bau der Cephalothorakallamellen, welche auch bei dieser stumpfe Spitzen haben. Ich sehe nicht ein, wie KulczYNSKI daraus schleßen kann, daß O. trimacutata und 0 . pieipes identisch sind.

2) l. c. p. 5 , f. 1 .

3) 1. c. 1ab. 7, p. 19. 1901 , p. I2.

4) Zur Kenntnis der Oribatidenfauna Finnlands. Acta Societatis pro Fauna et Flora Fennica, Bd. XXI, No. 2, Helsingtors 
Semlja; Spitzbergen; Bären-Insel (99); Jan Mayen (99); Ostgrönland: Cap Stewart (9I und 99), auf einer Insel n. $\mathrm{Br} \cdot 72^{\circ} 46^{\prime}, \mathrm{w} \cdot \mathrm{L} \cdot 22^{\circ} 5^{6^{\prime}}(99)$.

Weitere Verbreitung: Finnland?

\section{Oribatu lucens L. KOCH}

Textfig. 5-IO.

1879 Oribata lucens, L. Kocı, l. c. p. 115, tab. 4, fig. 2, 2a.

1901 Notaspis lucens, L. Kocu, Träg̊rdH, l. c. p. 59.

$1902 "$ " KULCZYNSEx, l. c. p. 15.

1902 setosa var. curta TGDil., l. c. p. 19, tab. 3, fig. 3.

Diese Art wurde zuerst aus Sibirien und Novaja Semlja von L. KocH beschrieben. In meiner vorläufigen Mitteilung hob ich hervor, daß sie O. notuta sehr nahe stand. Später habe ich sie in Lappland wiedergefunden, übersah aber zuerst, daß die lappländische Form mit $O$. lucens identisch war, und beschrieb sie als O. setosa var. curtı nov. var. Sie ist später von KulczrNski in einem Exemplar auf Spitzbergen

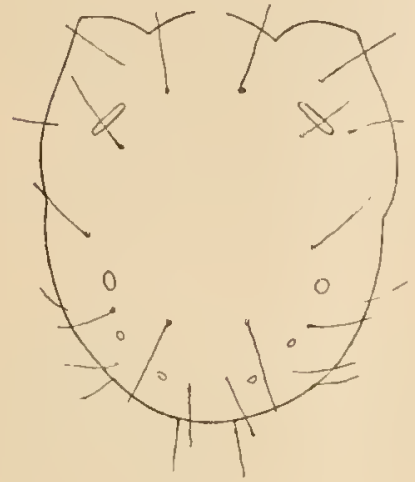

Fig. 5.

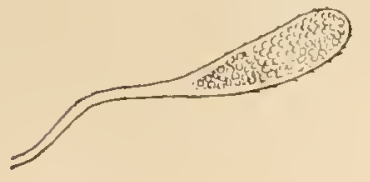

Fig. 6

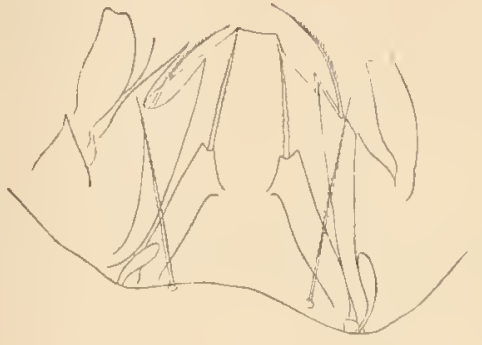

Fig. 7 .

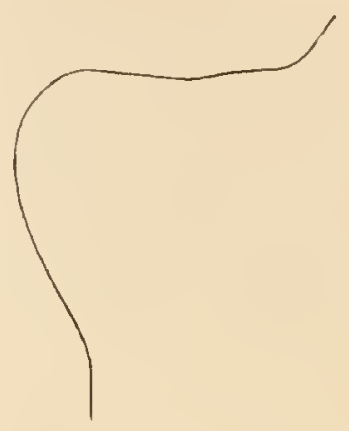

Fig. S.

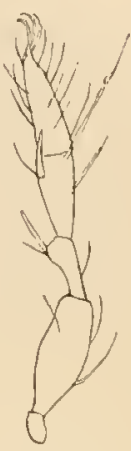

Fig. 9 .

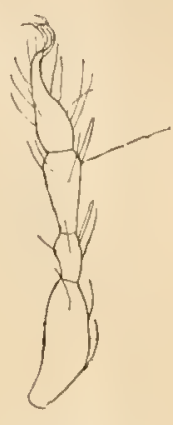

Fig. IO.

Fig. 5. Oribatu luerens L. KоСH. Abdomen mit Borsten und kraterförmigen Gebilden. Vergr. $75: 1$.

Fig. 6. Oribata lucens L. KocH. Pseudostigmalorgan. Vergr. 6z0: I.

Fig. 7. " " " $"$ Cephalothorax. Vergr. I55:1.

Fig. 8. " " " $"$ Linker Abdominalanhang. Vergr. I50: I.

Fig. 9. " " $"$ " linkes Bein. Vergr. 150: I.

Fig. 10. " $" \quad$ 2. rechtes Bein. I50: I.

wiedergefunden und vom Verf. in je einem Exemplare für Westgrönland und Island in der Kopenhagener Sammlung konstatiert. Die Länge der Art variiert ein wenig. Kóch's Exemplare haben o, $63 \mathrm{~mm}$, KuLczynski's : 0,65 und meine lappländischen $0,58 \mathrm{~mm}$. Breite $0,42-0,44 \mathrm{~mm}$. Die Art scheint, wie oben gesagt, 0 . notata und 0 . trimaculıta (= setosa) sehr nahe zu stehen. Sie ist jedoch von ihnen leicht dadurch zu unterscheiden, daß die Cephalothorakallamellen, die in ihren Spitzen nur ein wenig abgerundet sind, durch keine Translamelle verbunden sind (Textfig. 7). Das Abdomen trägt 24 Haare (nicht 22, wie Kulczynsk1 angiebt), deren Placierung Textfig. 5 zeigt. Die Chitindecke, die, wie K. hervorhebt, dicht punktiert ist, trägt wie bei 0 . notata und 0 . oblonga 4 Paar kraterförmige Gebilde (Textfig. 5). Das 1. und 2. Beinpaar trägt wie bei 0 . notata je 2 kräftige Borsten (Textfig. 9 und Io).

Fundorte: Sibirien; Novaja Semlja; Spitzbergen (99); Westgrönland 27. Juni is9o auf Lagopus alpinus bei Taitip ata.; Island, Heklahavn (92).

Weitere Verbreitung: Lappland. 


\section{Oribata oblonga L. KOCH}

Textfig. I I-I 8 .

1879 Oribata oblonga L. Косн, 1. c. p. 118, tab. 4, fig. 6.

Diese Art wird von Michael ${ }^{1}$ ) mit der vorigen Art O. lucens $\mathrm{K}$. Koch identifiziert. In der Tat ist sie jedoch eine selbständige, sehr gut gekennzeichnete Art.

Durch den Bau der Cephalothoracallamellen zeigt sie sich als mit O. lucens, O. setosa und der von KulczynSKI ${ }^{2}$ ) wiedergefundenen 0 . picipes C. L. KocH am nächsten verwandt, unterscheidet sich aber sofort von ihnen durch ihre viel bedeutendere Größe. Die Länge beträgt ungefähr o,9 mm. Die

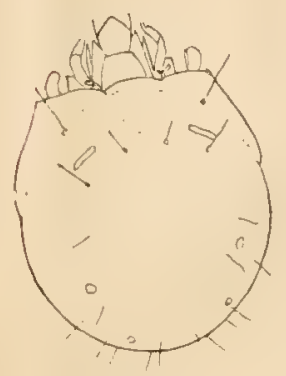

Fig. II.

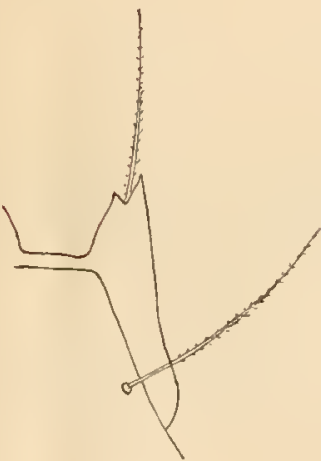

Fig. I2.

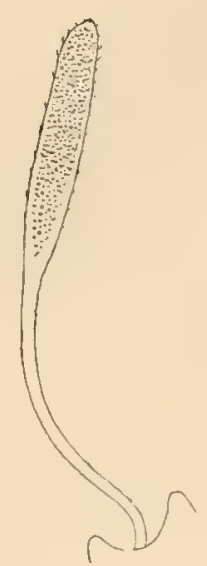

Fig. I3.

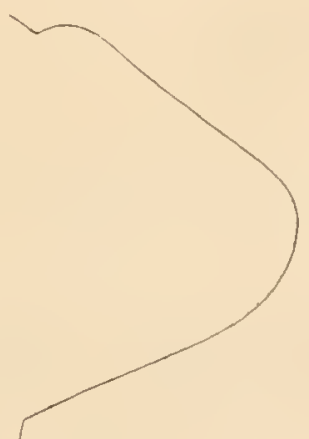

Fig. 14.

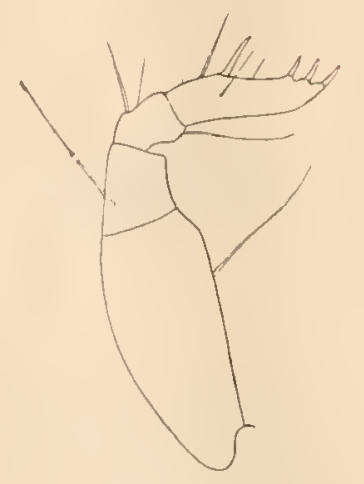

Fig. 15.

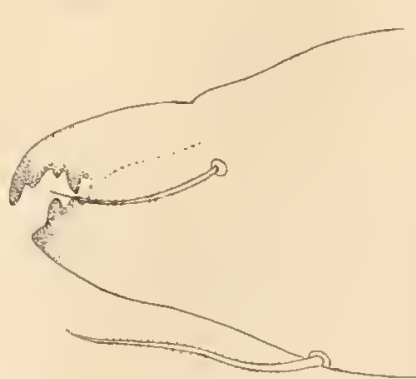

Fig. I6.

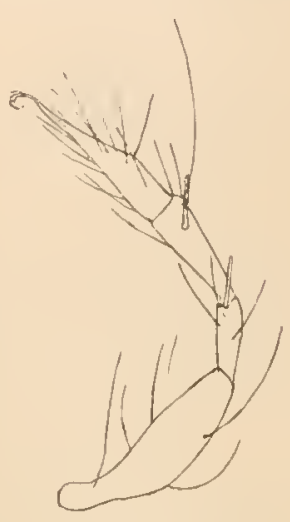

Fig. 17.

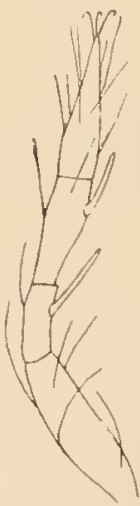

Fig. 18 .

Fig. 11. Oribata oblonga L. KocH. Totofigur. Vergr. 60:1.

Fig. 12. " " " " Rechte Cephalothorakallamelle mit Translamelle und Interlamellarborste. Vergr. I50: I.

Fig. I3. " " $"$ " $"$ Pseudostigmalorgan. Vergr. 620: I.

Fig. I4. " " " $"$ Rechter Abdominalanhang. Vergr. I00: I.

Fig. 15. " " " " Rechter Palp, von außen gesehen. Vergr. 620: I

Fig. 16. " $", \quad "$ Mandibel. Vergr. $413: 1$.

Fig. 17. " " " " Das I. rechte Bein, von innen gesehen. Vergr. I $20:$ I.

Fig. I8. " " " " " " Das 2. rechte Bein, von außen gesehen. Vergr. I20:I

größte Breite ist $0,63 \mathrm{~mm}$. Die Farbe ist kastanienbraun mit Ausnahme eines lichtgelben Fleckes auf dem Progaster. Die Chitindecke erscheint auch bei starker Vergrößerung glänzend und ohne jegliche Textur. Die Cephalothorakallamellen (Textfig. 12) sind ziemlich breit; sie nehmen nach vorn an Breite zu und endigen mit einer mit einem scharfen Zahn versehenen Spitze. In dem Winkel zwischen dem Zahne und der Spitze sitzen die Lamellarborsten, welche sehr fein, aber deutlich behaart sind, außerdem sanft gebogen und kaum

I) Tierreich, Lief. 3 , p. I5.

2) 1. c. p. I3, tab. 7 , fig. I8. 
die Länge der Lamellen erreichen. Die Interlamellarhaare sind auch sehr fein behaart und übertreffen die Lamellarborsten um die Hälfte an Länge. Die Pseudostigmata sind unter dem Progaster verborgen. Die Pseudostigmalorgane (Fig. I3) tragen auf ziemlich kurzem, nach vorn gebogenem Stiel einen schwach keulenförmigen, fast cylindrischen, äußerst fein behaarten Knopf. Die Mandibeln tragen je 2 gefiederte Borsten; ihren sonstigen Bau zeigt Textfig. I6, den Bau der Taster Textfig. I5. Die Tectopedia des I. Beinpaares erstrecken sich ebenso weit nach vorn wie die Lamellen und endigen mit einer breit abgestutzten, mit stumpfen Zähnen versehenen Spitze. Das Abdomen trägt 4 Paare hellgelber Gebilde, von denen das erste länglich-oval ist, die übrigen annähernd kreisrund sind. Ihre Placierung zeigt T.extfig. II. Diese Flecken stellen scharf abgegrenzte verdünnte Partien der Chitindecke dar. Bei starker Vergrößerung zeigt es sich, daß sie siebförmig durchlöchert sind. Es dürften diese merkwürdigen Gebilde allem Anschein nach mit den von Ounemans ${ }^{1}$ ) bei Eremaeus schneideri Oudns. und E. sanremensis Oudms. beschriebenen sog. mondkraterförmigen Gebilden homolog sein. Er giebt an, daß die Poren der Siebplatte bei 20oo-facher Vergrößerung deutlich sichtbar seien und daß zahlreiche einzellige Drüsen in die Poren einmünden. Das Abdomen trägt mehrere schwach gefiederte Borsten, von denen 2, die auf den "Schultern" placiert sind, die übrigen un das Doppelte an Länge übertreffen. Von den übrigen ragen I2 über den Hinterrand hervor, wogegen ca. 6 in einem Kreis auf dem höchsten Teil des Notogasters sitzen. Die Flügelanhänge (Textfig. I4) sind nach vorn sanft ausgerundet.

Die Beine sind reichlich mit gefiederten Borsten besetzt. Das I. und 2. Paar trägt auf den distalen Enden des Genu und der Tibia je eine kräftige stumpfe Borste (Textfig. I7 u. I8). An der Spitze der Tibia des I. Paares sitzt ein langes Tasthaar. Die Füße tragen 3 Klauen von gleicher Größe.

Fundort: Bis jetzt nur in Sibirien gefunden.

\section{Oribata fisheri MıcH.}

1897 Oributa fisheri Miснаец, l. с. p. 357.

Diese Art soll der von demselben Autor aus Südgeorgien beschriebenen 0. anturctica ${ }^{2}$ ) am nächsten stehen. Da ich sie nicht aus eigener Anschauung kenne, muß ich mich damit begnügen, ein Resumé von der von MiCHAEL gelieferten Beschreibung zu geben: Die Länge ist ungefähr 0,48 mı, die Breite ungefähr 0,28 mm. Die Farbe ist olivenbraun. Die Cephalothorakallamellen erreichen die halbe Länge des Cephalothorax, nehmen nach vorn allmählich an Breite zu und endigen mit langen, breiten, beinahe horizontalen Spitzen, die vorn sanft ausgerundet sind. Eine niedrige Translamelle ist vorhanden.

Die Pseudostigmalorgane sind sehr kurz, sanft gebogen und nehmen von hinten nach vorn allmählich an Dicke zu. Die Lamellar-, Interlamellar- und Rostralborsten sind lang und dick, nicht gefiedert. Das I. Tectopediumpaar nicht zugespitzt. Die Flügelanhänge des Abdomens kurz. Das Abdomen nur mit einer Reihe außerordentlich feiner Haare rings um den Notogaster versehen. Die Füße mit 3 Klauen versehen, von denen jedoch die lateralen nur bei starker Vergrößerung sichtbar sind.

Fundorte: Bis jetzt nur auf Cap Flora auf der Northbrook-Insel, in dem Franz Joseph-Archipel gefunden.

5. Oribnta cespirlata MicH. var. birulai KuLCz.

Textfig. I9- 23 .

I902 Notaspis birulai KulczYNsKi, l. c. p. 16, tal). 7, fig. 17, 20, 23.

Diese kleine Art wurde von KuLczYNSki nach einem einzigen Exemplar aus Spitzbergen beschrieben. Schon im Sommer 1900 fand ich dieselbe in 4 Exemplaren in Lappland auf dem Berge Kårsonjuonje,

1) Ueber Sanremeser Acari. Tijdschrift voor Entomologie, Bd. XLIII, I900, p. I38, Pl. VIII, Fig. 41, 43, 45, 46.

2) Mitt. Museum in Hamburg v. 12, p. 71, Textfig. 
ungefähr I000 m über dem Meere unter feuchten Steinen und unterschied sie unter dem Namen O. cuspidatiformis von $O$. cuspidata, welcher sie am nächsten stand. Aus Versehen wurde aber die Diagnose nicht in meinem Aufsatz über die lappländischen Acariden publiziert. Meine Exemplare übertreffen dasjenige von Kulczynski ein wenig an Länge, indem sie 0,42 $\mathrm{mm}$ messen, während dieses $0,39 \mathrm{~mm}$ lang ist. Die Breite beträgt ungefähr $0,26 \mathrm{~mm}$.

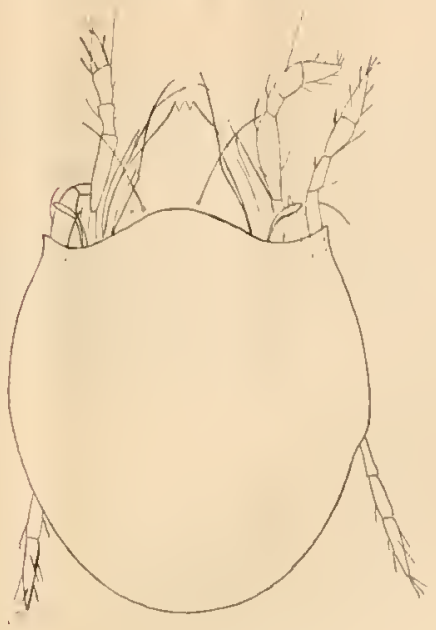

Fig. 19.

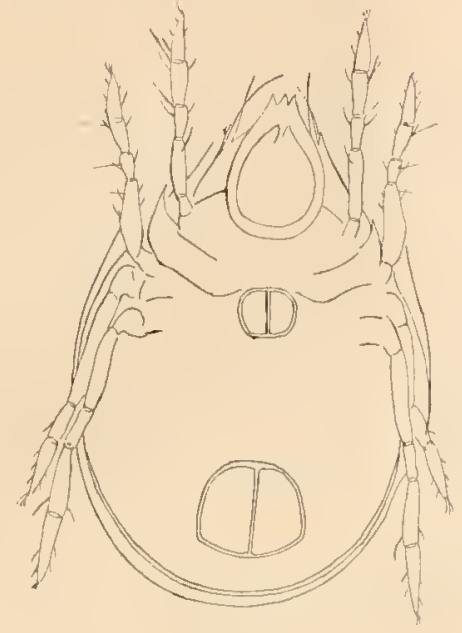

Fig. 20.

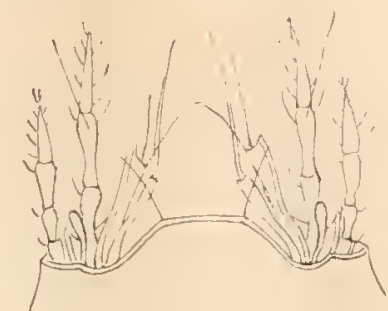

Fig. 21 .

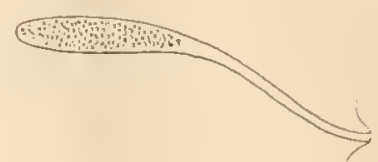

Fig. 22.

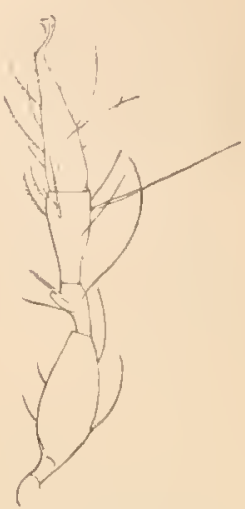

Fig. 23.

Fig. 19. Oribata cuspidate Mich. var. birulai KULCZ. Von oben. Vergr. 120: I.

Fig. 20. " $", \quad, \quad, \quad, \quad$ Von unten. Vergr. 120:1.

Fig. 21. " " " " " " " " " " " " "

Fig. 22. " " " " " " " " " "

Fig. 23. " $", \quad, \quad, \quad "$ 1. linkes Bein. Vergr. 206:1.

Die Cephalothorakallamellen sind sehr niedrig und nehmen nach vorn allmählich ein wenig an Breite $z u$, um in einer sehr kleinen Spitze zu endigen. Keine Translamelle. Die Lamellar-. Interlamellar- und Tectopediaborsten sehr fein behaart. Das Abdomen entbehrt vollständig der Haare. - Im übrigen verweise ich auf die Textfig. I9 und 20 und Kulczynski's Beschreibung.

Wie auch Kulczynsi hervorhebt, steht diese Form der O. cuspiduta Mich. sehr nahe und unterscheidet sich von ihr nur durch bedeutendere Größe ${ }^{1}$ ) und kürzere Lamellar- und Tectopediaborsten (vergl. Michael, British Oribatidae I, P1. X, Fig. 6), und meines Erachtens sind diese Verschiedenheiten zu klein, um die Aufstellung einer besonderen Art zu rechtfertigen. Jedenfalls ist aber der Unterschied für die Aufstellung einer besonderen Varietät groß genug, um so mehr, als die Form eine Variation in ganz derselben Richtung wie z. B. Notrspis bipilis var. sphaerica repräsentiert, d. h. sie unterscheidet sich von der Hauptform einerseits durch bedeutendere Größe, andererseits durch Verkürzung der Lamellar- und anderer Borsten, sowie der Spitze der Cephalothorakallamellen. Ich werde weiter unten diese ausgeprägte Variationsrichtung näher besprechen.

Fundort: Spitzbergen (I899).

Weitere Verbreitung: Lappland (I900).

\section{Oribnta ovalis C. L. KocH}

1835 Oribates ovalis, C. L. Koch, 1. c. fasc. 3 , tab. 5 .

1879 Oribata nitens, L. Koch, l. c. p. 115, tab. 4, fig. 4.

? 1899 Oribatella borerlis, Banks, 1. c. p. 349 , tab. A, fig. 2.

Der Typus von O. nitens L. Koch war in der Sammlung nicht zu finden. Da KocH eine Palpe abgebildet hat (Taf. IV, Fig. 4b), ist es sehr wahrscheinlich, daß das einzig vorhandene Exemplar bei der

I) K. giebt auch an, daß die Form der Pseudostigmalorgane verschieden wäre. Ich habe dies nicht finden künnen. 
Beschreibung verbraucht worden ist. Oribatu niteris wird von MıCHAEL ${ }^{I}$ ) mit O. ovalis C. L. KocH identifiziert, und mit Rücksicht darauf, daß beiden die sehr eigentümliche und äußerst charakteristische Beschaffenheit der Cephalothorakallamellen und Flügelanhänge gemeinsam ist, und nichts in L. KocH's Diagnose gegen eine Identifizierung spricht, ziehe ich beide Arten zusammen. Die Länge des sibirischen Exemplares ist größer als diejenige der englischen, indem sie $0,75 \mathrm{~mm}$ lang ist, während letztere nur eine Länge von $0,65 \mathrm{~mm}$ erreichen.

Bei dem Versuche, die von Banks aus den Kommandeur-Inseln beschriebenen Acariden zu identifizieren, was zufolge der sehr mangelhaften Diagnosen und der schlechten Abbildungen eine sehr undankbare Aufgabe ist, kam mir der Gedanke, daß eine Oribatella borealis möglicherweise mit 0 . ovalis identisch wäre.

Die Cephalothorakallamellen und die Flügelanhänge sind nämlich ganz wie bei dieser Art gebaut: "Tectal plate ${ }^{2}$ ) large, covering the whole of the cephalothorax, deeply deft, each side truncated at tip; two superior bristles; wing large, in front at base with a slender curved, acute projection reaching forward as tip of the head, below the wing is rolled in but from below shows a nearly square corner at the tip. Length $0,5 \mathrm{~mm}$." Ich führe sie daher unter Vorbehalt als Synonym unter 0 . ovalis auf.

Fund orte: Sibirien, Kommandeur-Inseln.

Weitere Verbreitung: England, Frankreich, Deutschland, Italien, Niederland, Finnland, ? Nordamerika.

\section{Oribata veticuleta L. KосH}

Textfig. 24 u. 25.

1879 Oribata reticulata, L. Kucri, l. c. p. 115.

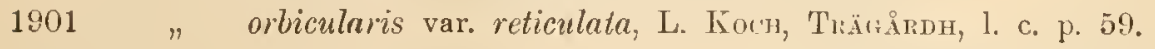

Das einzig vorhandene Exemplar unterscheidet sich von O. orbicularis, deı es am nächsten steht und zu welcher ich in der vorläufigen Mitteilung die Art als Varietät rechnete, vor allem durch seine

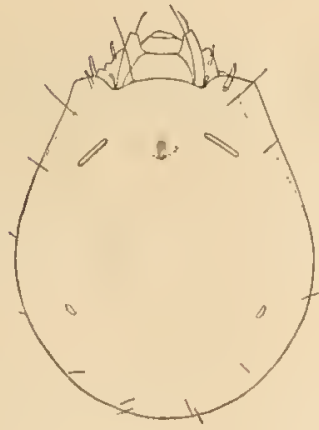

Fig. 24.

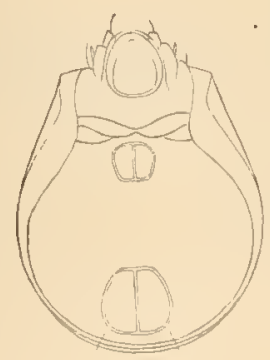

Fig. 25 .
Fig. 24. Oribata reticulata L. Koci. Von oben gesehen. Vergr. 30: 1 .

Fig. 25. Oribata reticulatn L. KoCH. Von unten gesehen. Vergr.21,5: I. Die Beine sind nicht eingezeichnet. weit bedeutendere Größe und die deutliche Punktierung. Im Bau der Cephalothorakallamellen zeigt sie insofern eine Uebereinstimmung nit der $O$. orbicularis äußerst nahe stehenden 0 . piriformis, als die Lamellenspitzen nach außen von den Lamellarborsten ziemlich scharf zugespitzt sind, ohne wie bei 0 . orbicularis gerundet zu sein.

Die Länge ist I mm (O. orbicularis nur 0,65 $\mathrm{mm}$ lang).

Die Farbe ist schwarzbraun mit Ausnahme von einem lichtgelben Flecke auf dem Progaster. Die Textur sowohl der Ober- als der Unterseite des Abdomens dicht punktiert ${ }^{3}$ ). Die Chitindecke hat die bei O. notrta, 0. oblonga und 0 . lucens beschriebenen sog. kratertörmigen Gebilde, von denen die beiden vorderen deutlich zu sehen sind, die am Hinterrande befindlichen dagegen bei der großen Schwierigkeit, die Oberseite des Tierchens genügend zu beleuchten, schwer zu sehen sind,

I) Tierreich, Lief. 3, p. I9.

2) Das sog. Tectum oder, "tectal plate"6 ist eine Benennung, die von Nicolet in die Terminologie eingeführt worden ist. Schon 1883 hat aber MiCHAEL gezeigt, daß sie unzuläsig ist, da keine besondere Platte, die die Basis des Cephalothorar bedecken sollte, vorhanden ist.

3) Nach Michael soll nur die englische Form von O. orbiculars sich durch Punlitierung auszeichnen. 
so daß ich mit Sicherheit nur ein Paar derselben konstatiert habe. Am Hinterrande des Abdomens sind - 6 kleine Haare eingefügt. Auf den "Schultern" sitzen 2 ziemlich kräftige Haare.

Da die Beine auf dem einzigen Exemplare vollständig unter die Flügelanhänge eingezogen sind, ist es mir unmöglich, sie zu beschreiben. So viel ist jedoch auch in dem zusammengezogenen Zustande zu sehen, daß die beiden vorderen Beinpaare auf der Tibia und dem Genu kräftige Borsten besitzen (Textfig. 24).

Fundort: Bis jetzt nur in Sibirien gefunden.

\section{8. : Oribata lucasii Nic.}

1878 Oribata lucasii, Nic, Merrar, 1. c. p. 121.

Da diese Art sonst nie in den arktischen Gebieten gefunden ist, dürfte es nicht ratsam sein, die Identifizierung ohne weiteres zu acceptieren. Ich werde daher in der Zusammenstellung diese Angabe nicht berücksichtigen.

Fundort: $82^{0} 30^{\prime}$ Baffins-Bucht, Juni i 876 , „common under stones".

\section{Oribata triangularis MURRAY}

1878 Oribata triangularis, MurRay, l. c. p. 121.

Von dieser Art, die nach MurRay ,außerordentlich gemein unter Steinen“ $82^{0} 27^{\prime}$ n. Br. vorkam, wird keine Diagnose gegeben, weshalb sie natürlich nicht berücksichtigt werden kann.

\section{Bestimmungstabelle der Subfamilie Notuspidinae.}

I. Körper skulptiert

(Körper ohne Skulptierung

2. (Die 3 hinteren Beinpaare auf der Unterseite des Abdomens eingelenkt.

I Die 3 hinteren Beinpaare auf den Seiten des Abdomens eingelenkt .

Gattung Scutovertex p. I9

. . . 2.

Gattung Lciosoma p. 22

Gattung Notaspis p. 22

\section{Bestimmungstabelle der Gattung Scutovertex Michael.}

I. Notogaster mit zickzackförmigen Leisten versehen

I Notogaster ohne solche Leisten

2. $\left\{\begin{array}{l}\text { Drei Klauen } \\ \text { Eine Klaue }\end{array}\right.$

3. $\left\{\begin{array}{l}\text { Cephalothorakallamellen breit, horizontal } \\ \text { Cephalothorakallamellen niedrig, leistenförmig }\end{array}\right.$

I 2. $S$. velatus p. 22

II. S. maculatus var. groenlandica p. 2 I

\section{Scutovertex limentus (THOR.)}

1871 Eremaeus lineatus, Throduc, 1. c. p. 696.

1875 Trombidium (sic!) fucicolum, Brany, A review of the British Marine Mites. Proc. Zool. Soc. London, p. 301 -311 , pl. XLI, fig. 1, 2.

1875 fuscum, Bradr, ebenda, p. 26.

1878 Eremaeus lineatus, Thonel, L. Косн, 1. с. p. 112.

1878 Claviccps rugosus, L. Косн, 1. c. p. 135, tab. 7, fig. 10.

1888 Scutovertex corrugatus, Michael, 1. c. Vol. II, p. 567, tab. 54, fig. 1-7.

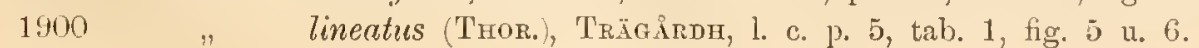

1901 " " (Thor.), Trägídi, 1. c. p. 58.

In einer früheren Arbeit (I900, p. 5, 23) habe ich durch Untersuchung der Typen THoRELL's gezeigt, daß diese Art mit der von MichaEc, aus England beschriebenen Scutovertex corrugrtus identisch ist und auch die Vermutung ausgesprochen, daß diese Art eine sehr weite arktische Verbreitung, ja ihre eigentliche Heimat in den arktischen Gebieten habe. 
Die Untersuchung des von der schwedischen Expedition nach Jan Mayen und Ostgrönland im Jahre I899 gesammelten Materiales hat diese Vermutung nur teilweise bestätigt, indem es sich herausstellte, daß sie zwar auf Jan Mayen ungemein häufig vorkam, dagegen gar nicht auf Ostgrönland. Dazu kommt noch die Thatsache, daß sie unter den großen Kopenhagener Sammlungen von grönländischen Acariden gar nicht zu finden war. Es ist dabei das größte Gewicht darauf zu legen, daß sie sich nicht unter den schwedischen Sammlungen aus Ostgrönland befand, denn diese sind durch Siebungen von Laub und Moos u. dgl. von einem von mir selbst instruierten Zoologen, dem Herrn Dr. J. Arwidsson, zusammengebracht und enthalten mehrere Acariden, die noch kleiner als S. lineatus sind wie z. B. Tectocephaus velatus, Notaspis exilis var. crassipes u. a.

Wenn auch zugegeben werden muß, daß es eine heikle Sache ist, aus einem solchen negativen Befunde Schlüsse zu ziehen, so bin ich jedoch geneigt zu glauben, daß die Westgrenze von Scutovertex lineatus über Jan Mayen geht.

Verbreitung: Sibirien, Novaja Semlja, Spitzbergen, Bären-Insel, England, Schweden.

Ich möchte schon hier die Aufmerksamkeit auf die Thatsache lenken, daß sie in England ${ }^{1}$ ) und Schweden nur an den $K$ ïsten und a uf den Schären vorkommt ${ }^{2}$ ).

\section{Sentovertex lineatus (Thor.) var. migrofiemorata (K. Kocii)}

Taf. I Fig. 4, 5 und 6, und Textfig. 26.

1879 Nothrus nigrofemoratus, L. Косн, l. c. p. 112, tab. 3, fig. 23, 23a.

1897 Damaeus niyrofemoratus (L. KoсH), MichaEL, 1. c. p. 57.

1900 Scutovertex lineatus (Тнов.) var. TRйG

1901 " " (Тнов.) var. nigrofemorata (L. Косн), ТкӓGÅRDH, 1. с. p. 58.

Die Art, die von Michael als eine gute Art der Gattung Damaeus aufgeführt wird, hat sich bei Untersuchung der Typen als identisch mit der von mir (I9OO) beschriebenen und auf der Bären-Insel gefundenen Varietät von Scutovertex lineatus entpuppt. Thatsächlich ist die von L. KocH gegebene Diagnose und Abbildung so schlecht, daß es nicht merkwürdig ist, daß sogar ein so hervorragender Acaridologe wie Michael die Stellung des Tieres nicht richtig beurteilen konnte. So erwähnt Koch z. B. nichts von der eigentümlichen Skulptur auf dem Notogaster, was allein genügt hätte, das Tier zu identifizieren.

Die Varietät unterscheidet sich von der Hauptform durch folgende Merkmale, wodurch sie sich dem S. bilineatus nähert. Die für S. lineatus so charakteristischen Leisten auf dem Rücken sind größtenteils reduziert; nur an folgenden Stellen sind noch Spuren davon vorhanden: am Progaster, wo die von ihnen hervorgerufene Zeichnung mit derjenigen der Hauptform genau übereinstimmt; in der Mitte des Notogasters, wo gewöhnlich jederseits 2 bis 3 ziemlich deutlich markierte längsgehende Leisten vorhanden sind; auch an den peripherischen Teilen des Rückens sind Reste von ihnen da. Die durch die Reduzierung der Leisten, die übrigens bei den verschiedenen Exemplaren ungleich weit fortgeschritten ist (s. Taf. I, Fig. 4, 5 und 6), entstandenen ebenen Partien zeigen eine eigentümliche Skulptur, welche durch kleine, punktförmige Erhöhungen hervorgerufen wird; dieselbe Skulptur besitzt auch der Cephalothorax, welcher übrigens mit der der Hauptform übereinstimmt. Weitere Verschiedenheiten zeigen die Füße, welche nur eine Klaue besitzen.

Alle diese Merkmale hat die Varietät mit S. bilineatus gemeinsam. Man könnte daher geneigt sein, sie zu dieser Art zu rechnen, aber ein großer Unterschied existiert, der jeden Gedanken an eine nähere

I) MICHAEL, 1. c. p. 570 .

2) TRÄG ÁRDH, Bären-Insel etc., p. 5 . 
Verwandtschaft zwischen beiden zunichte macht. Die Varietät hat sowohl die Pseudostigmata wie die Pseudostigmalorgane gut entwickelt, während diese bei S. bilineatus vollständig verschwunden sind.

Verbreitung: Wajgatsch, Novaja Semlja; Bären-Insel.

Neuerdings ist von Oudemans ${ }^{1}$ ) eine Scutovertex-Art, S. spoofi, beschrieben worden, die von Herrn R. Spoof in subsalinen Wasseransammlungen bei Åbo in Finnland gefunden ist. Diese sollte sich von der sehr nahestehenden S. bilineatus Мıсн, vor allem durch den Besitz von 3 Klauen an den Füßen unterscheiden. Später hatte Oudemans Gelegenheit, reichliches Material von der Art zu untersuchen, und kam dann zu der Auffassung, daß S. spoofi mit S. bilineatus identisch war, trotzdem erstere 3 Klauen, letztere nur eine Klaue besaßen.

Man könnte geneigt sein, diese dreiklauige Form als eine Zwischenform zwischen S. bilinentus und S. lineatus aufzufassen; da aber, wie ich (1. c. p. 6) schon hervorgehoben habe, die var. nigrofemorate als eine solche aufzufassen ist und bei letzterer schon die beiden Seitenklauen reduziert worden sind (die Pseudostigmalorgane sind noch vorhanden), muß die dreiklauige Form von S. bilincatus als eine weitere Entwickelungsstufe von dieser angesehen werden, die in Bezug auf die Zahl der Klauen mit $S$. lineatus konvergiert. Der einzige Unterschied zwischen

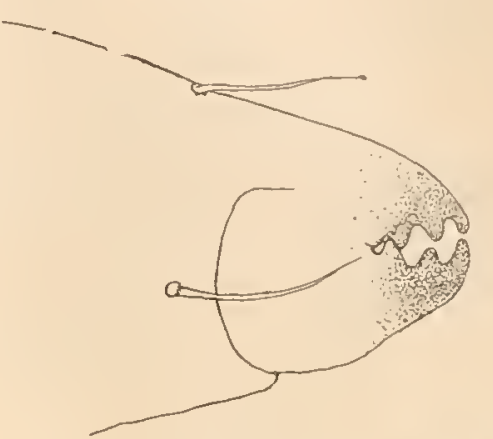

Fig. 26. Mandibel von S. lineutus var. nigrofemorata. Vergr. 620: I.

$S$. lineatus und $S$. bilineatus besteht somit nach dem Funde dieser beiden Varietäten nur in dem Vorhandensein resp. der Abwesenheit von Pseudostigmata und Pseudostigmalorgane.

11. Scutovertex maculatus Mich. var. groenlandica nov. var.

Taf. I, Fig. 7.

Diese Form, von der mir nur ein einziges Exemplar aus Fredrikshaab auf Westgrönland vorliegt, zeigt im großen und ganzen eine so beträchtliche Uebereinstimmung mit der von MichaEL ${ }^{2}$ ) von den Küsten Englands beschriebenen und vom Verf. an den Küsten von Schweden gefundenen S. waculatus, daß ich sie unbedenklich zu dieser Art rechne.

Einige Verschiedenheiten sind jedoch vorhanden, die mich aus Gründen, die ich in der Einleitung auseinandergesetzt habe, veranlassen, sie als eine besondere Varietät aufzuführen. Die Varietät zeichnet sich zunächst durch ihre geringe Größe von der Hauptform aus. Die Länge ist ungefähr 0,46 , die Breite ca. $0,27 \mathrm{~mm}$ (bei der Hauptform resp. 0,54 und 0,30). Es ist um so mehr bemerkenswert, daß die Varietät sich durch geringere Größe von der Hauptform unterscheidet, als im Gegenteil die arktischen Oribatiden für gewöhnlich in einer entgegengesetzten Richtung variieren. So unterscheidet sich z. B. Notaspis bipilis var. sphacrica (L. КосH), Oribata cuspidate var. birulai KvLCz. u. a. von ihren resp. Hauptformen durch bedeutendere Größe.

Weiterhin ist die Farbe braungelb, während die Hauptform dunkel-rotbraun ist. Vor allem ist die Skulptur des Cephalothorax sehr verschieden und vereinfacht. Von den Cephalothorakallamellen sind kaum sehr schwache Andeutungen vorhanden, und keine Borsten sind an ihrem Vorderende eingefügt.

Fundort: Westgrönland. - Die Hauptform kommt an den Küsten von England und Schweden vor.

1) Further Notes on Acari, Tijdschrift voor Entomologie, Bd. ILIII, I900, p. I12, Pl. V, Fig. 6-16.

2) Journ. Royal Micr. Society, Ser. 2, Vol. II, p. I3, Pl. I, Fig. I-5. 


\section{Scutovertex velatus (МiсH.)}

1880 Tegeocranus velatus Michafi, Journ. Royal Micr. Society, Vol. III, p. 189, tab. 6, fig. 6-9.

Ich stimme Oudemans bei, daß diese Art ohne Zweifel der Gattung Scutovertex angehört.

Fundort: Ein einziges Exemplar in Moos bei Cap Stewart in der Scoresby-Straße, Ostgrönland, 30. Juli I 899.

Weitere Verbreitung: Außerdem nur aus England bekannt.

\section{Leiosoma globifer KRAM.}

1897 Leiosome globifer Kramkr, Grönländische Milben. Bibliotheca Zoologica, Heft 20, Lief. 3, VI, p. 80, fig. 2.

Diese Art hat mit $L$. nitens das Vorhandensein einer zwischen den vorderen Cephalothorakallamellen liegenden unpaaren kurzen Spina gemeinsam.

Die Lamellen tragen an ihrer Spitze je ein längeres Haar, sind schmal, werden aber von hinten nach vorn breiter und rücken mit den vorderen Enden einander ziemlich nahe.

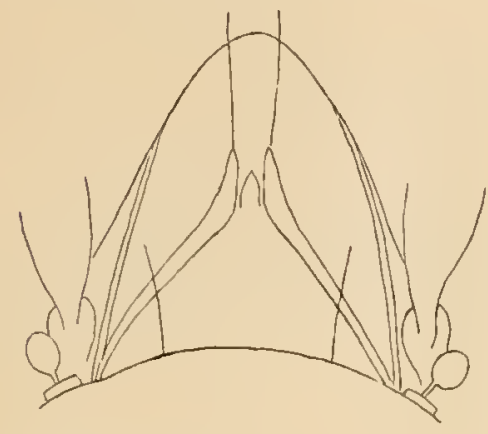

Fig. 27. Cephalothorax von L. globifer (nach KRANER).

Der Cephalothorax ist mit dem Abdomen unbeweglich verbunden. Seitliche Abdominalanhänge fehlen vollständig, und die Oberfläche des rundlich gewölbten Rückens ist glänzend. Ein Tectopedium für das 3. Fußpaar ist nicht zu bemerken. Die Pseudostigmalorgane besitzen ein kugelförmiges, auf einem dünnen Stiel sitzendes Endstück. Die Füße sind mit 3 Klauen ausgerüstet. Die Länge beträgt $0,45 \mathrm{~mm}$. Die Färbung ist ein lichtes Kaffeebraun.

Fundort: Grönland, Karajak-Nunatak, Juli I893. „Die Milbe wurde in einem Süßwassertümpel gefunden, in welchen sie offenbar durch das in dasselbe ausmündende Rinnsal hinabgespült tvar."

Die Art ist nachher von NoRdenskiöld in Finnland am Meeresufer unter Holzabfall gefunden worden. Die finnländischen Exemplare sind größer als die grönländische Form, o,640 mm.

\section{Bestimmungstabelle der Gattung Notaspis Hermann.}

I. $\left\{\begin{array}{l}\text { Beine mit einer Klaue } \\ \text { Beine mit } 3 \text { Klauen. }\end{array}\right.$

2. f Reste von Abdominalanhängen vorhanden . Keine Abdominalanhänge vorhanden 3. Cephalothorakallamellen kurz und niedrig

| Cephalothorakallamellen lang, mit langen Spitzen versehen

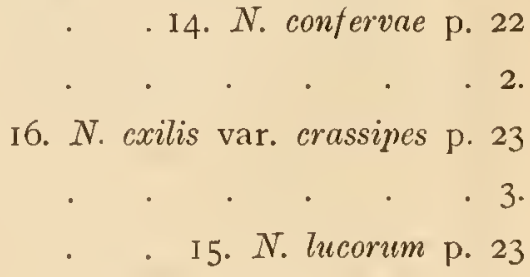

\section{Notaspis comfervae (SCHRANK)}

Taf. I, Fig. 8, und Textfig. 28 und 29.

1781 Acurus confervae, P. Schrank, Enmmeratio Insectorum Austriae indigenorum, No. 1054.

1896 Oppia confervoe (P. Schrank), Oddemans, Notes on Acari. Tijdschr, voor Entomologie, Bd. XXXIX, p. 175, tab. 5, fig. $1-4$

1901) Eremaeus confervae (Sichrank), Otmemaxs, New List of Dutch Acari. I. Ebenda Bd. XLIII, p. 163.

Diese Art liegt mir in 2 Exemplaren aus Ritenbenk auf Ostgrönland vor. Diese sind größer als die von Oudemans beschriebenen, nämlich $0,637 \mathrm{~mm}$ lang und 0,432 $\mathrm{mm}$ breit. Auch einige andere kleine Ver- 
schiedenheiten zeigen sie, indem die Farbe mehr hellbraun ist und die Grenze zwischen Abdomen und Cephalothorax deutlicher hervortritt (Taf. I, Fig. 8). Sonst ist aber die Uebereinstimmung auch in den kleinsten Details so vollständig, daß kein Zweifel über die Identität der grönländischen und der von OuDEIANS beschriebenen Form bestehen kann.

In Uebereinstimmung mit OUdenans' Angabe habe ich auch nicht Lamellenborsten finden können; unmittelbar vor den Vorderenden der Lamellen sind 2 Poren vorhanden, die wie Einlenkungsstellen für Borsten aussehen. Ich glaubte daher zuerst, daß die Borsten weggefallen waren. OudE-

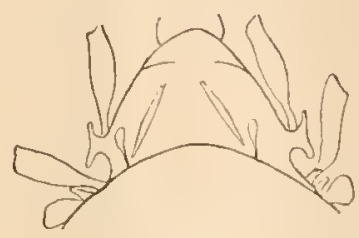

Fig. 28.

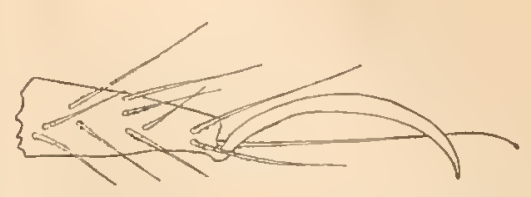

Fig. 29.

Fig. 28. Notaspis confervae (Schrank). Cephalothorax. Vergr. 75: 1 . Fig. 29. " " " Klaue. Vergr. 620:1. ıANS, der reichliches Naterial gehabt hat, erwähnt aber auch diese Poren, ohne Borsten zu beschreiben. Sie scheinen daher konstant zu fehlen.

Fund ort: Ostgrönland, Ritenbenk [W. Lundbeck $\left.\left.{ }^{1}\right)\right]$, IO. Aug. I89o.

Weitere Verbreitung: Niederland und Finnland (unter subsalinen Algen).

\section{Notaspis lucomem Mich.}

1810 Zetes lucorum, C. L. Koсн, l. c. Heft 31, tab. 13, fig. 18.

1888 Notıspis lucorum (Kocn) MichaeL, l. c. Vol. II, p. 371, tab. 30, fig. 1-5.

$1894 \quad$ " $"$ (Косн) Trouessali, l. c. p. 187.

Trouessart giebt an, daß diese Art unter von Spitzbergen heimgebrachtem Moos häufig gefunden wurde, und bemerkt, daß sie überall in den arktischen Gegenden, wo es Moos giebt, vorzukommen scheint. Thatsächlich hat aber niemand außer Trouessart diese Art in arktischen Gegenden gefunden. Eine andere Notaspis-Art dagegen, $N$. exilis var. crassipes, kommt überall in diesen Gegenden vor. Mir scheint die Sache daher etwas verdächtig zu sein. Andererseits kann man doch schwerlich annehmen, daß ein Acaridologe von Trouessart's Rang diese beiden Arten verwechselt hätte. Ich führe daher $N$. lucorum auf seine Autorität hin für Spitzbergen auf.

Fundort: Spitzbergen (TRT.).

Weitere Verbreitung: Ganz Europa.

\section{Notaspis exilis Nıc. var. crassipes (L. КосH)}

Textfig. 30 .

1879 Oribrta crassipes, L. Kocn, 1. c. p. 116, fig. 3, 3a.

1901 Eremaeus crassipes (L. Косн) Trïgárd, l. c.

1902 " $"$ (L. Косн) ТRÄGর̊R土, 1. c. p. 22, tab. 3, fig. 5.

In der vorläufigen Mitteilung über die Revision der von L. Koch beschriebenen Acariden wie auch in "Lappländische Acariden" trat ich MichaEL's Identifizierung dieser Art mit $N$. exilis Nic. entgegen und hob hervor, daß bei $N$. crassipes die Cephalothorakallamellen nicht in Spitzen auslaufen, sondern wie bei N. tilialis Nıc. der ganzen Länge nach eine sanfte Abrundung zeigen. Auch die Pseudostigmalorgane von $N$. crassipes ähneln mehr denjenigen von $N$. tibialis. Ich hatte damals aber eine Ilitteilung von OUdEMans übersehen, worin er konstatiert, daß $N$. exilis sowohl in Bezug auf das Vorhandensein der Lamellenspitzen wie in der Form der Pseudostigmalorgane sehr variiert.

I) Ob sie auch in Grönland unter Confervaceen in Wasser gefunden ist, wird nicht angegeben. 
Die Form crassipes steht somit in demselben Verhältnis zu $N$. exilis wie Oribata notata zu $O$. setosa. Auch die letztere zeigt in Europa eine Variation in Bezug auf die Lamellenspitzen, in den arktischen Ge-

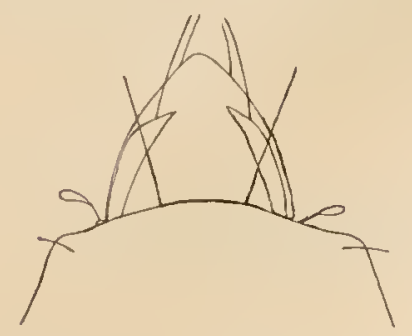

Fig. 30. Cephalothoras von Notaspis exilis Nic. var. crassipes (L. KOCH). bieten findet sich nur die Varietät mit kurzen Lamellenspitzen. Ich will deshalb auch in diesem Falle die arktische Form trotz des verhältnismäßig geringen Unterschiedes von der Hauptform als eine besondere Varietät aufrecht erhalten. Die Länge übertrifft diejenige der Hauptform (resp. 0,46 mm und $0,37 \mathrm{~mm}$ ).

Fundorte: Sibirien; Novaja Semlja; Cap Stewart, Scoresby Sound, Ostgrönland.

Weitere Verbreitung: Lappland.

\section{Notaspis bipilis HeRM. var. sphaerica (L. КосH)}

Textfig. $3 I-34$.

1879 Oppia sphaerica, L. Kocн, 1. c. p. 117, tab. 4, fig. 5, 5a.

1901 Eremaeus bipitis (НеRm.) var. sphaerica (L. Косн), Trägi̊ndh, l. c. p. 59.

1902 " $"$ (HerM.) " " (L. Koch), KuLCZYNski, l. c. p. 17.

Diese Form, zuerst aus Sibirien und Novaja Semlja von L. Koch beschrieben, wurde später von Michael mit $N$. bipilis identifiziert. Zweifelsohne steht sie auch dieser Art so nahe, daß sie nur als eine Varietät von dieser zu unterscheiden ist. Wie ein Vergleich zwischen den Figg. 3I und 32 uns zeigt, sind bei der Varietät nicht nur die Spitzen der Cephalothorakallamellen, sondern auch die Interlamellarborsten, die Pseudostigmalorgane und die Borsten auf den Coxalgliedern des 3. Beinpaares viel kürzer. Das Rostrum (Fig. 33) bei der Var. unterscheidet sich auch von demjenigen der Hauptform dadurch, daß es kaum

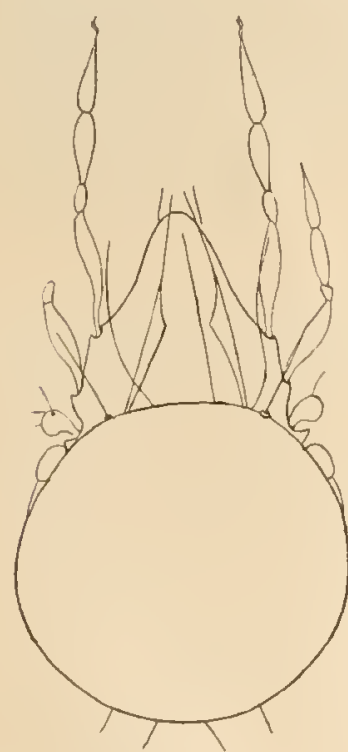

Fig. 3r.

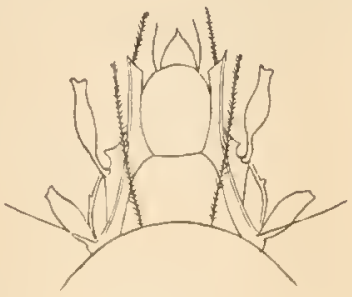

Fig. 32. Fig. 31. Notaspis bipilis var. sphaerica. Vergr. 60: 1 . Fig. 32. " " " " Cephalothorax (nach MiCHAEL). Vergr. 60 : I. Fig. 33. " " " " $\quad$ Rostrum. Vergr. I 50 : I. Fig. 34. " " " " "ephalothorax (nach MichaEL). Von unten gesehen. Vergr. 60: 1 .

merkbar zugespitzt ist. Die Länge der Koch'schen Typen beträgt $0,756 \mathrm{~mm}$, sie sind also größer als die Hauptform, welche nur 0,65 mm lang ist. KulCzYNSK1's Stücke aus Spitzbergen sind noch länger, o,8 mm ${ }^{1}$ ). Verbreitung: Sibirien; Novaja Semlja; Cap Stewart, Scoresby Sound, Ostgrönland; Jan Mayen.

1) Die Exemplare der Hauptform, die ich in Lappland gesammelt habe, sind auch $0,8 \mathrm{~mm}$ lang. 


\section{S. Notrospis aretica Banks}

1899 Opplia arctica, Banks, l. c. p. 349, tab. A, fig. 6.

Diese Art ist sicher mit keiner arktischen Notaspis-Art identisch. Ob sie sonst neu ist oder nicht, ist wegen der schlechten Diagnose und Abbildung unmöglich zu entscheiden.

Fundort: Copper-Insel, Kommandeur-Inseln (Banks).

\section{Damatus geniculatus (L.) C. L. Косн}

Nach Kramer soll diese große und charakteristische Art von der "Vega“-Expedition bei Port Clarence gefunden sein. Da ich das einzige vorhandene Exemplar im Reichsmuseum zu Stockholm nicht habe finden können, ist es mir unmöglich, die Richtigkeit der Identifizierung zu prüfen. Da aber diese Art, wie gesagt, sehr charakteristisch ist, dürfte man wohl annehmen, daß die Identifizierung richtig ist. Es ist allerdings dabei sehr auffallend, daß diese Art nicht und auch sonst keine andere Damaeus. Art in den arktischen Gebieten! gefunden ist, wenn wır von den unsicheren Angaben über "Damreus near geniculatus" bei $82^{0} 30^{\prime}$ n. Br. von FEILDEN und HART ${ }^{1}$ ) und über Damaeus sp. von Grönland ${ }^{2}$ ) absehen.

Verbreitung: Port Clarence; Grönland? Baffins-Bucht $82^{\circ} 30^{\prime} \mathrm{n}$. Br.?

$$
\text { Bestimmugstabelle der Subfamilie Nothrinae. }
$$

I. Rüickenseite des Abdomens konvex

Gatt. Hermannia p. 25

| Rückenseite des Abdomens konkav

Gatt. Nothrus p. 26

Bestimmungstabelle der Gattung Hermanuir Nicolet.

I. Notogaster mit netzförmiger Skulptierung

| Notogaster grob punktiert

20. $H$. reticulata p. 25

21. H. scabra p. 26

\section{DO. Hermannia retialata THORELL}

1871

1879

1888

1899

Hermunia reticulata, Thokell, 1. с. p. 696.

Thomelt, L. Kосн, l. c. p. 112, tab. 3, fig. 21.

Michael, Vol. II, p. 458, tab. 42, fig. 1-7.

quadriscriata, Baxks, 1. c. p. 349 , tab. A, fig. 6 .

Die arktischen Exemplare dieser Art sind von derselben Größe wie die englische Form. Von seiner neuen Art sagt Banks: „This looks much like MıCHAEL's figure of Hermemia reticuluta ThORELL, but certainly is not the species figured by KосH under the name, which, through allied, is easily separated by the longer legs, larger stigmata etc." Es ist kaum vonnöten, hervorzuheben, mit welcher großen Vorsicht man nach Abbildungen urteilen muß, denn auch an den besten Abbildungen können kleine Fehler vorkommen. Daß man sich unter solchen Umständen nicht auf so alte und schlechte Abbildungen wie die von Kосн ohne weiteres verlassen darf, ist natürlich. Ich kann, auf meine Untersuchungen sowohl von THORELL's als Koch's Exemplaren grestützt, versichern, daß sie in den kleinsten Details mit MicHAEL'S H. reticulata übereinstimmen, und BANks hat nicht ein einziges Merkmal, das seine Art von dieser unterscheiden könnte, anzugeben vermocht. Wenn wir noch dazu bedenken, daß H. reticulata sowohi auf Ostgrönland als auf Novaja Semlja, sowohl auf Spitzbergen als auf Jan Mayen gefunden ist, sich also einer weiten Verbreitung in den arkischen Gebieten erfreut, so dürfte dies auch dafür sprechen, daß wir H. quadriseriata Banks sehr ruhig einziehen können.

Fundorte: Novaja Semlja; Spitzbergen, Bären-Insel ; Jan Mayen; kleine Pendulum-Insel, Ostgrönland.

1) NAREs, Narrative of a voyage to the Polar-Sea etc.

2) VANHÖfFEN, Die Flora und Fauna Grönlands. 
Weitere Verbreitung: England. - Es mag hervorgehoben werden, daß sie in England an den Küsten unter Moos und Algen vorkommt.

\section{Hermannia scabra (L. KocH)}

1879 Nothrus scaber L. Косн, 1. c. p. 113, tab. 3, fig. 24.

Fu n dorte: Sibirien, Novaja Semlja, Bären-Insel.

Weitere Verbreitung: Schweden (am Meeresufer unter Steinen in großer Menge, TRÄG̊̊RDH), Finnland [unter Holz am Meeresufer, Nordenskiöld $\left.{ }^{1}\right)$ ], England „in freshwater algae“.

Bestimmungstabelle der Gattung Nothrus C. L. Косн.

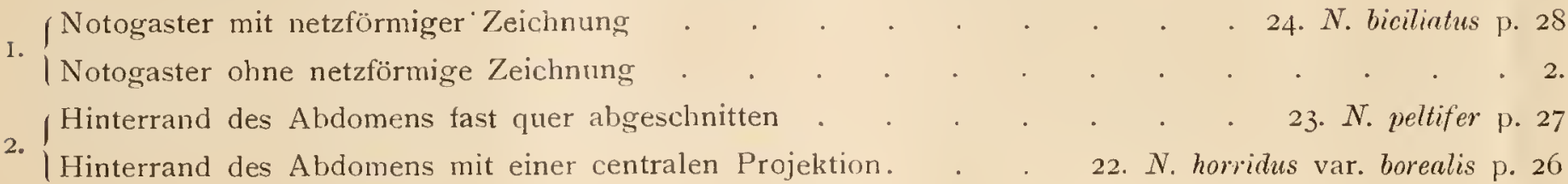

\section{Nothrus homillus (HerM.) Mich. var. borealis (Thor.)}

Textfig. $35-40$.

1871 Nothrus borealis, Thoreli, 1. c. p. 697.

1879 " "Thorels, L. Kocn, l. c. p. 112, tab. 3, fig. 22a-d.

1901 Camisia horrida (Herm.) Triginin, l. c. p. 58.

$1902 \quad " \quad$ " (Herm.) Trägindi, l. c. p. 15, tab. 7, fig. 22 u. 24.

$1902 \quad " \quad$ (Herns.) var. borealis (Thon.) Kúdczynsk, l. c. p. 17.

Diese von ThORElL aus Spitzbergen beschriebene Form wurde später von MichaEL ${ }^{2}$ ) init $N$. horradus (HERu.) identifiziert, und sowohl in der vorläufigen Mitteilung dieser Revision wie in "Lappländische Acariden" vertrat ich dieselbe Ansicht. Kulczynski aber, welcher Gelegenheit hatte, 2 Exemplare derselben aus Spitzbergen zu untersuchen, weist einige kleine Verschiedenheiten zwischen beiden Formen nach und stellt $N$. borealis als eine besondere Varietät von $N$. Twrridus auf. Die Varietät soll sich nach ihm von der Hauptform durch folgende Merkmale unterscheiden: Die Pseudostigmalorgane sind geben die Spitze nicht so ausgebreitet. Die Haare am Hinterrand sitzen in annähernd gleichem Abstand voneinander, während bei der Hauptform die beiden mittleren ungefähr doppelt so weit voneinander entfernt sitzen, wie der Abstand von ihnen zu den lateralen Borsten beträgt. Schließlich ist der mittlere Fortsatz am Hinterrande des Abdomens bei der Varietät viel länger als bei der Hauptform

Um diese Frage endgültig zu entscheiden, habe ich sowohl die Typen von THOrELL und L. Koch als das große Material, das ich teils im Sommer I900, teils im Sommer I903 in Lappland eingesammelt habe, einer neuen Untersuchung unterworfen. Das Resultat dieser ist, daß man berechtigt ist, die arktische Form als eine besondere Varietät anzusehen, nicht aber aus den von Kulczynski angegebenen Gründen, sondern weil es andere kleine Verschiedenheiten giebt. Wie ich bei der Beschreibung von $N$. biciliatus L. KocH auseinandersetzte ${ }^{3}$ ) und auch KuLCzynski zugesteht, ist die Kontur des Hinterrandes nicht unbeweglich, und es ist daher nicht ratsam, zu großes Gewicht auf die von diesem gebotenen Charalitere zu legen. Bei $N$. horridus und der arktischen Varietät desselben, die noch weichhäutiger sind als $N$. liciliatus, variiert diese Kontur sehr erheblich, je nachdem die Tiere in wohlernährtem Zustand sich befinden oder nicht. Un dieses Verhältnis zu beleuchten, brauche ich nur auf die beigefügten Textfiguren hinzuweisen.

\footnotetext{
I) Znr Kenntnis der Oribatidenfaumau Finlands. Acta Soc. pro Fauna et Flora Fennica. I90I, Bd. 21, No. 2, p. 26.

2) Tierreich, p. 72 .

3) Zur Kenntnis der schwedischen Acaridenfauna, 1, p. I4.
} 
Textfig. 35 und 36 zeigen einen großen mittleren Fortsatz, und demgemäß sind die Haare annähernd gleich weit voneinander entfernt. Die Textfig. 37 und 38 sind dagegen sehr wohl ernährte Exemplare und haben demgemäß einen sehr wenig hervortretenden Processus, und die Folge davon ist natürlich, daß die mittleren Haare den lateralen mehr genähert werden und der Abstand zwischen den medialen untereinander relativ größer ist als zwischen ihnen und den lateralen. Das Pseudostigmalorgan (Textfig. 39), das ich mittels Zeichenapparates abgebildet habe, ist gar nicht schmäler als bei der Hauptform.

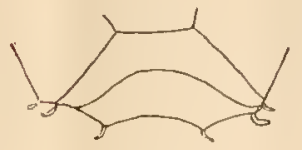

Fig. 35 .

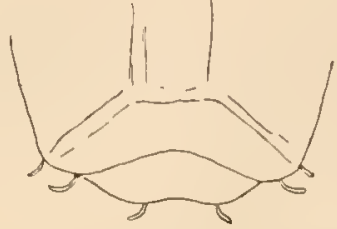

Fig. 36.

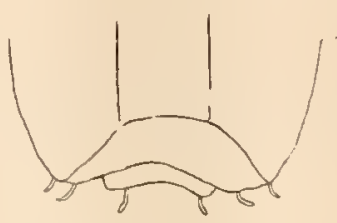

Fig. 37 .

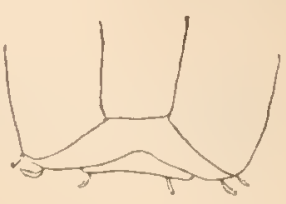

Fig. 38.

Wenn somit die von Kulczraski hervorgehobenen Merkmale eine Unterscheidung von beiden Formen nicht ermöglichen, so giebt es andere, die es thun. So sind die bei der Hauptform vorhandenen sog. Apophysen, auf denen sowohl die Hinterrandhaare wie die übrigen Haare auf dem Abdomen befestigt sitzen, so klein, daß sie nur bei starlier Vergrößerung wahrnehmbar sind. Auch die Haare selbst sind viel kleiner als bei der Hauptform. Zu diesem Unterschied kommt noch, daß die Mandibeln ganz verschieden gebaut sind (Textfig. 40).

Fundorte: Besimanja, Jugor Sharr (Wajgatsch); Sopotschnaja Korga $\left(\mathrm{Br} .7 \mathrm{I}^{0} 4 \mathrm{O}^{\circ}\right.$ )

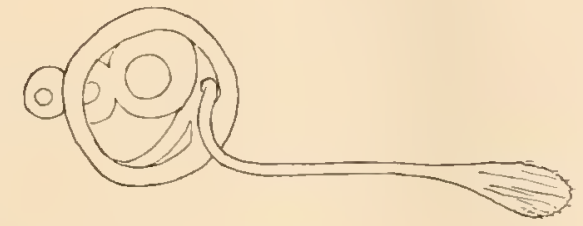

Fig. 39 .

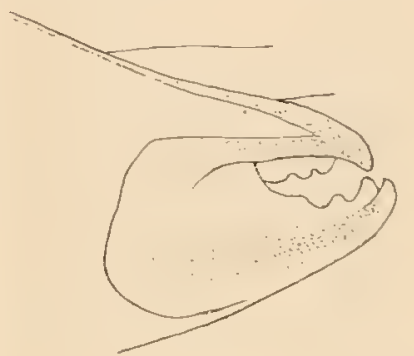

Fig. 40.

[L. Koch]; Spitzbergen (Thorell); Cap

Stewart, Scoresby-Straße, Ostgrönland (5. August IS9I Ryder's-Expedition); Taitip ata, Westgrönland, 27. Juni ISgo auf Lagopus alpinus W. LundBEck.

Weitere Verbreitung: Auf Kărsonjuonje (arktisches Lappland) I050 m über dem Meere I900, TRÄGÅRDH.

Verbreitung der Haupt form: Finnland, Schweden, England, Frankreich.

23. Nothrus peltifer C. L. KocH

1840 Nothrus peltifer, C. L. Косн, 1. c. Fase. 29, tab. 9.

1878 munctatus, L. Косн, l. c. p. 114, tab. 3, fig. 25.

1897 Neoliodes peliffer C. L. Koun), Mronate, Tierreich, Lief. 3, p. 65.

1898 Hermannia carinata, Kr.AMer, 1. c. p. 81, fig. 3.

1901 Camisia peltifera C. L. Косн), Твӓginuн, 1. с. p. 59.

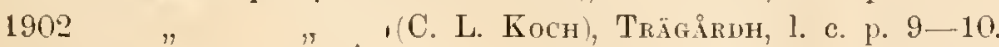

In Bezug auf diese Art und ihre Synonymik verweise ich auf meine Auseinandersetzungen in "Lappländische Oribatiden und Trombididen" und füge nur eine Figur bei.

Fundorte: Gảskap (Novaja Semlja, L. Koch); Bären-Insel, Jan Mayen (NATHORST-Expedition); Karajaknunatak in Umanakdistrikt, Umanatsiak im Umanakfjord Westgrönl., igo3 P. Kraner); Clausholm, IO. August I890, Orpiksuit, I9. Juli i 890 (W. LunDBECK).

Weitere Verbreitung: Kirsonjuonje an der oberen Birkengrenze

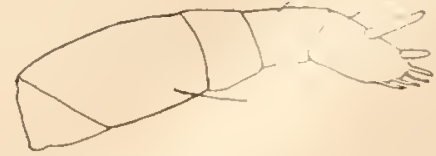

Fig. 4I. Taster von $\boldsymbol{N}$. peltifer. Lappland (TRÄG̊̊RDH); Deutschland. 
24. Nothrus bicilintus (C. L. КосH) TGDH.

1844 Nothrus biciliatus C. L. Косн, 1. c. Fasc. 38, tab. 2.

1902 Camisia biciliata (C. L. Босн), Träg̊̊nd, l. c. p. 10, tab. 2, fig. 4-8.

Auch in Bezug auf diese Art verweise ich auf meine oben citierte Ablandlung.

Fundorte: Auf Harelia glacialis bei Kangersunek, Westgrönland (2I. Juli I89o, W. LundBECK); Hekla-Hafen, Island (I892, Deichiann).

Weitere Verbreitung: Schweden, Kårsonjuonje an der oberen Birkengrenze, unter feuchten Steinen I000-1050 m über dem Meere, Vorovardo, Tarrakoski (TRÄGÅRDH); Finnland (NoRdENSKıöLD); Deutschland, England, Frankreich, Italien, Algier.

\section{Familie Parasitidae.}

Bestimmungstabelle der arktischen Subfamiliender Familie Parasitidae.

I.

(Die Genitalöffnung des ¿ zwischen dem Vorderrand des Sternalschildes und dem Mentum gelegen 2. Die Genitalöffnung des $\delta$ in der Mitte des Sternalschildes gelegen . . . . . . . 4 . 2 .

Das 2. Beinpaar bej dem of größer als bei dem $q$ und mit Hörnern und Zapfen bewaffnet

Das 2. Beinpaar bei beiden Geschlechtern gleich Subfamilie Purasitinae p. 34

Die erwachsenen Individuen leben frei und sind wohl chitinisiert

Subfamilie Laelaptinae p. 32 3. Die erwachsenen Individuen parasitieren auf Vertebraten und sind schwach chitinisiert oder ganz weich Subfamilie Spinturnicinae p. 28 4 .

Die Genitalöffnung des $q$ ist ein transversaler Schlitz zwischen dem Sternal- und dem Genitalschild

Die Genitalöffnung des $q$ mündet in den Sternalschild

Subfamilie Epicriinae p. 40 Subfamilie Uropodinae p. $4 \mathrm{I}$

Bestimmungstabelle der Gattungen der Subfamilie Spinturnicinae.

I. $\left\{\begin{array}{l}\text { Nur die } q \text { mit einem äußerst schwachen Rückenschild versehen; die Oberseite des Körpers unbehaart } \\ \text { Gatt. Sommatericola p. } 28 \\ \text { Beide Geschlechter mit Rückenschild versehen; die Oberseite des Körpers behaart Gatt. Liponyssus p. } 3 \text { I }\end{array}\right.$

Sommatericola nov. gen.

Die Gattung ist 'aut eine Art S. levinseni n. sp. gegründet, die von Herrn Prof. LEvinsen in der Nasenhöhle von Sommaterin mollissima auf Grönland gefunden worden ist. Durch die dorsale Lage der Stigmata und die Abwesenheit des Mentums zeigt sie sich als der Subfamilie Spinturnicinne angehörig. Sie steht dem Genus Ptilonyssus Berl. u. Trouessart am nächsten, unterscheidet sich jedoch so sehr von demselben durch den eigentümlichen Bau der Mandibeln und andere Charaktere, daß sie einen freilich von Ptilonyssus ableitbaren, aber durch eine in Zusammenhang mit der parasitischen Lebensweise bedingte regressive Entwickelung gan $\iota$ besonders gestalteten Typus darstellt.

Diagnose: Körper auf der Oberseite ohne jegliche Behaarung. đohne Rücken schilder. + mit einem Rückenschild. ơ die Klauen des I. Beinpaares: reduziert. q das I. Beinpaar nur mit einer gefältelten Saugscheibe versehen. Mandibeln plump, mit kräftigen Dornen besetzt. 
25. Sommatericola levinsemi nov. spec.

Textfig. $42--47$. Fig. I, 2 und 9 , Taf. 1.

Von dieser Art liegen mir 4 Exemplare vor, darunter 3 Weibchen und I Männchen.

Wie aus den Figg. I und 3, Taf. I, ersichtlich ist, sind die Männchen kleiner als die Weibchen, nach vorn mehr breit abgerundet, nach hinten dagegen mehr zugespitzt und in der vorderen Hälfte des Körpers schmäler als in der hinteren Hälfte. Zwischen den Beinpaaren ist der Seitenrand sanft abgerundet. Die Oberseite des Körpers ist ohne Schilder und ohne Haare oder Borsten. Die Unterseite ist ebenfalls ohne Schilder, dagegen finden sich von Borsten jederseits der Analöffnung eine Gruppe von Io, die eigentümlich gebaut sind, indem sie mit breiter, kegelförmiger Basis beginnen, um in ein feines, peitschenschnurförmiges Ende auszulaufen. Die Taster (Textfig. 42) sind fünfgliedrig und besitzen am vorletzten Glied 2 kräftige Dorne, von denen der innere etwas kräftiger ist. Am letzten Gliede sind 4-5 Borsten vorhanden, von denen die beiden am Ende des Gliedes eingefügten länger sind und fast die Länge des Gliedes erreichen.

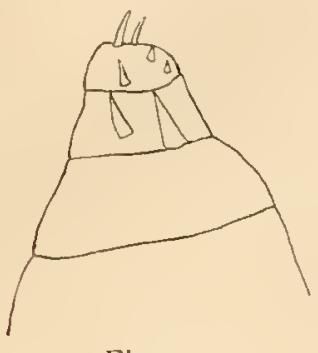

Fig. 42 .

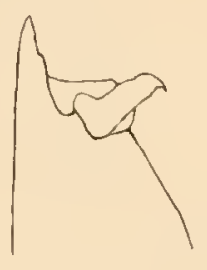

Fig. 43.

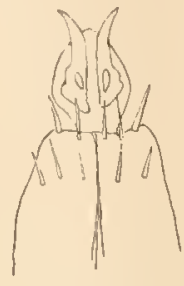

Fig. 44.

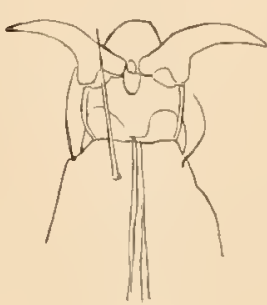

Fig. 45 .

Fig. 42. Sommatericola leninseni $\delta$. Taster. Vergr. 620:1.

Fig. 43. " " " Nandibel. 620: I.

Fig. 44. " " Klaue des 1. Fußes. Vergr. 310:1

Fig. 45. " " " Klaue des 2. Fußes. Vergr. 310:1.

Durch dieses Merkmal, das allein den Männchen eigen ist, nähert sie sich dem Genus Ptilonyssus, und es erweist sich somit in dieser wie in anderen Hinsichten, daß die Männchen nicht so stark umgebildet sind wie die Weibchen.

Den Bau der Mandibeln zeigt Textfig. 43. Die Beine sind sehr kurz und plump und mit Ausnahme des I. Paares unter dem Körper zurückgebogen. Sie sind mit sehr kurzen Borsten ausgerüstet. Das I. Beinpaar trägt am Ende des Tarsalgliedes mehrere kurze Borsten (Textfig. 44), die übrigen Beinpaare tragen nur 3 längere und feinere Borsten (Textfig. 45). Die Klauen und Haftlappen des I. Beinpaares sind kleiner als diejenigen der übrigen Paare (vergl. Textfig. 44 u. 45), welche sehr kräftig entwickelt sind. Sie sind an ihrer Basis mit 2 Gelenkflächen versehen, mit denen sie gegen ein wirbelförmiges Mittelstück gelenkig verbunden sind. Dieses Mittelstück läuft nach hinten in einen Fortsatz aus, der mit einer Sehne verbunden ist. Von der Rückenseite des Mittelstückes entspringt eine kleinere Sehne. Mittels dieser Sehnen wird das Mittelstück um seine Transversalachse gedreht und bewirkt somit das Zurückziehen und das Hervorstrecken der Klauen. Die Stigmata sind äußerst klein und auf der Rückenseite in gleicher Höhe wie der Hinterrand des 4. Beinpaares placiert. Die Analöffnung ist sehr klein, ihre Ränder sind fein gezähnt. Die Genitalöffnung ist vermutlich eine feine Ritze, die auf der Höhe des 4. Beinpaares quer hinüberzieht. Länge ca. 1,5 mm.

Die Weibchen sind ein wenig größer als die Männchen und von einer mehr phumpen Gestalt. Sie sind nach vorn von den Hüften des 2. Beinpaares an breit zugespitzt und am Hinterende sehr breit abgestutzt. Zwischen dem 3. und 4. Beinpaare sind die Seitenränder ein wenig ausgerundet; sie gewinnen 
dadurch eine gewisse habituelle Aehnlichkeit mit Dermanyssus-Arten. Die Oberseite entbehrt der Haare und trägt einen Schild, dessen Form aus Fig. 8, Taf. I, hervorgeht und der die vordere Hälfte des Rückens bedeckt. Der Schild besitzt eine eigentümliche netzartige Skulptur. Auf der Bauchseite ist ein Sternalschild vorhanden, der nach hinten quer abgeschnitten ist und bis zum hinteren Beinpaare reicht. In der Mitte des Sternalschildes sitzen 2 Reihen von je 3 Borsten, die ganz wie bei dem Männchen gebaut sind (Textfig. 46).

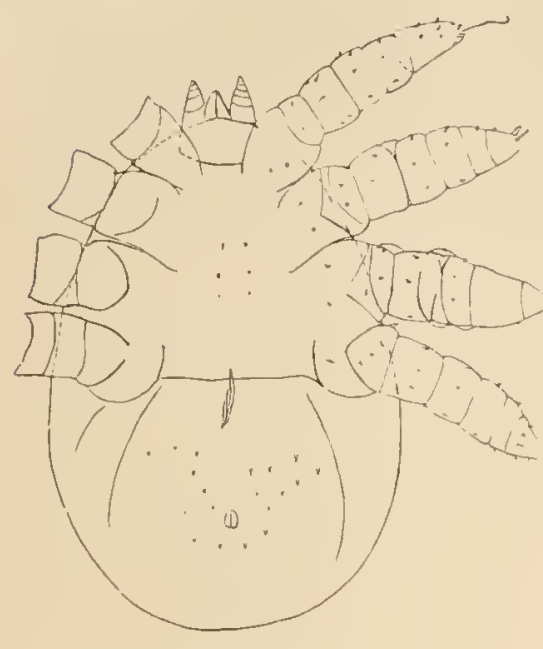

Fig. 46 . Die Analöffnung ist sehr klein und wie beim Männchen von 2 Gruppen von je Io Borsten umgeben. Die Genitalöffnung besteht aus einer feinen, quer hinüberziehenden Ritze dicht hinter dem Sternalschild. Die Taster (Textfig. 47) sind wie beim Männchen plump und haben das 5. Glied doppelt so lang wie das 4., also

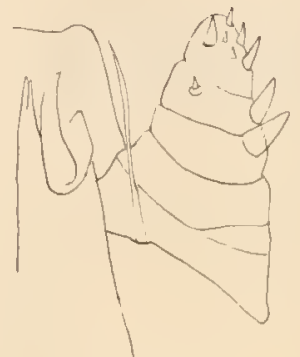

Fig. 47.

Fig. 46. Sommatericola levinscni t. Von der Unterseite gesehen.

Fig. 47

Vergr. 40 : I.

, Mandibel und Taster. Vergr. $406: 1$. länger als beim Männchen, bei dem das 5 . nicht länger als das 4 . ist. Außerdem zeichnen sich die Taster des Weibchens durch mehr dolchförmige Borsten aus, indem das 3. Glied auf der Außenseite eine mächtige Borste, das 4. zwei Borsten trägt, die eine fast so groß wie die des 3. Gliedes und am lateralen Rande eingefügt, die andere sehr klein. Am 5. Glied sind 5-6 Borsten auf der Unterseite eingefügt. Den Bau der Mandibeln zeigt uns Textfigur 47. Das Epistom ist breit-zungenförmig mit 2 abgerundeten, hervorspringenden Ecken.

Die Beine sind gröber als beim Männchen, insbesondere das I. Paar, das auch abweichend gebaut ist, indem die Klauen fast vollständig ${ }^{1}$ ) reduziert sind, während der Haftlappen mächtig entwickelt ist. Die übrigen Klauen sind ungefähr wie beim Männchen gebaut; der Haftlappen ist jedoch größer. Die Stigma ta sind viel größer als beim Männchen und liegen ein wenig mehr nach vorn. Keine besonderen Stigmenschilder vorhanden. Die Peritremata sehr kurz. Die Farbe ist nach der Angabe von Prof. LEvınsEN weiß mit violetten Zeichnungen. Länge I,8 mm.

Die Merkinale, die nach der obigen Beschreibung die Gattung Sommatericola von den übrigen Gattungen der Subfamilie Spinturnicinae unterscheiden - die weiche, nackte Haut, die kurzen Beine und Mandibeln und die Reduzierung der Peritremata - sind sämtlich Charaktere, die unschwer auf die mehr ausgesprochen parasitischen Lebensweise, die sie führt, zurückzuführen sind. Dies geht sofort aus einem Vergleich mit anderen parasitischen Acariden hervor. Mit den Leiognathus- und Dermanyssus-Arten, die ebenfalls sehr gut geschützt auf ihren Wirtstieren leben, hat sie die weiche Konsistenz der Haut gemeinsam. Daß sie jedoch nicht mit diesen Gattungen in näherer Verwandtschaft steht, lehrt uns ein Vergleich der Mundteile. Die Mandibeln und auch die Beine erinnern durch ihre plumpe Gestalt sehr an diejenigen einiger Sarcoptidengattungen, wie z. B. Sarcoptes und Laminosioptes, die tief in der Haut ihrer Wirte vergraben leben. Schließlich steht augenscheinlich auch die Reduktion der Peritremata, die als Sinnesorgane aufgefaßt worden sind, mit der verborgenen Lebensweise in Zusammenhang.

Fundort: In der Nasenhöhle von Sommaterin mollissima auf Grönland (Levınsen).

I) Ob nur das oben beschriebene Mittelstïck oder auch kleine Reste von den Klauen vorhanden waren, konnte nicht festgestellt werden. 
Bestimmungstabelle der Gattung Liponyssus KLtr.

I. Zwei dorsale Schilder bei dem $q$ vorhanden. Der Dorsalschild beim of schmal . 27. L. musculi p. 32 I Nur ein Dorsalschild bei dem $q$ vorhanden.

26. L. semitectus $3 \mathrm{I}$

\section{Liponyssus semitectus (L. КосH)}

Textfig. $48-5$ r.

1879 Sejus semitectus, L. Kосн, I. c. p. 123, tab. 5, fig. 5, 5a.

1883 Lachins prechypus (KосH), Kramer, „Vega"-Expedition.

1883 " hilaris (Косн), KRAмеr, "Vega"-Expedition.

Die grönländischen Exemplare, die auf Myorles torquatus gefunden sind, stimmen gut mit den Typen von L. semitcctus (L. KOCH) überein. Die von KrRAMER mit Laelaps pachypus und hilaris C. L. Koch identifizierten Liponyssus-Arten, die auf Myodes obensis resp. torquatus gefunden waren, gehören wohl auch zu dieser Art, was aus dem Vorkommen auf demselben Wirte mit ziemlich großer Sicherheit geschlossen werden kann. Jedenfalls ist die Identifizierung mit den KocH'schen Arten als vollständig unbegründet zurückzuweisen ').

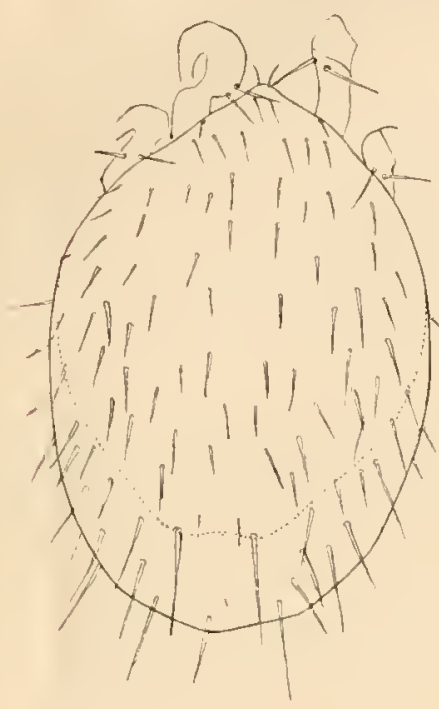

Fig. 48 .

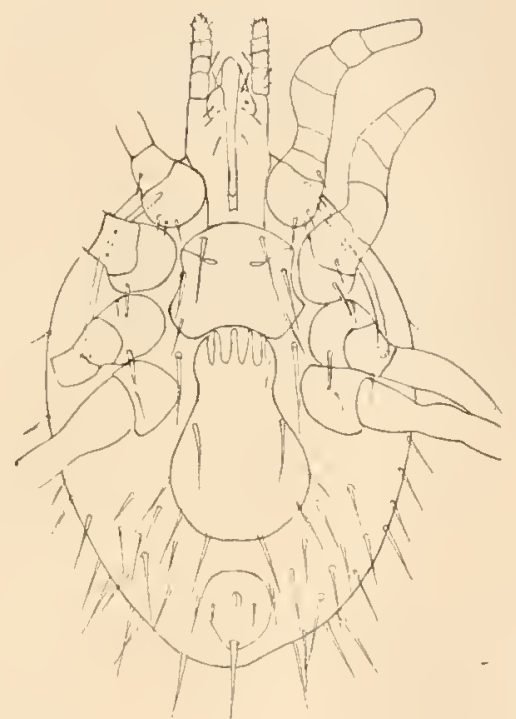

Fig. 49.

Fig. 48. Liponyssus semitectus (L. KOCH). Oberseite. Vergr. 4$^{8}$ : I. Fig. 49. " " " " $\quad$ Unterseite. Vergr. 48: r. Fig. 50. $" \quad, \quad " \quad$ Epistom. Vergr. 620: I. Fig. 51. " " $\quad " \quad$ I. Beinpaar. Vergr. 150: I

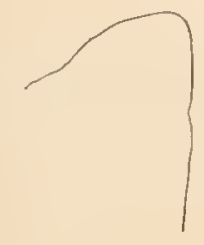

Fig. 50 .

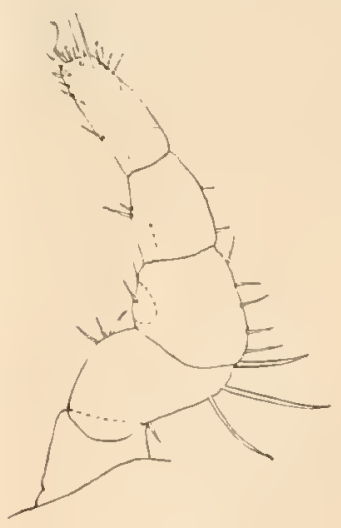

Fig. 5I.

Diese Art steht $L$. albatus und albato-affinis am nächsten, unterscheidet sich aber sotort von ihnen dadurch, daß sie auf der Coxa des 2. und 3. Beinpaares nur je eine grobe Borste besitzt, während L. albatus an diesen je 2, und L. albato-affinis auf der Coxa des 2. Beinpaares eine und auf derjenigen des 3. zwei Borsten besitzt. Der Dorsalschild läßt hinten einen breiten Saum unbedeckt und ist an dem Hinterende zwischen den 2 größeren Hinterrandborsten ein wenig ausgerundet. Die auf dem unbedeckten Teil des Rückens sitzenden Borsten nehmen nach hinten an Größe zu und sind durchschnittlich länger als diejenigen des Rückenschildes. Die Form und den Borstenbesatz des Rückenschildes zeigt Textfig. 49. Das Epistom ist breit zungenförmig (Textfig. 50).

Fundort: Auf Myodes obensis und torquatus. Sibirien (L. Koch, „Vega"-Expedition), Novaja Semlja (L. KOCH), Ostgrönland (W. LUNDBECK).

I) Diese sind nachher nicht wiedergefunden worden, sondern werden mit $L$, agilis von BERLESE identifiziert. 


\section{7.? Limonyssus musculi (C. L. KосH)}

1882 Dermanyssus musculi? (Косн), Kramer, "Vega"-Expedition, p. 528.

Die auf Arctomys eversmanni bei Pitlekaj gefundenen Acariden waren nach KRAMER so jung, daß er sie nicht mit Gewißheit bestimmen konnte. Dermanyssus musculi KocH wird von BerLeSE ${ }^{1}$ ) mit Liponyssus

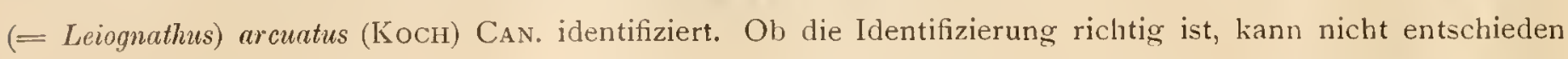
werden, da keine Exemplare in den Sammlungen vorhanden waren.

Fundort: Sibirien, Pitlekaj („Vega"-Expedition).

\section{Bestimmungstabelle der Subfamilie Laelaptinae.}

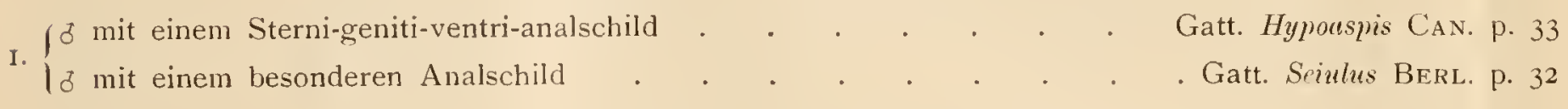

\section{Seinlus ammatus (L. KOCH)}

Textfig. 52-54. Fig. 3, Taf. 1.

1879 Gamasus u:mutus L. Kocn, l. c. p. 119, tab. 4, fig. 8, 8a, 8b.

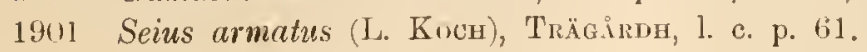

Trotzdem die vorliegende Art insofern von dem Genus Seiulus (Seius) abweicht, als sie 2 Rückenschilder besitzt, zeigt sie doch in anderen Beziehungen so große Uebereinstimmung damit, daß sie unzweifelhaft hierher gehört. Sie zeigt die größte habituelle Aehnlichkeit mit S. hirsutigenus BERL.

Nur Männchen sind vorhanden.

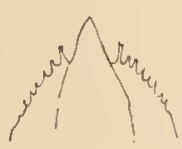

Fig. 52.

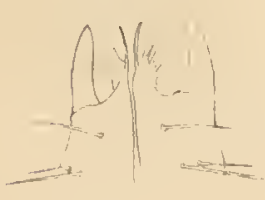

Fig. 53 .

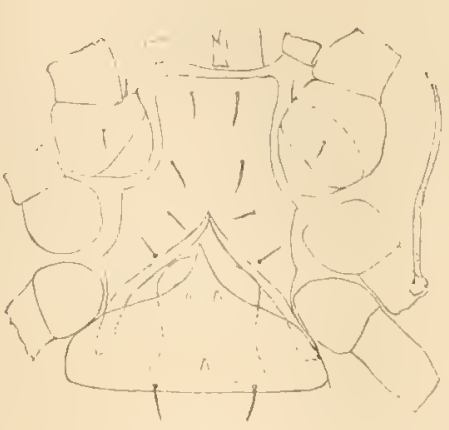

Fig. 54.

Fig. 52. Seiulus armatus (L. KOCH) TGDH. Epistom. Vergr. 150: 1.

Fig. 53. " " " " " Hypostom. Vergr. 150:1.

Fig. 54. " " " " " "

Vergr. $56:$ I.

Die Rückenschilder, die durch eine kaum merlibare Querfurche voneinander getrennt sind, decken fast die ganze Oberseite des Tieres und sind schwach chitinisiert. An dem vorderen Schild treten die Schultern sehr deutlich hervor. Der hintere Schild ist am Hinterende quer abgeschnitten. Die Schilder zeigen eine eigentümliche und luübsche Skulptur, indem sie mit polygonalen Vertiefungen, die durch ein netzförmiges System von niedrigen Leisten begrenzt werden, geschmückt sind. Die Rückenhaare sind schwach weißlich schimmernd und in der Spitze mit kleinen Härchen besetzt. Die Unterseite ist von 3 Schildern gedeckt, von denen der Ventri-analschild sehr groß ist und dieselbe Skulptur wie die Dorsalschilder besitzt. Er ist nach vorn quer abgeschnitten und grenzt unmittelbar an den Genitalschild, welcher dreieckig ist. Der Sternalschild ist nach hinten breiter als vorn und mit 4 Paar Borsten versehen (Textfig. 54). Das Epistom (Textfig. 52) läuft jederseits in einen medianen, zungenförmigen Fortsatz aus, der durch eine kleine Ausbuchtung von den scharf gezähnten Seitenrändern getrennt ist. Den Bau des Hypostoms zeigt Textfig. 53 .

1) Ordo Mesostigmata, p. 21 . 
Ihren Namen armatus verdankt die Art dem Umstand, daß bei dem $\delta$ das 2. Beinpaar mit kräftigen Spornen versehen ist, die nach dem bei den Parasitus-Arten gewöhnlichen Typus gebaut sind (s. Fig. 8, Taf. IV bei L. KocH).

Fundort: Novaja Semlja (L. Kосн).

Bestimmungstabelle der Gattung Hypoaspis Can.

I. Epistom zungenförmig, gezähnt .

I Epistom abgerundet
29. H. amlulans p. 33

30. II. bombicolens var. groenlandica p. 34

\section{Hypoaspis ambulans (THOR.)}

Textfig. $55-58$.

1872 Dernanyssus ambulans, Thовец, l. c. p. 164.

1878 Gamasus ovalis, L. Kón, 1. c. p. 121, tab. 5, fig. 3, 3a.

1901 Laelaps ovalis (L. KoсH), TrägindH, l. c. p. 61.

Das einzig vorbandene Exemplar von D. ambulans stimmt mit denjenigen von G.ovalis vollständig überein.

Von der vorliegenden Art finden sich nur Nymphae generantes. - Im Bau des Epistoms nähert sie sich am meisten $H$. campestris BERL. Das Epstom übertrifft jedoch dasselbe des H. campestris bedeutend an Länge und nähert sich dadurch demjenigen der Gattung Emeus MÉGN. Der Umrißß des Körpers ist eiförmig, nach vorn zugespitzt, nach hinten wohl abgerundet. Am Seitenrande vor den Schultern jederseits eine sanfte Einbuchtung. Die Oberseite des Tieres ist von einem ungeteilten Schild so vollständig bedeckt, daß nur ein sehr kleiner weißlicher Randsaum unbedeckt bleibt. Die ganze Oberseite ist mit kurzen, dicht anliegenden Härchen ${ }^{1}$ ) besetzt, nur am Vorderrand sitzen 2 etwas längere, nach vorn gerichtete Haare. Auf der Unterseite sind Sternal-, Genital- und Analschilder vorhanden, deren Form Textfig. 56 zeigt. Außerdem sind Spuren von Metapodialschildern vorhanden. Die ganze Unterseite ist wie die Oberseite mit kurzen Härchen besetzt. Auf dem Sternalschild sitzen, regelmäßig verteilt, 5 Paar etwas größere Haare und auf dem Genitalschild 7 Paar

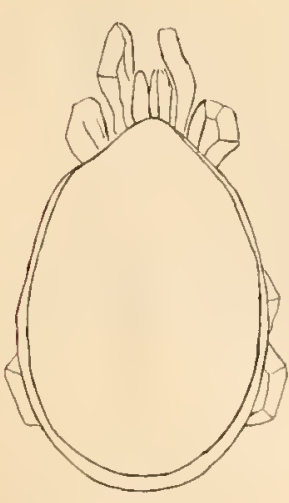

Fig. 55 .

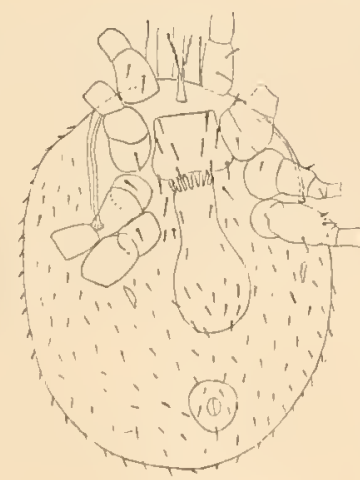

Fig. 56 .

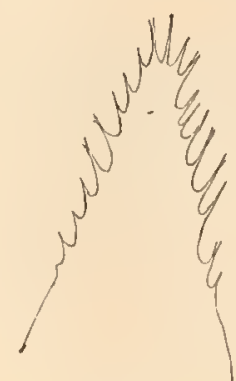

Fig. 57 .

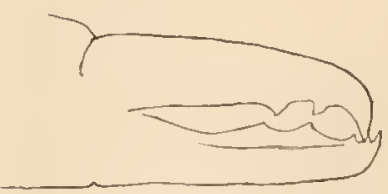

Fig. 58 .

Fig. 55. Hypoaspis ambulans (THOR.). Die Oberseite. Vergr. 30: I. Fig. 56. " " " Die Unterseite. Vergr. 37,5: I Fig. 57. " " " Epistom. Vergr. 620:1 Fig. 58. " " $\quad " \quad$ Mandibel. Vergr. $620: 1$.

(Textfig. 56). Das Epistom (Textfig. 57) läuft in eine Spitze aus, deren Rand tief sägeförmig eingeschnitten ist ; die Zähne sind oft gabelförmig geteilt. Die Mandibeln sind in Textfig. 58 abgebildet. Die bei anderen HypoaspisArten vorhandenen, auf dem unbeweglichen Teil der Schere sitzenden Borsten habe ich nicht finden können.

Im Bau der Taster und Beine findet sich nichts Bemerkenswertes. Länge: I mm.

Fundort: Sibirien: Jenissej (L. Koch); Grönland: Tasersuak, I5. August I89o (W. LundBECk), Quanersoit (Thorell); Ostgrönland, Rıde $\sigma$ (Ryder's Expedition); Island, Hekla-Hafen, I892 (Deıchuann).

I) Diese sind in der Textfig. 55 nicht eingezeichnet. 
30. Hypoaspis bombicolens (CAN.) var. groenlandiea nov. var.

Textfig. 59 u. 60 .

1842 Laelaps nanus? Mign., Kriamer, "Tega"-Expedition, Bd. III, p. 259.

Die vorliegende Varietät ${ }^{1}$ ) wurde in großer Menge auf Bombus sp. zusammen mit Parasitus bomborum bei Tigsalük auf Grönland gefunden. Sie hat alle Hauptmerkmale mit H. bombicolens (CAN.) ${ }^{2}$ ) gemeinsam, wie uns ein Vergleich der beigefügten Figuren ('Textfig. 59 u. 60) mit BerLese's Abbildungen zeigt. Da auch die Mandibehn miteinander völlig übereinstimmen, so ist es außer Zweifel gestellt, daß man auf

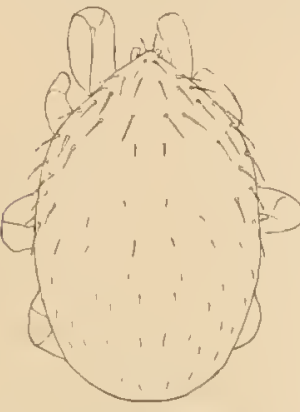

Fig. 59.

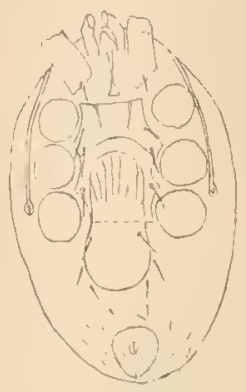

Fig. 60.
Fig. 59. Hypoaspis bombicolens (CAN.) var. groenlandica nov. var. Dorsalausicht. Vergr. $48: \mathbf{r}$.

Fig. 6o. Hypoaspis bombicolens (CAN.) var. groenlandicn nov. var. Ventralansicht. Vergr. $48: 1$.

Areolierung, die nur bei stärkerer Vergrößerung deutlich hervortritt, und durch die ebenfalls nur bei stärkerer Vergrößerung wahrnehmbare feine Punktierung der Chitindecke.

Die von der ,Vega“-Expedition bei Jinretlen gesammelte und von KRAMER als Laelıps nanus? MÉGN. bestimmte Acaride war glücklicherweise in den Sammlungen vorhanden. Sie entpuppte sich als mit $H$. bombicolens var. groenlandica identisch.

Fundort: Sibirien, Jinretlen (,Vega"-Expedition); Grönland, Tigsaluk auf Bombus sp. (W. LundBeck).

Bestimmugstabelle zu den Gattungender Subfamilie Parasitinae.

If Genitalschild nach vorn abgerundet, parallel mit dem Hinterrand des Sternalschildes . . . 2.

Iq Genitalschild triangulär, nach vorı zugespitzt

Gatt. Parasitus Latr.p. 35 f Das I. Beinpaar ohne Ambulacren

I Das I. Beinpaar mit Ambulacren

Gatt. Macrocheles LATR. p. 39 Gatt. Cyrtolaclaps BERL. p. 34

I. $\left\{\begin{array}{l}\text { Epistom mit } 3 \text { Spitzen } \\ \text { Epistom mit einer Spitze }\end{array}\right.$

31. C. koehi p. 34

32. C. exeisus p. 35

\section{\$1. Cyrtolaelaps kochi TGDH}

Textfig. 6 I u. 62.

1879 Gumasus emarginntus, C. L. Konн, L. Косн, 1. с. p. 119, tab. 4, fig. 7, 7a.

1901 Cyrtolaelaps kiochi, TrägínoH. Torläufige Mitteilung, 1. 61.

Die von L. Koch als G. emarginatus ${ }^{3}$ ) abgebildete Art gehört der Gattung Cyrlolaelaps an, was sofort aus dem charakteristischen Epistom hervorgeht.

I) Daß diese Varietät nicht mit A. colectptratorum. FABR. jdentisch sein kann, geht durch den Ausdruck „ano abicante“ der Diagnose hervor. Bei der Var. bedeckt nämlich der Rïckenschild den ganzen Körper. während bei $P$. bomborum hinten ein 'leil unbedeckt ist.

2) Ordu Mesostimmatid.

3) Die von Berlese vorgenommene Identitizierung mit Pueciluchivus cmaryinalus ist unrichtig 
Durch den Besitz von 2 Rückenschildern und getrennten Anal- und Ventralschilden zeigt sie sich als mit C. nemorensis (C. L. KocH) am nächsten verwandt. Anderseits hat sie mit C. cormutus KRAM. 2 kileine Zapfen am Hinterende des hinteren Dorsalschildes gemeinsam. Diese sind allerdings sehr klein, und es scheint nir daher nicht unmöglich, daß man sie bei $C$. nemorensis übersehen hat.

Diese Art kommt auch auf Grönland vor. Die grönländischen Exemplare weichen im Bau des Epistoms (Textfig. 62) von den sibirischen ein wenig ab.

In Bezug auf die Form der verschiedenen Schilder verweise

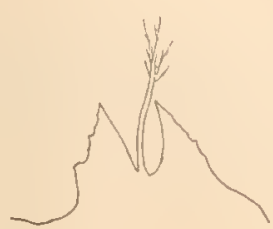

Fig. 61.

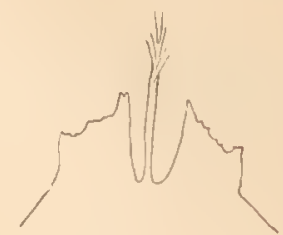

Fig. 62. ich auf L. Koch's Abbildungen, die ziemlich gut sind.

Fundort: Sibirien, Novaja Semlja (L. Koch); Grönland, Ipiutat, 6. September I889 (W. Lundbeck).

\section{Cyrtoluelays excisus (L. КОСН)}

Textfig. 63 u. 64.

1878 Sejus excisus, L. Kuch, 1. c. p. 122, tab. 5, fig. 4, 4a.

Der schlechte Zustand des einzigen Exemplares erlaubte keine eingehendere Untersuchung. Die Form der 2 Rückenschilder stellt die Art in die Nähe von C. nemorensis (C. L. KocH), von dem sie sich jedoch durch den Bau des Epistoms (Textfig. 64) deutlich unterscheidet. In Bezug auf die Unterseite verweise ich auf L. Koch's Abbildung.

Fundort: Sibirien, Jenissei (L. Koch).

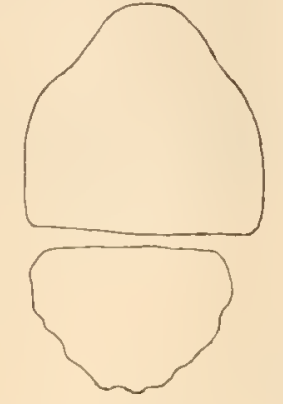

Fig. 63.

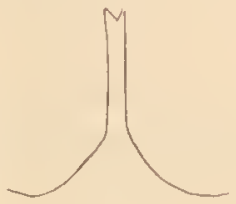

Fig. 64 .

Fig. 63. Cyrtolaelaps exeisus (L. KOCH). Rückenschilder. Vergr. 60: I,

Fig. 64. Cyrtolaelaps exeisus (L. KOOCH). Epistom. Vergr. 620:I.

Bestimmungstabelle der Gattung Parasitus LATr.

I. $\left\{\begin{array}{l}\text { Epistom mit } 3 \text { Spitzen Epistom mit einer medianen Spitze und } 2 \text { lateralen, gerundeten Loben } \\ \text { Epistom mit einer medianen Spitze und mehreren kleinen lateralen Zähnen }\end{array}\right.$

f Die mediane Spitze vorn ausgerundet

I Die mediane Spitze nicht ausgerundet

f Die lateralen Spitzen ausgerundet

3. I Die lateralen Spitzen nicht ausgerundet

\section{Parcsitus bomborm OUdms.}

Textfig. 65 .

1780 Acarus coleoptratorum, Fabricius, Fauna groenlandica, p. 224.

190. Parasitus bomborum, Oudexaxs, New list of Dutch Acari. Tijdschr, voor Entomologie, $\mathrm{XLV}$, p. 33, tab. 3 , fig. $54-57$.

Die grönländischen Exemplare stimmen in Bau und Behaarung des Rücken- und Bauchschildes vollkommen mit Oudemans überein. Das Epistom weicht insofern ab, als der mediane Zahn viel größer als die lateralen ist und alle 3 mehr zugespitzt sind als bei seiner Form. Da
33. P. bombormm p. 35
35. P. spinipedformis p. 37
35. P. spinipes p. 36 36. P. fucicola p. 38
37. P. colcoptratorum p. 39 


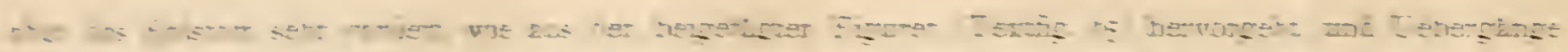

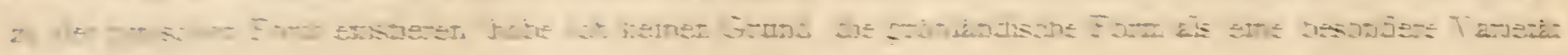

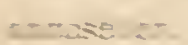

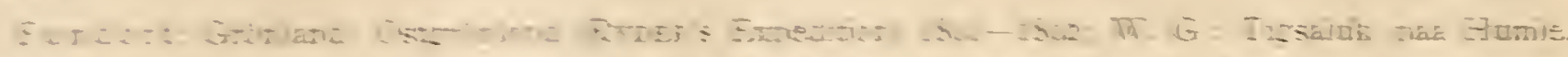
: Sersertate

W.

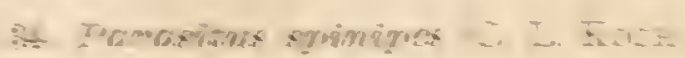

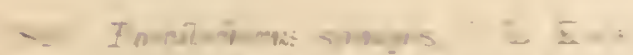

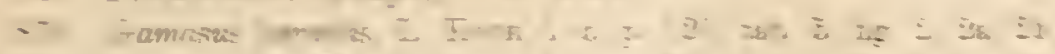

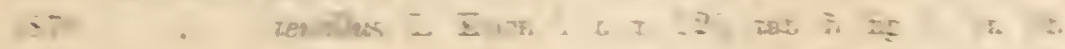

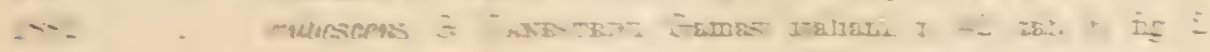

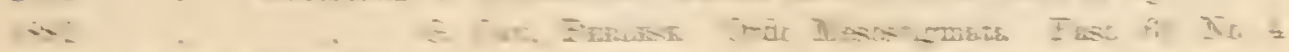

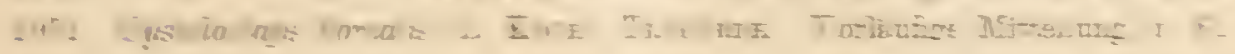

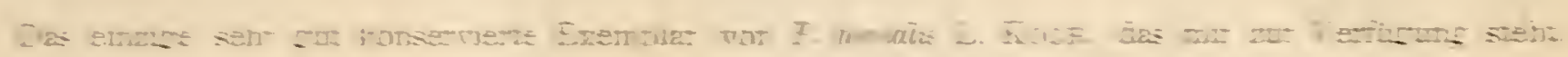

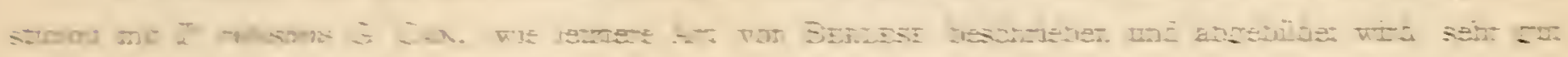

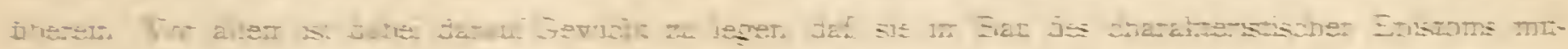

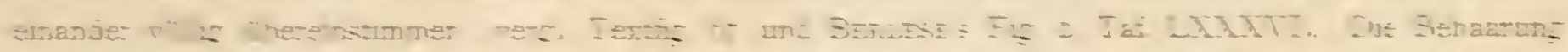

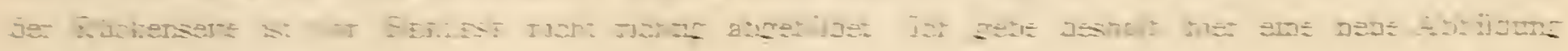

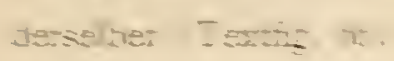

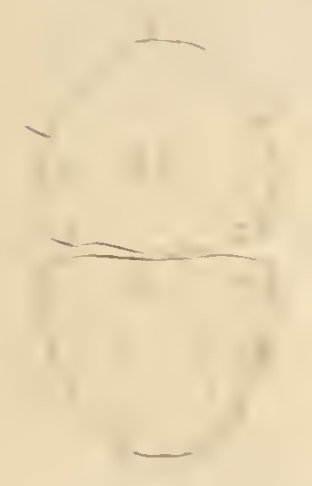

Tis n

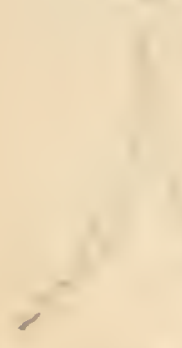

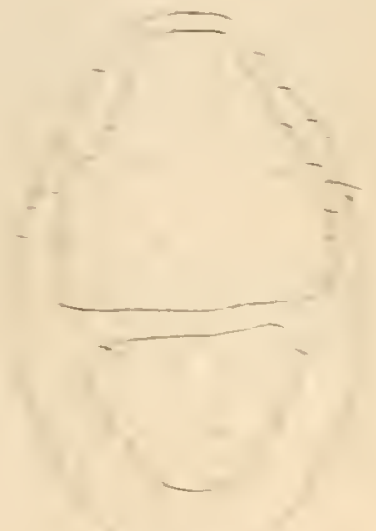

$-$

$=1-$

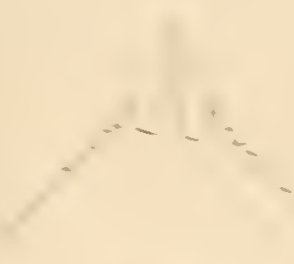

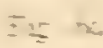

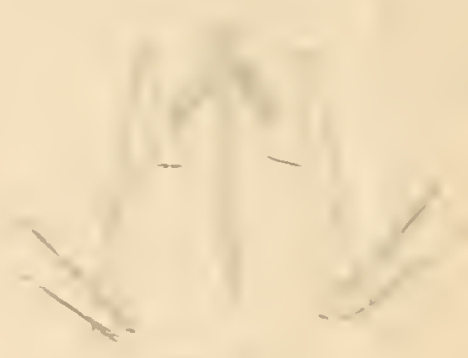

$\equiv=$

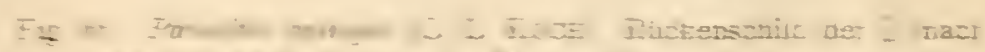

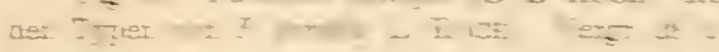

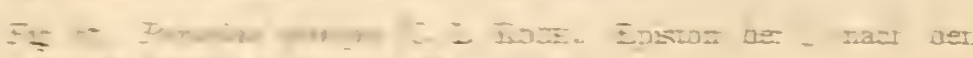

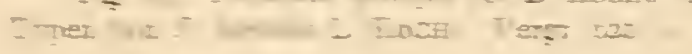

E-

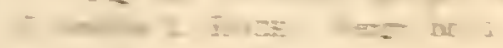

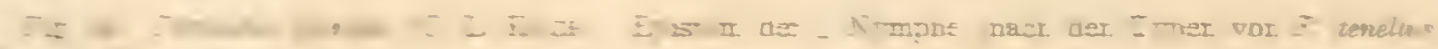

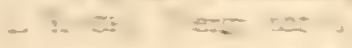

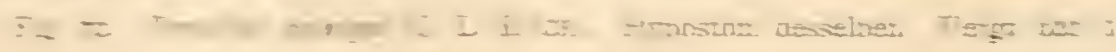

$=-\cdots$

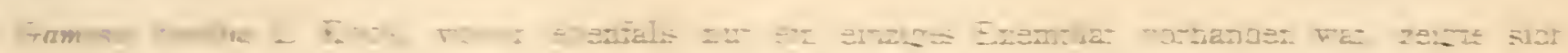

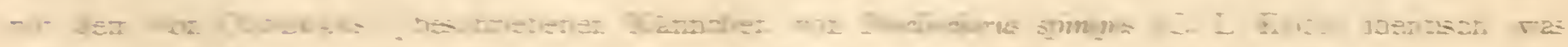

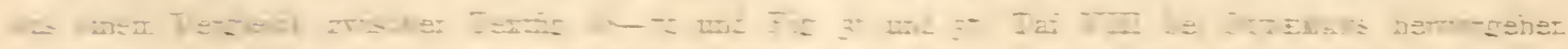

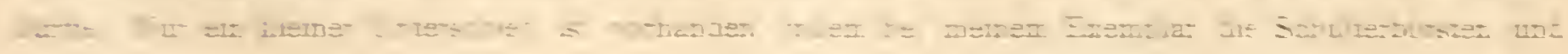




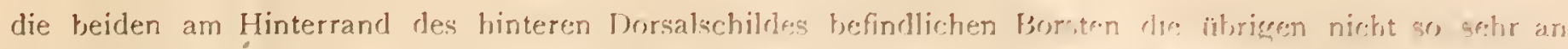

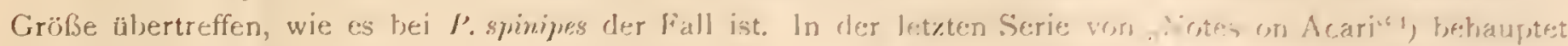

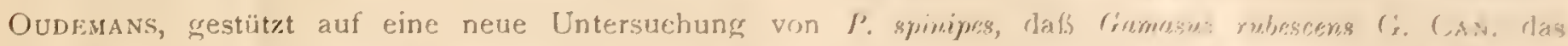

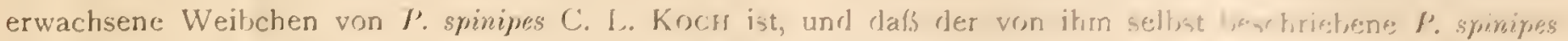

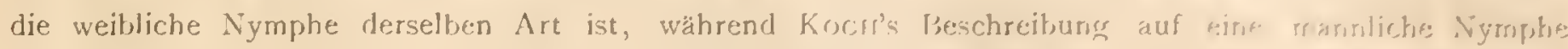
gegründet ist. Da ich keine Ursache habe, die Richtigkeit dieser Pechauptung nu he\% weifen, irdentifixisere

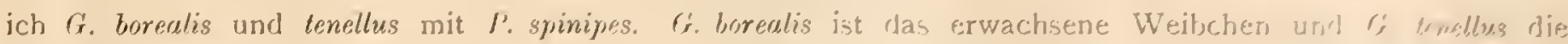
weibliche Nymphe.

Fundort: Sibirien, Jenissej (L. Kocrr); Novaja Semlja (L. Kor:rr).

Weitere Verbreitung: Niederland, Deutschlanrl, Italien.

\section{3.). Iromsitus spimiperlifommiss nov. spec.}

Textfig. $7 x-76$.

Durch die Form der Dorsalschilder und des Epistoms nähert sich vorliegende Art I'. spripipes (I,. Kor, fs). wie Oudewans (1. c.) sie abbildet. Die Form des Epistoms schließ̉ aber jeden Gedanken an eine Irleritiät der beiden Formen aus (vergl. Textfig. 73 und Fig. 40, Taf. VIll bei Ounewavs).

Nur ein einziges Exemplar ist vorhanden, eine Nympha coleoptrata, die auf einer Fliege auf (irínlarid gefunden wurde. Sie nähert sich also auch in der Lebensweise f'. spinipes, dessen Nymphae coleoptratae anf Dipteren gefunden werden.

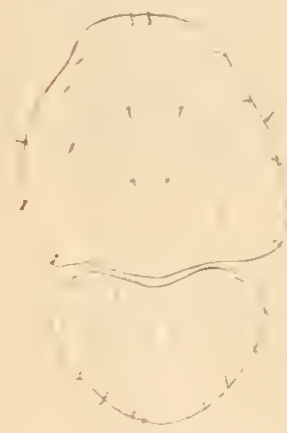

Fig. 71 .

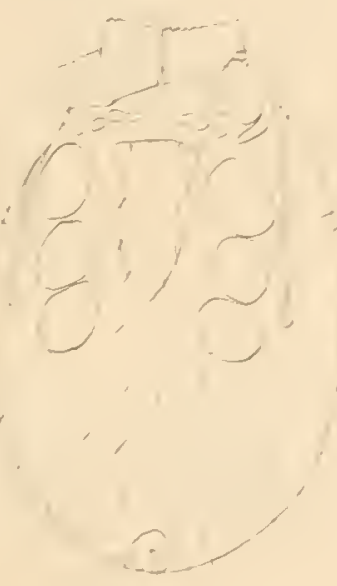

Fig. 72.

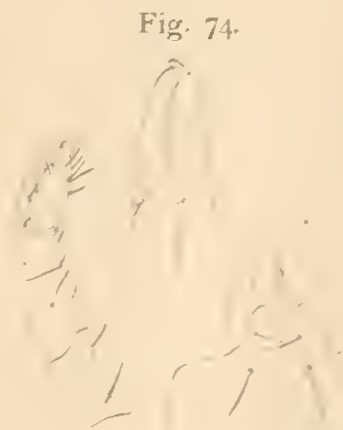

Fig. 75

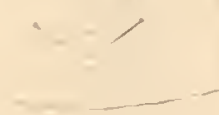

Fig. 76.

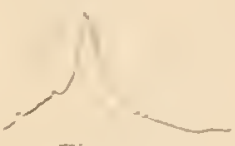

Fig. 73 .

Fig. 71. F. spiniperliformis nov. spec. Die Rückenschilder. Vergr. $56,25: 1$.

Fig. 72. P. spinipediformis nov. spec. Ventralansicht. Veror. $56,25: \mathrm{i}$.

Fig. 73. F. sprinipediformis nov sper. Epistom. Vercr. 1:0 : 1.

Fig. it. P. spinipediformiz nov. spec. Wandibel. Vergy. $112,5: 1$.

Fig. 75. F'. sprinipestrformis nov. spec. Taster. Verer. $1125:$ i.

Fig. ${ }^{6}$. P. spinipodiformis nov. spec. Hypostom. Vergr. 112.5: I.

Die Farbe ist lichtgelh. Die Haut ziemlich weich. Die Rückenseite von 2 Schildern berleckt (Textfig. 7I). Der vordere ist nach vorn ziemlich breit abgestutzt und an den Schultern ein wenig ausgerundet; die Kontur des Hinterrandes zeigt eine sanfte centrale Aushuchtung. Der hintere schild ist nach vorn breit ausgerundet und mit einer fast kreisrunden hinteren Kontur versehen. Beide Schilder sind nur sel: spärlich mit kleinen Haaren besetzt, deren Verteilung Textfig. Tr zeigt. Auf der Unterseite ist ein Is:eckiger Sternalschild der 4 Paar Haare trägt, und ein kleiner Analschild wrorhanden. Auferder. - 1 3 Paar Jugularschilder vorhanden (Textfig. 72 ). Die Behaarung ist spärlich. Die Stigmata lieger. L L Ler Höhe des 4. Beinpaares. Das Epistom läuft in eine scharfe Spitze aus (Textfị. 73), die dopta.: 3 lang wie ihre Basalbreite und ohne Zähne ist. Zu beiden Seiten derselben finden sich kleintre Zähre. Die

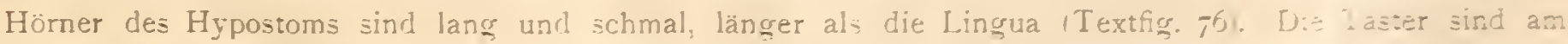
1 Eight series. Tijdschr. d. Vied. Dierk, Vereen., 2, Vol. VTII, Afl. 2. p. 75 , Tâf. V, Fig İ- 5 
I. Glied auf der Innenseite mit einem stumpfen Zahn versehen (Textfig. 75). Die Mandibeln ohne Borsten, init schwachen und stumpfen Zähnen (Textfig. 74). Die Beine zeigen keine besonderen Merkmale. -Länge ca. I $\mathrm{mm}$.

Fundort: Grönland, Ritenbenk, 20. Aug. 1890, auf einer Fliege (W. Lundbeck).

\section{Pardesitus fucicola n. sp.}

Textfig. $77^{--} 82$.

?1779 Acarus fucorum, Fabricius, Reise uach Norwegen.

Diese Art steht $P$. fucorum (DE GEer), wie sie Monifz beschreibt ${ }^{\mathrm{I}}$ ), sehr nahe. Sie unterscheidet sich jedoch deutlich davon durch den abweichenden Bau des Epistoms, der Taster und Mandibeln. Der von FABRICIUs auf seiner Reise in Norwegen unter Fucus gefundene Acarus fucorum wird von MoniEz und Oudemans mit $P$. marinus Bradr ${ }^{2}$ ) identifiziert. Moniez begründet nicht seine ldentifizierung, Oudemans dagegen macht den Hinweis, daß die von FABRICIUs gegebene Diagnose „pallidus; lineis duabus dorsalibus flexuosis nigris, pedibus posticis brevissimis incurvis" ganz auf seine Exemplare von $P$. marimus (BRADY)

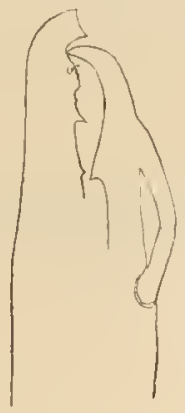

Fig. 77.

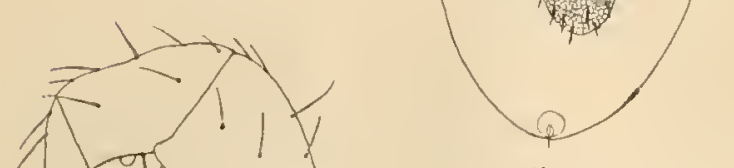

Fig. 79.

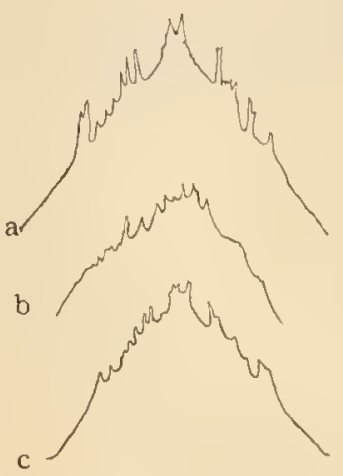

Fig. So.

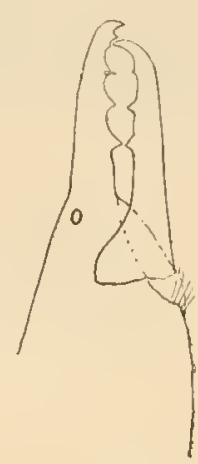

Fig 8r.

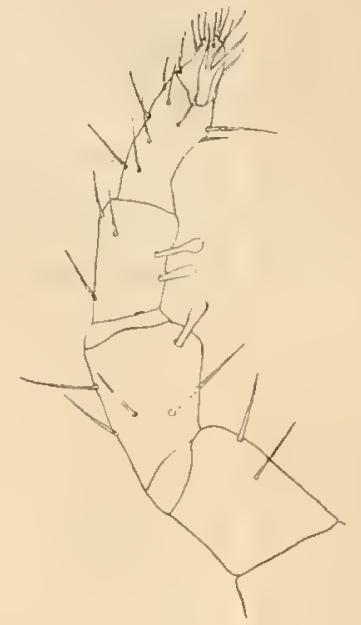

Fig. 82.

paßt. Diese zeigen nämlich auf dem Rücken 2 schwärzliche Linien (die durch den Darminhalt hervorgerufen werden) und tragen die hinteren Beine unter dem

Fig. 78 . Abdomen zurückgebogen. Die beiden Charaktere, die wohl ziemlich zufälliger Natur sind, hat aber $I$. fucicola mit $P$. marinus gemeinsam. In der FABRICIUSschen Diagnose finden sich keine Angaben, welche zu Gunsten einer ldentifizierung mit der einen oder der anderen dieser Arten sprechen. Wegen der nördlichen Fundorte von A. fucorum Fabricius bin ich aber geneigt, sie mit meinem $P$. fucicola zu identifizieren, was leider noch nicht entschieden werden kann, da die Parasiten Norwegens noch nicht untersucht worden sind. Da die Art, wie oben gesagt, $P$. fucormm ${ }^{4}$ ) (DE GEER) sehr nahe steht, genügt es, den Unterschied hervorzuheben.

1) R. Moniez, Acariens et Insectes marins des côtes du Boulonnais. Revue Biol. du Nord de la France, ISgo, p. I52 bis 159, Fig. $1-7$.

2) ]. c.

3) Der vordere Dorsalschild hat dieselbe Zeichnung wie der hintere.

4) Ob wirklich der von MoNiEz beschriebene $l$. fucorm mit dem von BERLEsE beschriebenen identisch ist, erscheint mir sehr fraglich. Ich vergleiche hier meine Art nur mit der von M. beschrielsenen. 
ठ. Unter den Exemplaren war ein ơ vorhanden, der im Bau des I. Beinpaares (Textfig. 7S) mit dem von Monıez beschriebenen $P$. fucorum var. $\beta$ fast vollständig übereinstimmt (s. 1. c. Fig. 5). Auch die Mandibeln zeigen eine große Aehnlichkeit, wenn wir von dem Unterschied absehen, der daraut beruht, daß MonıEZ wohl nicht genau alle die kleineren Zähne abgebildet hat. Das Epistom ist bei der Präparation der Mandiheln zerstört worden, so daß ich nicht sagen kann, ob es ebenfalls mit demjenigen von $P$. fucorum var. $\beta$ übereinstimmt.

9. Auf der Oberseite des Tieres sind die Haare auf den Rückenschildern, wie Textfig. 79 uns zeigt, plaziert. MonıEz erwähnt überhaupt nicht die Plazierung der Haare. Das Epistom (Textfig. 80) variiert sehr: zuweilen kann man, wie bei $P$. fucorum, außer dem medianen Zahn, der immer zweigespaltet ist; jederseits 2 größere Zähne bemerken. Fast immer ist das Epistom mehr oder minder asymmetrisch, bisweilen ist die Asymmetrie sehr ausgesprochen (Textfig. 80). Wenn man auf die Genauigkeit der von Monız gegebenen Zeichnungen sich verlassen kann, so ergiebt sich als Unterschied, daß bei $P$. fucorum der mediane Zahn verhältnismäßig länger ist und daß die Seitenränder mit Ausnahme von 3 bis 4 größeren Zähnen völlig eben sind, während sie bei $P$. fucicola meist fast der ganzen Länge nach unregelmäßig gezähnt sind. In Anbetracht der großen Variation dieses Organes, sowohl bei $P$. fucorum wie bei $P$. fucicola, ist aber auf diesen Unterschied kein größeres Gewicht zu legen. Im Bau der Mandibeln (Textfig. 8I) stimmen die Formen insofern miteinander überein, als sie beide im berveglichen Teil der Schere 3 und im unberveglichen 5 Zähne haben. Sonst unterscheiden sie sich dadurch, daß ersterer Teil bei $P$. fucicola kürzer, bei $P$. fucovum dagegen länger als der unbewegliche Teil ist. Auch in der relativen Größe der verschiedenen Zähne existieren Verschiedenheiten (vgl. Textfig. 8I und Fig. 3, p. I56, bei MonıEz). Die Taster (Textfig. 82) tragen 3 umgewandelte Borsten, die sog. Calceoli, von denen 2 auf der Innenseite des 3 . und eine auf der Innenseite des 2. Gliedes ${ }^{1}$ ) sitzen. Sie sind nicht zugespitzt, sondern mit einer meißelförmigen Schneide versehen.

Fundort: Grönland: Godhaab, 20. August 1883 (Th. NeErgaArd); Ikamint, I4. Juli I8go [unter faulendem Tang] (W. LundBEck).

\section{Parasitus coleoptratomum (L.) KR.}

1879 Gemasus coleoptratorum (L.), L. KncH, 1. c. p. 119.

$1882 \quad$ " $\quad$ (L.), KrajLer, "Vega"-Expedition, Bd. III, p. 529.

Von der mit diesem Namen von L. Kock bezeichneten Acaride finden sich keine Exemplare in den Sammlungen, und da er keine Abbildung davon giebt, ist es unmöglich zu entscheiden, ob die Identifizierung berechtigt ist. Dagegen dürfte man mit Sicherheit annehmen können, daß KRAMER's Bestimmung zuverlässig ist, da es gerade KRAMER ist, welcher die jetzt allgemein mit dem Namen $P$. coleoptratorum (L.) bezeichneten Acariden ausführlich beschrieben hat.

Fundort: Sibirien: Krasnojarsk (L. KocH), Jinretlen („Vega“-Expedition).

Weitere Verbreitung: Ganz Europa.

Bestimmungstabelle der Gattung Macrocheles LATR.

1. Körper mit wohl abgesetzten Schultern, an Hinterrande breit abgerundet .

38. MI. arcticus p. 40

[ Körper ohne wolı] abgesetzte Schultern, am Hinterende zugespitzt

39. $M$. exilis p. 40

4) Wenn Moniez für $P$. fucorum angiebt, daß 2 solcher Borsten auf dem 3. Gliede und eine auf dem 4. steht, dürfte dies so zu erklären sein, daß er die Glieder vom Endglied rechnet. 
38. Mracrocheles arcticus (KRA. U. NEUM.)

Textfig. $83-87$.

1883 Gumasus arcticus Kramer u. Neumane, "Vega"-Expedition.

Diese Art wird von BerLesE ${ }^{1}$ ) mit M. terreus CAN. u. FAnz. identifiziert. Tatsächlich steht sie auch letzterer am nächsten, unterscheidet sich aber sehr wohl von ihr durch den Bau des Epistoms, der Mandibeln und durch andere Charaktere. Auf der Oberseite sind am Vorderrand 2 etwas größere Haare, die jedach nicht wie bei $M$. teireus kolbenförmig erweitert, sondern von dem bei dieser Art gewöhnlichen Habitus sind. Uebrigens sind die Haare so auf dem Rücken verteilt, wie uns Textfig. 83 zeigt, also nicht wie bei $\boldsymbol{M}$. terreus. Auf der Unterseite (Textfig. 84) sind die Schilder hauptsächlich wie bei $\boldsymbol{M}$. terreus gebaut, abgesehen davon, daß der Ventri-analschild halb so lang wie breit ist, während bei $M$. terreus die Breite die Länge ein wenig übertrifft. Ob sie sich auch in der Verteilung der Haare unterscheiden, ist

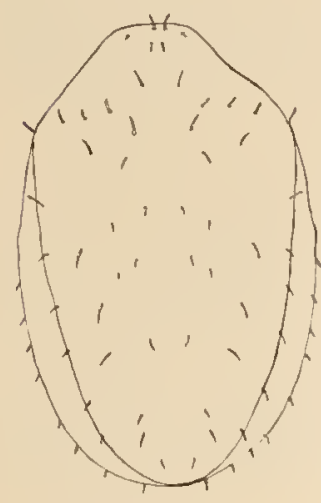

Fig. 83 .

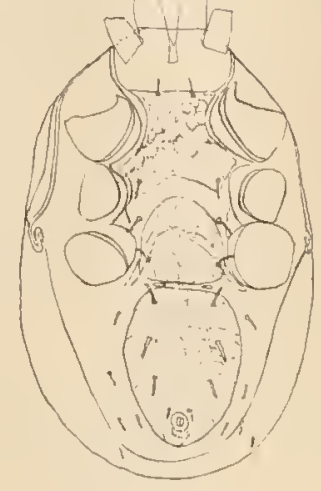

Fig. 84 .

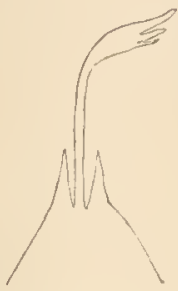

Fig. 85 .

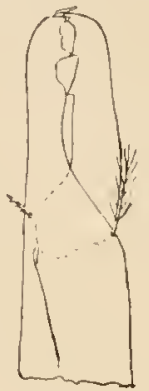

Fig. S6.

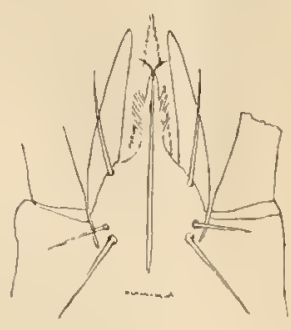

Fig. 87 .

Fig. 83. Macrocheles uretieus KR. u. NEux. Dorsalansicht. Vergr. 24:1.

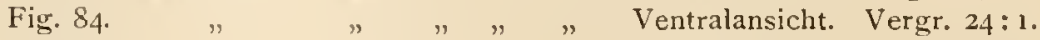

Fig. 85. " " " " " "

Fig. 86. " $" \quad ", \quad "$ Mandibel. Vergr. 150:I.

Fig. 87. $" \quad " \quad ", ", \quad "$ Hypostom. Vergr. 120:1.

unmöglich zu ermitteln, da BERLESE keine Haare abgebildet hat. Ueber den Bau des Epistonıs (Textfig. 85) bin ich zufolge seiner großen Durchsichtigkeit trotz Anwendung von 970-facher Vergrößerung nicht ganz ins klare gekommen. So viel ist aber sicher, daß es nicht wie bei $M$. terreus (Oudemans, 1. c. Fig. I85) gebaut ist, sondern an den Seiten der medianen Spitze 2 kleine spitze Zähne hat. Ob die Asymmetrie der medianen Spitze normal ist, kann ich nicht entscheiden, da mir nur ein einziges Exemplar zur Verfügung stand. Der bewegliche Teil der Mandibelschere (Textfig. 86) hat 2 Zähne und ist auf der Einlenkungsstelle mit einer Fiederborste versehen. (Bei M. terreus hat derselbe 3 größere und melurere kleinere Zähne.) Den Bau des Hypostoms zeigt Textfig. 87 .

Fundort: 2 o auf der Bering-Insel (,Vega"-Expedition).

\section{Macrocheles cxilis (BAnks)}

1900 Holostaspis exilis Banks, Papers from the Herriman-Alaska-Expedition. XI. Entomological Results, (5) Araclunida, in: Proceedings of the Washington Academy of siciences, Vol. II, 1900, p. 485, tab. 29, fig. 1.

Fundort: Alaska: Yakutat, Berg-Bucht, Sitka und Popof Insel.

\section{Subfamilie Epicriinae.}

Gattung: Zercon (AscA).

40. Zercon triangularis C. L. KocH.

Fundort: Jan Mayen, 16. Juni 1899, unter Moos (J. Arwidsson); 23. Juni 1899 Englische Bucht unter Amblystegium etc. (J. Arwidsson); Island, Hekla-Hafen i8g2 (Deichuann).

Weitere Verbreitung: Italien, Deutschland. 


\section{Zercon Iumbecki nov. spec.}

Textfig. 88 u. 89 .

Es liegen mir ¡von dieser Art 4 Männchen vor, die auf einer Fliege (Anthomyia sp.) bei Egedesminde auf !Grönland von W. LUNDBECK lgefunden sind. Sie steht $Z$. affinis OUdEMANS am nächsten und stimmt mit dieser Art in Bau und Form der Dorsalschilder überein (Textfig. 88 u. 89). Sie entbehrt aber der bei Z. affinis am Hinterende und an den Schultern vorhandenen längeren und dickeren Borsten. Das Sternigenitalschild verschmälert sich nach hinten und endet zungenförmig abgerundet (Textfig. 89). Den Bau des Epistoms habe ich nicht genau ermitteln können.

Soviel dürfte jedoch sicher sein, daß das Epistom nicht in eine lange Spitze ausläuft, sondern wahrscheinlich sanft abgerundet ist.

Länge $0,75 \mathrm{~mm}$.

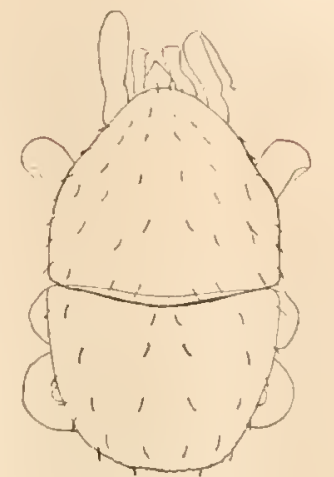

Fig. 88 .

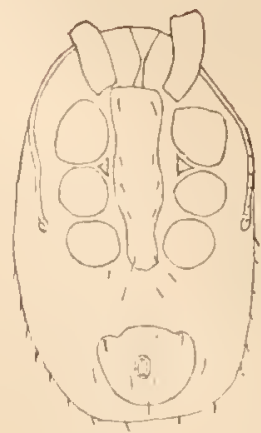

Fig. 89.

Fig. 88. Zercon lundbecki nov. spee. Dorsalansicht. Vergr. 75: 1 . Fig. 89. , " " , " Ventralansicht. Vergr. 75: 1.

Fund ort: Grönland, auf einer Fliege (Anthomyin sp.), Egedesminde, 5. Juli I8go (W. LundBECk). Subfamilie Uropodinae.

\section{Gattung: Urosejus.}

\section{Urosejus acuminatus (КOCH) BERLESE}

1894 Urosepis acuminutus (Koch) Berlese, Trodessart, Revision des Acariens des régions arctiques. Mém. de la Soc. Nat. des Sci. nat. et math. de Cherbourg, 1892-95, T. XXIX, p. 188.

Ein typisches Männchen ist nach Trouessart von M. Pouchet auf einem Rentiercranium aus Spitzbergen gefunden.

Fund ort: Spitzbergen.

Weitere Verbreitung: Deutschland, Italien.

\section{Laelups sp.}

Eine Nymphe (Trouessart).

Fundort: Spitzbergen.

\section{Parrasitus sp.}

Verschiedene Arten auf Necrophorus sp., Alaska: Sitka und Kadik. Keine erwachsenen Individuen (BANks). Fundort: Alaska.

\section{Familie Trombidiidae.}

Bestimmungstabelle der arktischen Subfamilien der Familie Trombidiidae. I. (Die Larven weichen in Körperform und Bau der Mundteile von den Erwachsenen völlig ab . . 5. I (Die Larven ähneln den Erwachsenen (ahgesehen von der Zahl der Beine) . . . . . . 2.

2. $\left\{\begin{array}{l}\text { Penis vorhanden } \\ \text { Kein Penis vorhanden. }\end{array}\right.$

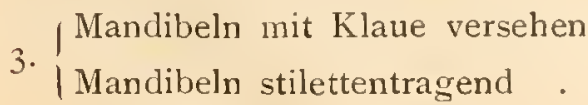

4. Mandibeln mit Schere versehen

4. I Mandibeln mit Klaue versehen

5. Mandibeln stiiettförmig

$$
\begin{aligned}
& \text {. . . 4 } \\
& \text { Erythracurinae p. } 49 \\
& \text { Raphignathince p. } 49 \\
& \text { Bidellinae p. } 45 \\
& \text { Erpodinae p. } 42 \\
& \text { Erythraeinae (Rhyncholophinae) p. } 54 \\
& \text { Trombidiinae p. } 50
\end{aligned}
$$


Bestimmungstabelle der Subfamilie Eupodinae.

I. $\left\{\begin{array}{l}\text { Mandibeln scherenförmig } \\ \text { Mandibeln nicht scherenförmig }\end{array}\right.$

. Der Exkretionsporus öffnet sich auf dem Rücken

\section{Penthaleus arcticus TGDH.}

Textfig. 90-92.

1900 Penthaleus arcticus, TräGÅmDH, 1. c. p. 19, tab. 2, fig. 5, 6.

1902 " "TRÄGÅRH, l. c. p, 6.

Wie ich bei der Beschreibung dieser Art betonte, steht sie C. ovatus (Koch) BerLese sehr nahe. Da diese letztere Art aber ziemlich oberflächlich beschrieben worden ist und ich kein Material davon habe, ist es mir auch heute unmöglich, zu entscheiden, ob die beiden Arten specifisch verschieden sind oder nicht.

Bei einer näheren Untersuchung des auf der Bären-Insel gesammelten Materiales stellte es sich heraus, daß3 C. arcticus einerseits mehr mit $C$. ovatus übereinstimmte, als ich anfangs vermutete, andererseits von BerLese's Diagnose ganz bestimmt in einigen Beziehungen abweicht. Schließlich habe ich dabei auch einige Charaktere gefunden, die gewiß von generischem Werte sind, von BERLESE aber gar nicht erwähnt werden. Die Chitindecke ist ganz wie bei $C$. ovatus gebaut, d. h. mit punktförmigen Erhöhungen, die in polygonale Felder begrenzenden Reihen sitzen, geschmückt. Die V-förmige Depression auf dem Rücken wird durch 2 verdickte Chitinleisten begrenzt, die hinten zusammenlaufen, nach vorn sich bis zu den Schultern erstrecken, wo sie jederseits nach innen und hinten gebogen sind (Textfig. 92). Die kleine dadurch gebildete, nach hinten gerichtete Konvexität ähnelt sehr einer Augenlinse. Ja, es ist sogar möglich, daß die Augen gerade hier placiert sind, denn sonst habe ich weder an durch Glycerin erhellten, noch an Kalilaugepräparaten irgendwelche Augen gefunden. A uf der Oberseite des Tieres sind folgende Borsten vor-

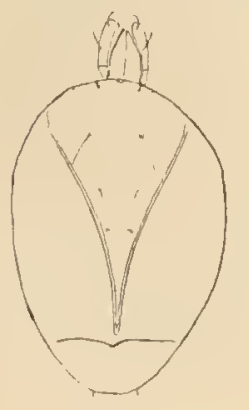

Fig. 50 .

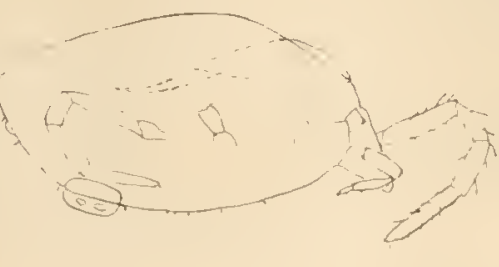

Fig. 9I

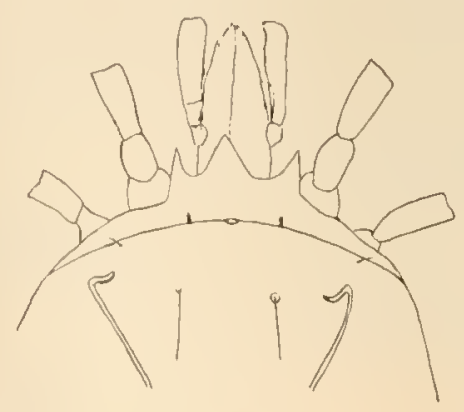

Fig. 92 . handen: An dem Vorderrand 2 nur bei sehr starker Vergrößerung sichtbare Borsten "), die tief in einer von einem starken, lichtbrechenden Chitinring begrenzten Grube eingesenkt sitzen (Textfig. 92). Es entspricht dieses Gebilde ohne Zweifel dem sog. Capitulum, denn sonst

findet sich kein Capitulum

von dem gewöhnlichen Bau. BerLese sagt in der Gattungsdiagnose von Chromotydeus „... anterius capitulo minus conspicuo". In der Beschreibung von C. ovatus erwähnt er nicht das Capitulum, auf Fig. 5, Taf. XXVIII, die zu der Gattungsdiagnose gehört, welcher aber allem Anschein nach die Art P. ovatus zu Grunde liegt, ist jedoch ein deutliches, mit 2 Borsten versehenes Capitulum zu sehen. Hierin ist also ein bedeutender Unterschied zwischen $C$. ovatus $\left.^{3}\right)$ und $C$. aveticus vorhanden. Am Vorderrande sind weiterhin 2 Paar gefiederter

1) Ueber die geänderten Namen der Gattungen Notophallus und Pcnthaleus, siehe: BERLESE, Acari nuovi, Estr. dal „Redia“, Vol., fasc. 2, 1903, p. 252.

2) Diese sind auf Fig. 92 nicht zu ersehen.

3) Nach BerLese's Abbildung zu urteilen, Acari Myriapodi etc., Ordo Prostigmata. 
Borsten vorhanden, von denen das mediale Paar kürzer und dicker ist als das laterale (Textfig. 92). Auf der Oberseite des Körpers finden sich außerdem ein Paar lange Schulterborsten, die nicht gefiedert sind, und hinter ihnen, mehr einander genähert, 2 Paar sehr kurzer Fiederbörstchen. An den Seiten des Körpers sind einige kaum merkbare gefiederte Börstchen vorhanden und ebenso 2 am hinteren Rande des Körpers. Auf der Unterseite des Körpers sind an der Genital- und der Analöffnung je 2 Paar Borsten vorhanden, das eine vor, das andere hinter den resp. Oeffnungen. Außerdem sitzen vereinzelt einige kleine Borsten. Eine sehr beachtenswerte Thatsache ist, daß ein Epistoma vorhanden ist, das die Basis des Rustrums umfaßt und in einen breit-zungenförmigen Fortsatz ausläuft. Zu beiden Seiten dieses Fortsatzes ragt ein spitzer Zapfen hervor, auf dem die Tracheen auf der Unterseite inünden. Diese Fortsätze entsprechen somit den bei Bryobia, Geckobia u. a. vorhandenen Peritremata. Daß man diese Gebilde bis jetzt nicht beobachtet hat, mag so erklärt werden, daß der Körper so hoch hervorgewölbt ist, daß er sie ganz überdeclit. In Bezug auf Taster und Mandibeln verweise ich auf die in meiner oben citierten Abhandlung gegebenen Figuren.

Die Farbe ${ }^{1}$ ). Der Körper dunkel-rotbraun, an den Seiten blaßrot; die dreieckige Vertiefung am Rücken weißlich; die Füße sind hellrot.

Fundort: Bären-Insel (G. Andersson).

Weitere Verbreitung: Lappland (TRÄG̊RDH).

Bestimmungstabelle der Gattung Penthaleus C. L. Koch.

I. $\left\{\begin{array}{l}\text { Die Beine länger als der Körper; das letzte Tasterglied zugespitzt . } \\ \text { Die Beine von der Länge des Körpers; das letzte Tasterglied abgestutzt }\end{array}\right.$.

44. $P$. haematopus p. 43

45. P. insulanus p. 44

44. Penthaleus haematomes (K. R. CAN.)

Textfig. 93.

1840 Penthateus huematopus, C. L. Kосн, 1. c. Fasc. 1, fig. 12.

1886 Notophallus haematopus (C. L. Кoch), R. CAnestrin1, Acarofauna It., p. 210.

$1882 \quad " \quad$ (C. L. Koch), A. Berlese, l. c. Fasc. 9, No. 5, tab. 36.

Diese Art ist durch den eigentümlichen Bau der Mandibeln sehr leicht erkennbar. Um die Identität der grönländischen Exemplare mit den von BERLESE abgebildeten außer Zweifel zu setzen, bilde ich eine Mandibel der grönländischen Form ab.

Bei einer genauen Vergleichung zwischen der grönländischen und der italienischen Form (wobei ich leider nur BERLesE's Figur als Material hatte) stellte es sich heraus, daß erstere sich von der südlichen Form in ganz derselben Weise unterscheidet, wie so viele andere arktischen Formen, nämlich durch Reduzierung der Beine und der Mundteile.

Fig. 93. Penthaleus haematopus. Schere der Mandibel. Vergr. 310: I.

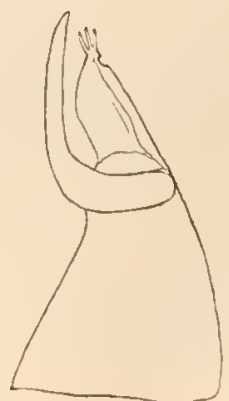

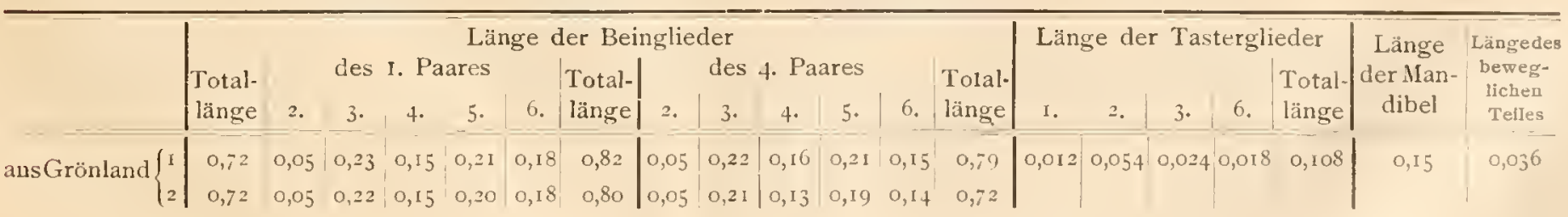

Wenn wir die gesamte Körperlänge als I bezeichnen, verhält sie sich also bei der grönländischen Form zu der Länge des I. Beinpaares wie I : I,I3, während bei BERLESE's Figur dasselbe Verhältnis I: I,5

1) Nach in Lappland 1900 an lebendigen Exemplaren gemachten Beobachtungen. 
ist. Vergleichen wir die relative Länge der Mandibel und des beweglichen Teiles derselben, so ist sie bei der grönländischen Form (s. die Tabelle) 4: I, während sie bei BERLESE's Figur 2,6: I ist. Also ist bei der grönländischen Form eine Verkürzung des beweglichen Teiles eingetreten. Vergleichen wir die Länge der Taster und Mandibeln bei beiden Formen, so finden wir, daß diese bei der grönländischen Form $2: 3$ ist, während sie bei Berlese's Figur $4: 3$ ist. Die Taster sind also bei der grönländischen Form im Verhältnis zu den Mandibeln gewaltig reduziert.

Fundorte: Westgrönland: Arsăk, Io. August 1889, „auf Taraxacum" (W. LundBeck); Tasiusak, 23. Juli I889, „unter Steinen" (W. LundBECk); I8. Juli I889 Nekamiut (W. LundbecK); 3. August I89o Claushavn (W. LundBeck); Ritenbenk, IO. Oktober I890; Ostgrönland: Cap Stewart, 5. August I89I (Ryder's Expedition); 30. Juli 1899 in Moos (J. Arwidsson).

Weitere Verbreitung: Italien, Deutschland.

\section{Penthaleus insulanus (THOR.) TGDH.}

1871 Penthaleus insulanus, THoreld, 1. c. p. 702.

1878 Tetranychus borealis, L. Koci, 1. c. p. 129, tab. 6, fig. 7.

1900 Notophallus insulanus (Thor.), Тrägårnh, 1. c. p. 16, Textfig. 2, tab. 2, fig. 4.

In Bezug auf die Synonymik verweise ich auf meine oben citierte Abhandlung (I900).

Die daselbst gegebene Beschreibung der Mandibeln ist insofern zu korrigieren, als das unbewegliche Glied der Schere ganz wie bei den übrigen Penthaleus-Arten fingerförmig geteilt ist. Bei der der Abbildung zu Grunde liegenden Mandibel waren diese Finger abgebrochen. Sie nähert sich dadurch sehr $P$. minor R. CAN., derjenigen von den Penthaleus-Arten, der sie durch den Bau der Taster, die Länge der Beine und die Behaarung des Körpers auch sonst am nächsten kommt. Der einzige Unterschied, den ich zwischen ihnen habe finden können (nach BERLESE's Beschreibung und Abbildung zu urteilen, denn ich hatte nicht Gelegenheit, P. minor zu untersuchen), ist, daß die Palpen bei $P$. minor 3 rückständige Borsten am 2. Glied haben, während $P$. insulanus deren 2 hat, und daß die Schere bei $P$. insulunus verhältnismäßig kürzer ist. Bei $P$. minor erreicht sie nämlich nach BerLese $1 / 4$ der ganzen Mandibularlänge, bei $P$. insulanus nur $1 / 6$. (Länge der Mandibel 0,I4I, der Schere 0,024.) Auf diesen Unterschied ist aber wohl nicht großer Wert zu legen, und es ist daher einzig und allein der Unstand, daß ich nicht Gelegenheit gehabt habe, $P$. minor selber zu untersuchen ${ }^{1}$ ), der mich veranlaßte, vorläufig $P$. insulanus nicht als eine Varietät von P. minor aufzustellen.

Fund orte: Sibirien: Novaja Semlja (L. Koch); Bären-Insel (Thorell, G. Andersson); Jan Mayen, 23. Juni I899, an der englischen Bucht, unter Moos und Saxifraga oppositifolia (J. Arwidssov); Ostgrönland: Cap Stewart, Scoresbory-Straße, 30. Juli I899, unter Moos (J. Arwidsson), und 5. August I8gI (Rrder's Expedition).

\section{Rhagidia gelida THOR.}

1871

Rhagidia gelida, Thoreut, 1. c. p. 700 .

$$
\text { THOReLL, L. Korm, 1. c. p. 123, tab. 5, fig. 6a-d. }
$$

Penthaleus crussipes, L. Kocn, l. c. p. 130, tab. 7, fig. 1.

borealis, K. Kucli, l. c. p. 129 , tab. 6, fig. 8 .

Scyphius hamatus, Krameir u. Neumann, "Vega"-Expedition, p. 524, tab. 40, fig. 1a, b, c.

Rhagidir gelida, Tuoreld, Träg̊̊nDH, 1. c. p. 18, tab. 2, fig. 2, 3.

$"$ Thoreli, TrägR̂RDH, l. c. p. 7.

"gelosa, Thonelu, Michael, Report etc., p. 656.

1) P. minor ist bis jetzt nur in Italien gefunden worden. 
Ich verweise in Bezug auf die Synonymik auf meine oben citierte Arbeit (I90o). Es wurde damals von mir hervorgehoben, daß die Gattung Nömeria R. CAN. und Rhagidia Thor. miteinander zusammenfallen und daß somit, da letztere sich der Priorität erfreut, der Name Norneria gestrichen werden muß. Kurz bevor meine Abhandlung fertig war, erschien ein Aufsatz von NATHAN Banks in "The Canadian Entomologist"1), worin er dieselbe Meinung vertrat und auch zeigte, daß die von CAuBRIDGE aufgestellten Gattungen Poecilophysis) und Scyphoides BERLESE mit Rhagidia zusammenfallen.

$\mathrm{Zu}$ der Gattung stellte er außerdem unter anderem Scyphius hamatus und japonicus KRAMER u. NEUMANN aus Japan.

Im Juni r897 lenkte auch MichaEL die Aufmerksamkeit darauf, daß Rhagidic ${ }^{2}$ ) und Nörneriø einander decken.

Von S. hamatus und S. japonicus liramer u. Neumann, von welchen nur ersterer hier in Betracht kommt, sind in den Sammlungen keine Exemplare vorhanden. Wie aus den von dem Taster und der Mandibel des ersteren gegebenen Abbildungen ohne weiteres bervorgeht, ist diese Art mit $R$. gelida identisch.

Die vorliegende Art steht $R$. gigas $\mathrm{R}$. CAn. sehr nahe. Sie unterscheidet sich jedoch deutlich von ihr durch den Bau der Taster, bei denen das 4. Glied länger ist als das 2. (bei R. gigas ist das 2. Glied länger als das 4.) und die Borsten des 4. Gliedes kürzer als das Glied selbst, während bei $R$. gigas die Borsten am Ende des Gliedes die Länge desselben fast um die Hälfte übertreffen.

Auch das bewegliche Glied der Mandibelschere unterscheidet sich, und zwar durch seine weniger schlanlie Gestalt, von demjenigen der $R$. gigas. Es sind dies jedoch ziemlich unbedeutende Merkmale, und möglicherweise ist $R$. gelida nur eine nördliche Form von $R$. gigas, eine Frage, die ich aus Mangel an Material noch nicht entscheiden kann ${ }^{3}$ ).

F un dorte: Sibirien: Preobraschenie-Insel, St. Lawrence-Bucht (Kramer u. Neumans); Novaja Semlja (C. Koch); Spitzbergen (Thorell); Bären-Insel (Träg̊̊Rd); Jan Mayen, in Moos 23. Juni I899 (J. Arwidsson); Westgrönland: Ritenbenk (nahe 70\%), 27. August I89o (W. LundBeck); Island: Helila-Hafen I892 (DEICHMANN); Franz Josephs-Archipel, Northbrook-Insel, Cap Flora (Michael).

Weitere Verbreitung: Arktisches Lappland, Ig0o (TRäGARDH)).

\section{Bestimmungstabelle der Subfamilie Bdellinae.}

(Das 3. Tasterglied undeutlich von dem 2. abgesetzt.

Gatt. Cytu v. Heyden p. 49 I Sämtliche Tasterglieder voneinander wohl abgesetzt.

Gatt. Bdella LATr. p. 45

Bestimmungstabelle der Gattung Bdella LATR.

I. $\left\{\begin{array}{l}\text { Die Mandibeln tragen nur eine Borste. } \\ \text { Die Mandibeln tragen } 2 \text { Borsten } \\ \text { Die Mandibeln tragen mehrere Borsten }\end{array}\right.$.

2.

Die Endborsten des 5. Tastergliedes länger als die übrigen

I Die Endborsten des 5. Gliedes nicht länger als die übrigen

3 .

Das 2. Tasterglied mehr als doppelt so lang wie das 5.

I Das 2. und das 5. Tasterglied von annähernd derselben Länge
50. B. longirostris.

3.

2.

48. B. capillata var. pellipes.

47. B. littoralis.

49. B. vulgaris var. decipiens. 51. B. groenlandica.

1) On two genera of Mites, Vol. XXXII, Februar, 1900, p. 30

2) Er nennt die Art irrtümicherweise $R$. gelosa.

3) Es möchte hier erwähnt werden, daß TROUESSART eine in der Antarktis gefundene $R$.-Art, nur als Subspecies von R. gigas unterscheidet. Exp. Antarct. Belge, Rapports scientifiques, Zoologie, Acariens, Igo3, p. 4. 


\section{4\%. Bdella littovalis (L.)}

1900 B. sanguinea, Trt., ТRÄğ́rdr, ibid.

1901 B. Zasteri, Johnst., f. arctica (Thor.), TrägÅrpH, Revision etc., Zool. Anzeiger, Bd. XXV, No. 660, p. 61.

1902 B. littoralis (L.), Träginne, Zur Kenntnis der litoralen Arten der Gattung Bdella Latr., Bih. t. Kongl. Sv. Vet.-Akad. Handl., Bd. XXYII, Afd. 4, No. 9.

In Bezug auf die Synonymik dieser Art verweise ich auf meine oben citierte Abhandlung (I902). Ich wiederhole jedoch hier einen Teil der Beschreibung. Die Länge des erwachsenen Tieres variiert zwischen 2 und $3 \mathrm{~mm}$ bei einer Körperbreite von 0,8-I,2 mm. Die Mandibeln tragen auf ihrer Rückenfäche IO--I4 Haarborsten. Die Taster sind lang und kräftig entwiclielt. Das 2. Glied, das die anderen an Diclie übertrifft, nimmt nach dem distalen Ende zu allmällich an Dicke zu. Die übrigen Glieder sind ihrer ganzen Länge nach von gleicher Dicke; das 5. ist fast cylindrisch, schmäler als die übrigen und an der Spitze abgerundet. Die Längenverhältnisse der Glieder vom 2. bis zum 5. sind durch 0,459, 0,08I, 0,I7I, $0.432 \mathrm{~mm}$ (bei einem Exemplare von $3 \mathrm{~mm}$ Länge) ausgedrückt. Hieraus ist ersichtlicl, daß das 2. Glied das 5. ein wenig übertrifft und daß das 4. eine etwas größere Länge als das 3. erreicht. Uebrigens variieren die Glieder an Länge nicht unbeträchtlich, wie ich in der Revision dargethan habe. Die Borsten der Tasterglieder sind in folgender Weise geordnet. Am 2. Gliede sind die Haarborsten wesentlich in der inneren distalen Hälfte aufgestellt - am Grunde des Gliedes befindet sich, auf der Unterseite inseriert, nur eine Borste - und in 2 Reihen geordnet; die eine Reihe entlält 2 Rückenborsten, die andere gewöhnlich 4, welche distalwärts an Länge zunehmen. Ziemlich oft trifft man deren nur 2 an, und zwar sind dabei die beiden kleineren proximalen verschwunden. Das 3. Glied trägt nur eine Rückenborste. Am 4. Gliede sind 4-6 Borsten vorhanden; diejenigen 4, die sich regelmäßig wiederfinden, sind sehr weit nach dem Vorderende des Gliedes gerückt. 2 von ihnen sind nach oben, die 2 anderen nach unten gerichtet; von den letzteren ist die auf der Innenseite des Gliedes befindliche kräftiger und erreicht die Länge der längsten Borsten des Endgliedes. Das 5. Glied trägt eine große, ziemlich variierende (I7-23) Anzahl von Borsten, die gleichmäßig über das ganze Glied verteilt sind. Die am Ende des Gliedes eingefügten übertreffen, obwohl ziemlich unbedeutend, die übrigen an Länge. 
Fund orte: Arktisches Sibirien, Novaja Semlja, Spitzbergen, Bären-Insel, Jan Mayen, Island, Ostgrönland, Jamesons-Land, 8. Mai I89I (Ryner's Expedition), Rode o (RyDER's Expedition), Westgrönland, Holstenborg, Kristianshaab, Egedesminde, Vistnaes, Jakobshavn, Agpiletak, Ikamiut u. a. Lokalitäten.

Weitere Verbreitung: England, Schweden, Norwegen, Frankreich.

\section{Balella eapillata Kran. var. pallipes (L. KOCH)}

1879 Bdella pallipes, L. Kocir, 1. c. p. 131, tab. 7, fig. 4.

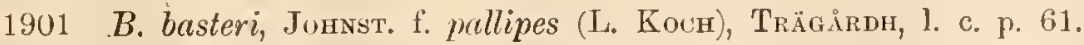

1902 B. capillata, Kran. var. pallipes, L. Косн, 1. c. p. 16, tab. 1, fig. 2, tab. 2, fig. 4.

Die Varietät unterscheidet sich von der Hauptform im Bau der Taster, indem eine Borste hinzugekommen ist, welche die Mitte zwischen den beiden Endborsten, von denen die dorsale ein wenig länger ist (bei B. capillata sind sie von gleicher Länge), und den übrigen Borsten des 5. Gliedes hält und auf der dorsalen Seite nahe dem Vorderende eingefügt ist. Im übrigen ist sie durch mehrere kurze Borsten auf diesem Gliede und durch den Besitz von 4-5 Borsten am 2. Gliede (also nicht so viele wie bei B. capillata) gekennzeichnet. Die Längenverhältnisse stimmen mit denjenigen bei $B$. capillata überein.

Fundort: Sibirien, Novaja Semlja (L. Косн).

Verbreitung der Hauptform: Deutschland.

\section{4!. Bdella vulgaris (HERM.) K. var. decipiens (THOR.)}

? 1851-52 Bdella podurophila, Wнтте, 1. c. p. 210.

1871 Bdella decipiens, Thorelu, 1. c. p. 699.

$1879 "$ "Thorell, L. Koch, l. c. p. 131, tab. 7, fig. 2.

1883 " borealis, Kraner u. Neumans, 1. c. p. 525, tab. 41, fig. 1a-d.

$1899 "$ " Kraner n. Neumann, Banks, 1. c. p. 349.

1901 "decipiens, Thoreld, Trägårdh, l. c. p. 61.

1902 " Thorell, Trägåroh, l. c. p. 23, tab. 1, fig. 1, 3 ,

In meinem oben citierten Aufsatz (IgO2) hob ich hervor, daß der Unterschied zwischen B. decupiens und $B$. vulgaris sehr klein war, und sprach die Vermutung aus, daß erstere sich als nur eine Varietät von letzterer zeigen würde, was ich jedoch aus Mangel an Vergleichsmaterial damals nicht entscheiden konnte. Ich habe seitdem freilich nicht Material von B. vulgaris bekommen, aber der weitere Ueberblick über die Verwandtschaftsbeziehungen zwischen den arktischen und den paläarktischen Acariden, den ich seitdem bekommen, hat in mir die Ueberzeugung befestigt, daß B. vulgaris nur eine nördliche Varietät von B. vulguris ist. Die Varietät unterscheidet sich von der Hauptform im Bau der Taster, indem sie eine Reduzierung des letzten Gliedes und der beiden Endborsten desselben aufweist ${ }^{1}$ ).

Fundorte: Sibirien, Novaja Semlja, Spitzbergen, ? Cornwallis-Insel, Bering-Insel, Jan Mayen.

Weitere Verbreitung: Lappland.

\section{Brlella longirostris (HERn.)}

1804 Scirus longirostris, Hermanx, Mémoire aptérologique, p. 62, tab. 3, fig. 13.

1882 Bdella longirostris (Herm.), Berlese, 1. c. Fasc. 45, No. 6, tab. 56.

$1897 "$ frigida, Baxks, Fur seals and Fur Seal Islands of the North Pacific Oceau, Part IV, Arachnida, p. 348, tab. A, fig. 5.

1901. B. frigida, Banks, Trägirdh, 1. c. p. 16.

1902 B. longirostris (Heim.), Trägizdh, l. c. p. 7.

1) Eine Tabelle der Längenverhältnisse der Glieder und der Endborsten findet sich in dem citierten Aufsatz p. 23. 
In der oben citierten Arbeit über die litoralen Arten der Gattung Bdellu (Igor) wagte ich über B. frigida kein Urteil auszusprechen. Ich übersah damals die große Uebereinstimmung der Taster derselben mit denjenigen von $B$. longirostris (HERM.) BERLESE, welche Art ich seitdem im arktischen Lappland gefunden habe. Diese Uebereinstimmung ist so groß, daß ich die beiden Arten unbedenklich miteinander identifiziere. Die Angabe, daß die Mandibeln der $B$. frigidı 4 Borsten besitzen, spricht scheinbar gegen diese Identifizierung, da ja B. longivostris nur eine Borste auf den Mandibeln besitzt. Banks hat aber offenbar nicht die Mandibeln herauspräpariert, und er faßs daher 3 Borsten, die auf der Unterseite des Rostrums sitzen (und auch bei $B$. longirostris vorhanden sind) und über den Seitenrand hervorragen, als den Mandibeln angehörend auf.

Länge von BANKs' Exemplaren I,3 mm, der lappländischen Fxemplaren 1,125 mm, von BERLEsE's bis $2 \mathrm{~mm}$.

Fund ort: Bering-Insel.

Weitere Verbreitung: Ganz Europa und arlitisches Lappland.

51. Bdella groemlandica n. sp.

? 1780 Acarus longicormis, FaBricius, Fanna groenlandica.

Vorliegende Art, die sich zusammen mit B. littoralis in großer Menge in einer Glastube, etikettiert „Grönland, Levinsen" befand, steht B. virgulatr CAN. u. FAnz. sehr nahe. Sie unterscheidet sich durch ihre geringe Größe (Länge $0,7 \mathrm{~mm}$ ), durch den reichlicheren Borstenbesatz des letzten Tastergliedes, sowie durch die Abwesenheit von Zähnen an der Mandibelschere. Sie scheint mit keiner bis jetzt beschriebenen Bdella-Art identisch zu sein. Man könnte jedoch an eine Identifizierung mit dem grönländischen Acarus longicornis Fa Bricıus denken. Von den arktischen Bdelliden-Arten ist es nur B. groenlandica und Cyta brevirostris, die mit A. longicornis FABR. identifiziert werden können. Die Größenangabe 0,7 mm und die Angabe „Antennae rostro longiores, pedibus tertiis sublongiores" spricht zu Gunsten der B. groentandica.

Mit $B$. longirostris (= frigidı Banks) kann sie wegen der völlig verschiedenen Behaarung der Taster $\mathrm{n}$ icht identisch sein. Die Länge ist ca. $0,7 \mathrm{~mm}$. Die Gestalt ist plumper als bei den übrigen Bdella-Arten und verschmälert sich inach vorn nicht allmählich, sondern sehr plötzlich. Die Taster ${ }^{1}$ ) sind wesentlich nach dem Plane von $B$. virgulata gebaut. So sind am Innenrande des 2. Gliedes $4-5$ Borsten vorhanden, am Außenrande desselben nur eine. Am 3. Gliede sitzt auf der äußeren Seite eine Borste, und am 4. Gliede 5 Borsten. Auf dem 5. Gliede sind im Gegensatze zu B. virgulata, die nur 5-6 Borsten besitzt, die sämtlich nahe dem Ende des Gliedes eingefügt sind, nicht weniger als 9 Borsten vorhanden, die mehr gleichmäßig über das ganze Glied verteilt sitzen. Die Längenverhältnisse der Glieder sind aus der beigefügten Tabelle ersichtlich. Das letzte Glied ist am Ende ein wenig erweitert und quer abgestutzt.

\begin{tabular}{|ccccc|cc}
\hline \multicolumn{3}{|c|}{ Länge der Tasterglieder } & Länge der Endborsten \\
2. & 3. & 4. & 5. & 1. & 2. \\
2. & 0,138 & 0,03 & 0,033 & 0,106 & 0,102 & 0,084 \\
0,135 & 0,03 & 0,03 & 0,12 & 0,105 & -
\end{tabular}

Die Mandibeln tragen 2 Borsten; ihre Schere entbehrt der Zähne. Die Art ähnelt im Bau der Taster und Mandibeln der von KRAMER ${ }^{2}$ ) aus Südfeuerland beschriebenen Bdelı symmetricu, die jedoch bedeutend größer ist.

Fundort: Grönland (Levinsen).

1) Sie erinnern an diejenigen von B. capillata var. prellipes, welche jedoch zu der Gruppe der Gattung Bdella gehört, die mehr als 2 Mandibelborsten besitzt.

2) Hamburger Magalhaensische Sammelreise, Hamburg 1898, Acariden, p. 14, Fig. 14. 
52. Cyta ${ }^{1)}$ Iatilostris (Hern.) var. brevirostris (L. KOCH)

$187 ! 1$

1879

1900

1901

Billla Trevirostris, L. Kıсн, l. c. p. 132, tah. 7, fig. 5 .

" mollissima, L. Kocн, 1. c. p. 132 , tab. 7, fig. 15 .

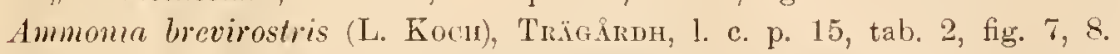

(L. Kuch), Trägardh, l. c. p. 61 .

Diese Art steht, wie ich schon hervorgehoben habe, der aus Italien und Deutschland bekannten C. latirostris (Herm.) K. sehr nahe, und der Unterschied erscheint mir jetzt nicht melır groß genug, um die Aufstellung der arktischen Form als eire besondere Art zu rechtfertigen. Da letztere aber von der Hauptform in ganz analoger Weise abweicht, wie z. B. B. vulgaris var. decipiens, Trombidium bicolor var. curtipalpe u. a. von ihren Hauptformen, so halte ich es für angemessen, sie als eine besondere Varietät aufzustellen. Die Varietät unterscheidet sich von der Hauptform durch Verkürzung der Taster. Die Längenverhältnisse werden in der beigefügten Tabelle veranschaulicht. Das 3. Glied, das in BErLEsE's Fig. 2, Taf. LXl und meiner Fig. 8, Taf. 11, dieselbe absolute Länge hat, ist als Einheit genommen.

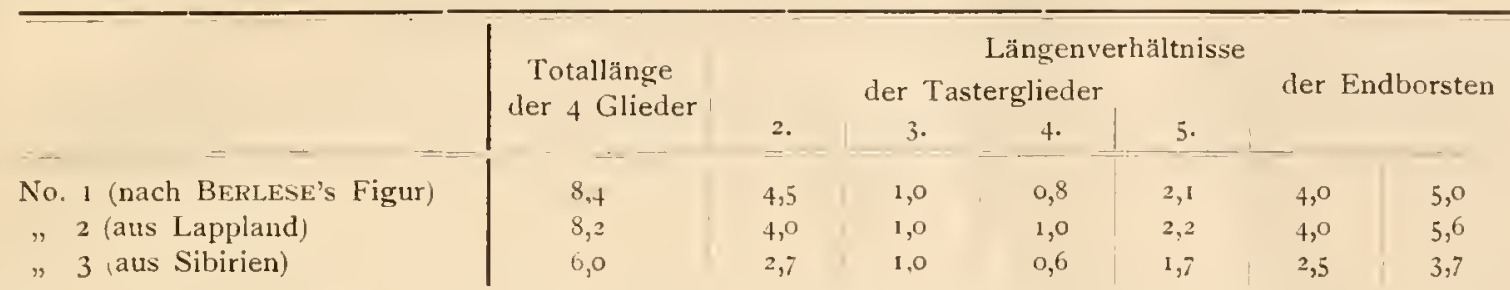

Es ist aus der Tabelle ersichtlich, daß die lappländische Form aufs genaueste mit der italienischen übereinstimmt ${ }^{2}$ ).

Fundorte: Sibirien, Novaja Semlja, Bären-Insel, Jan Mayen, 23. Juni ISg9 (J. Arwidsson), Grönland.

Verbreitung der Hauptform: Schweden, Finnland, Deutschland, Italien, Frankreich.

\section{Subfamilie Raphignathinae.}

Gattung: Bryobia C. L. KocH

\section{5:3. Bryobia pretiosa C. L. KoçH}

? 1876 Torynophora serretr, Cambridge, Proc. Zool. Soc. London.

1879 " "Camiri, L. Kocli, l. c. p. 134.

1883 Bryobia speciosa, C. L. Koch, Kraner u. Neumann, "Vega"Expedition.

1900 "scrula, CAмвr, Trägind, 1. с. p. 20, tab. 2, fig. 9, 10.

1902 "praetiose, C. L. Koch, Тrägardh, l. c. p. 8.

In Bezug auf die Synonymik dieser Art verweise ich auf Oudenans' Arbeit ${ }^{3}$ ) und meine Abhandlung über lappländische Acariden (I902).

Fundorte: Sibirien: $30^{\circ}$ östlich von Cap Jakan (K. u. N.), Jenissej (L. Koch), Novaja Semlja (L. Koch); Bären-Insel; Ostgrönland, 5. August I8yı (Rrder's Expedition).

Weitere Verbreitung: Schweden, Niederland, Deutschland, ltalien, ? Kerguelen.

Bestimmungstabelle der Subfamilie Erythracarince.

fDie Taster viergliedrig

Gatt. Anystis v. HEYDEN p. 50

I Die Taster fünfgliedrig

Gatt. Erythracurus C. L. KoCH p. 50

1) Der Name Ammonis muß nach SIG. THOR gestrichen werden, da Cyta v. HEvDEN die Priorität IISzo) hat (ThOR, Zur Systematik der Bdellidne etc., in Verhandl. k. k. zool.-bot. Gesellschaft in IVien, I902, p. I60).

2) In „Lappländische Acariden" rechnete ich sie unrichtigerweise zu der arktischen Form.

3) Ueber Sanremeser Acari, Tijdschr. v. Entomologie, Bd. XLIII, p. I38, tab. 8, pl. 50-58. 


\section{Anystis baccarum (L.) BERLESE ${ }^{1}$ )}

1758 Acarus baccarum, Linse, Systema Naturae, Bd. X, p. 617.

1879 Actineda setosa, L. Kocr, 1. c. p. 127, tab. 5, fig. 6.

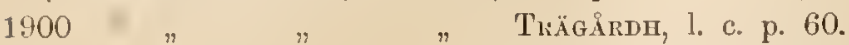

In der vorläufigen Mitteilung führte ich die von $\mathrm{KocH}$ aufgestellte Art noch als gute Art auf, trotzdem ich betonte, daß sie der A. baccarum (L.) sehr nahe stand und möglicherweise nur eine Varietät derselben war.

Ich urteilte damals nach den von BERLESE gegebenen Abbildungen, von denen diejenige der Taster in Bezug auf die Behaarung kaum richtig sein kann. Seitdem habe ich aber Gelegenheit geliabt, Material sowohl aus Schweden als aus Norwegen zu untersuchen, und es geht daraus hervor, daß $A$. setosa nicht einmal als eine Varietät von $A$. baccarum anzusehen, sondern mit derselben identisch ist.

Fundorte: Sibirien (L. Kосн); Grönland: Fjord Kugsiarsuk in lgalika, 29. August 1889 (W. LuNDBECK).

Weitere Verbreitung: Ganz Europa und Centralamerika.

\section{Erythracame harmsworthi MicH.}

? 1883 Erythracarus parietinus, C. L. Косн, Kraner u. Neumann, "Vega"-Expedition.

1897 Erythaeus harmsworthi, Michael, Report on the Acari collected by Mr. H. Fisiler, Naturalist of the JacksonHarmsworth Polar Expedition, at Cape Flora, Northbrook Islind, Franz Joseph-Archipelago, in, 1896 , Journal of Linnean Society 1897, Vol. 26, Zoology, No. 168, p. 356, pl. 21.

Diese Art ist sehr wahrscheinlich, wie auch Michael vermutet, nach sehr jungen Individuen beschrieben worden. Dafür spricht schon ihre unbedeutende Länge, $0,3 \mathrm{~mm}$, und der schwache Borstenbesatz des Körpers und der Beine ${ }^{2}$ ). (Die kleinste bis jetzt bekannte Erythracarus-Art erreicht o,8 Länge, alle übrigen sind $\mathrm{I} \mathrm{mm}$ und darüber.) Die Tiere waren so schlecht konserviert, daß es MıCHAEL unmöglich war, eine gute Diagnose zu liefern. Da außerdem einige der Merkmale wohl jugendliche Charaktere und die jugendlichen Formen der Erythracarus-Arten nicht beschrieben sind. wird es doppelt schwer zu entscheiden, ob sie eine gute Art oder nur eine Jugendform einer schon bekannten ist. Jedenfalls ist es sehr wahrscheinlich, wenn auch kein positiver Beweis dafür gegeben werden kann, daß sie mit dem von KRAMER u. NEUMANN aus Dicksons-Hafen erwähnten E. parietinus KосH identisch ist. Auf ihre Identifizierung ist bei der damaligen Kenntnis der Erythacarus-Arten aber nicht viel Gewicht zu legen, und es ist viel wahrscheinlicher, daß ihre Art mit einer von mir in Norwegen und Schweden gefundenen, bis jetzt nicht beschriebenen ErythracurusArt identisch ist. In der That zeigt auch E. lurmsworthi eine gewisse Aehnlichkeit mit dieser Art insofern, als die Farbe (wenn wir davon absehen, daß E. harmsworthi etwas lichter gefärbt ist) des Körpers und der Beine dieselbe ist, und die Beine sind durch die dunkleren Querbänder sehr charakteristisch. Auch die längeren Borsten am hinteren Rand des Abdomens finden sich, wenn auch in größerer Anzahl bei der norwegischen Form.

Fundorte: Cap Flora, Northbrook-Insel, Franz Joseph-Archipel (MrchaeL); ?Sibirien (Kramer u. NEUMANN).

Weitere Verbreitung: Norwegen?

Subfamilie Trombidinae.

Bestimmugstabelle der Gattung Trombidium FaBr.

Körperhaare ungefiedert

|Körperhaare gefiedert
56. T. bicolor var. curtipalpe p. $5^{\mathrm{I}}$ 57. T. sucidum P. 52

I) Betreffs der übrigen Synonymik siehe BERLESE 1. c. p. IIO und Oudemans, List of dutch Acari, P. 5, Tijilschr. v. Entomologie, Bd. XL, p. 123.

2) Nach KOCH zeichnen sich die Jungen von E. parictinus da lurch aus. 
56. Trombidium bicolor (C. L. Koch) var. emptipulpe SiG. Thor

Textfig. $94-98$.

1770 Acarus holosericeus, Fabricuss, Fauna groenlandica, p. 222.

1883 Trombidium laevicupillatum, Kranel, ..Vega"-Expedition, Vetensk. Jakttagelser, Bd. III, p. 522, tab. 39, tig. 1a-d. 1897 Kram., Oudemars u. Komine, Acari collected during the Trillem Barents-Expedition of 1881 and 1882, in: Tijdschr. voor Entomologie, Bd. XL, p. 239.

1900 " filipes (Косн), Sig. Тнов, Forste Ondersngelse Norges Trombididae, Christiania Tid. Selsk. Forhandl., 1900, No. 2 , p. 7 , tab. 1, fig. 24 u. 25.

nec 1837 Trombidium filipes (C. L. Косн).

Meine Exemplare, die auf Grönland gefunden sind, stimmen vollständig mit den Abbildungen und der Diagnose, die Sig. THOR von $T$. filipes C. L. Koch giebt, und mit den Exemplaren dieser Art, die ich aus Norwegen besitze, überein. BERLESE hat die beiden Koch'schen Arten, die langbeinige T. filipes und die mit kürzeren Beinen ausgerüstete $T$. bicolor (HERM.), zu einer Art, T. bicolor, zusammengezogen, und wie mir scheint, thut er es mit vollem Recht. Derm er hat in ltalien sowohl eine kurzbeinige als eine langbeinige Form gefunden und konstatieren können, daß sie Taster von ganz demselben Bau besitzen und Männchen und Weibchen derselben Art sind. SiG. Thor dagegen verwirft ohne jegliche Motivierung BerLese's Identifizierung und „nimmt an, daß3 KocH's Abbildungen 2 gute Arten darstellen“. Für die norwegische Form nimmt er gleichfalls ohne Grund den Namen T. filipes in Anspruch. Er hätte jedoch aus BERLESE's Abbildungen sehen können, daß, wenn auch $T$. filipes und $T$. bicolor nicht identisch sind, so doch jedenfalls die von BERLEsE abgebildete Form noch langbeiniger als Koch's Abbildung von T. filipes ist. Die italienische Form und nicht die norwegische wäre also mit $T$. filipes zu identifizieren. Darin stimme ich aber THOR bei, daß die norwegische Form (mit welcher meine Exemplare aus Grönland und Lappland übereinstimmen) und die von BERLESE beschriebene auseinandergehalten werden müssen. Ich benenne die Varietät mit dem von THOR für die kurzbeinige norwegische Form vorgeschlagenen Namen curtipulpe.

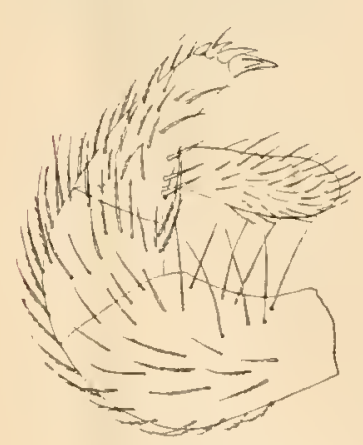

Fig, 94 .

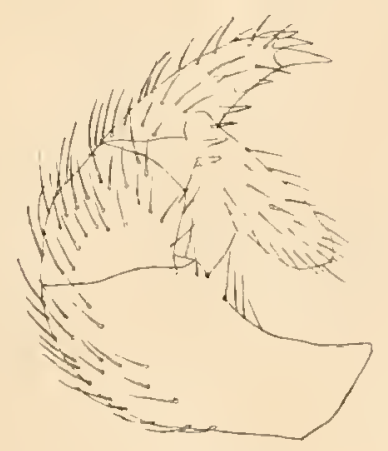

Fig. 95.

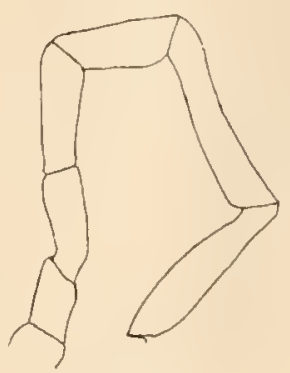

Fig. 97.

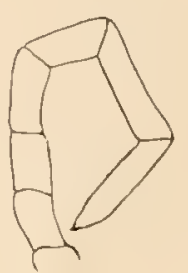

Fig. 98.

Fig. 96 .

Fig. 94. Trombidium bicolor (C. L. Koch) var. "urtipalpe SIG. THOR. Taster eines Exemplares aus Norwegen. Vergr. 100: I.

Fig. 95. Trombidum bicolor (C. L. KOCH) var. curtipalpe SIG. THOR. Taster eines Exemplares aus Grönland. Vergr. 100:1. Fig. 96. " " " " " " " " "

Fig. 97. " ", " ",$\quad "$, Das I. Bein. Vergr. 30:1.

Fig. 98. " $", ", \quad ", \quad " \quad, \quad$ Das 2. Bein. Vergr. $30: 1$.

Der Unterschied ist jedoch nicht bedeutend genug, um die Aufstellung dieser Form als eine besondere Art zu rechtfertigen, und ich führe sie daher als Varietät von T. bicolor auf. Die Varietät unterscheidet sich von der Hauptform durch Verkürzung der Beine und der Taster (vergl. Textfig. 94, 95, 97 u. 98 und Fig. I, 3, 4 und Io bei Berlese, Prostigmata, Taf. CLXV). Die Tasterglieder sind nicht nur verkürzt, sondern auch verdickt; das Endglied überragt nur mit einem Drittel seiner Länge diejenige des vorletzten (die Zähne desselben nicht mitgerechnet), während es bei der Hauptform um etwa 2 Drittel länger ist. Schließlich sind die zahnförmigen Borsten am Ende des vorletzten Gliedes viel kürzer und von einer viel 
plumperen Gestalt. Der übrige Borstenbesatz dieses Gliedes ist spärlicher als bei der Hauptform und variiert übrigens, wie die beigefügten Figuren zeigen.

SIG. Thor hebt als weiteren Unterschied hervor, daß bei der norwegischen Form die Crista nicht nach vorn vor der Oese verlängert ist, während dies bei $T$. bicolor der Fall, und weiterhin soll bei der norwegischen Form das Epistom ausgerundet sein, während es bei $T$. bicolor nach vorn konvex ist (s. BERLESE, Fig. 2, Taf. CLXV).

Es ist wahr, daß diese Merlimale der norwegischen Form eigen sind. Ich bin aber überzeugt, daß wenigstens die Crista bei der Hauptform vollkommen wie bei der Varietät gebaut ist, und daß BERLESE sie nicht richtig abgebildet hat ${ }^{1}$ ). Die Haare sind jedenfalls, wie es BerLese wiedergiebt, placiert, und bei oberflächlicher Beobachtung scheint es daher, als ob die Crista, welche thatsächlich nach vorn nicht scharf begrenzt ist, die länglich-ovale Form hätte, die BERLEsE abbildet ${ }^{2}$ ).

Wenn wir die Beschreibungen und Abbildungen von arktischen Trombidium-Arten durchmustern, so finden wir, was auch zu erwarten war, da ihre Zahl verhältnismäßig hoch ist, daß mehrere von ihnen Synonyme sind. So ist T. laevicapillatum Kramer ohne Zweifel mit $T$. filipes identisch. Zwar habe ich von dieser Art nicht die Typen gefunden, es ist diese Art aber durch den Bau der Taster und Augen und den ganzen Habitus so äußerst charakteristisch, daß es sehr leicht ist, sich mit Hilfe der Figur und Diagnose von der Identität zu überzeugen.

Man braucht nur Textfig. 94 u. 95 mit KRAMER's Fig. ıa u. c, Taf. XXXIX, zu vergleichen und die ausfübrliche Beschreibung der Augen zu lesen. „Die Augen stehen auf einem kurzen, breiten Stiel; die beiden Hornhäute, welche in jedem Augenorgan bemerkt werden, sind etwa gleich groß, und zu jedem konnte der Nervenkegel deutlich wahrgenommen werden. Das Innere des Augenstiels hängt durch eine feine kreisförmige Oeffnung mit dem Leibesraum zusammen, und durch diese Oeffnung treten die 2 Nervenstämme, um die Hornhäute zu erreichen."

Die Abbildung und Beschreibung der Taster spricht zwar insofern gegen diejenige von T. filipes, als KRAMER nur 3 „krallenförmige Fortsätze“ an denselben erwähnt, während T. filipes 4 besitzt. Die letzte Borste ist aber ziemlich klein und leicht zu übersehen. Hat doch KRAMER nicht eine genügend starke Vergrößerung benutzt, um sehen zu können, daß es sich nicht um „Fortsätze“ handelt, sondern um umgewandelte Borsten, die mit freier Basis eingelenkt sind. Die grönländischen Exemplare sind wie die norwegischen ca. $2 \mathrm{~mm}$ lang, also länger als die italienischen, die nur $\mathrm{I}, 3 \mathrm{~mm}$ erreichen.

Fundorte: Arktisches Sibirien: Port Clarence, Grantley Harbour (,Vega"Expedition, KRAMER), Selivaninskoj $\left(65^{\circ} 55^{\prime}\right.$ n. Br.), Jenissej (L. КОсн); Westgrönland: „mellem Sukkertappen og Kangermint", 5. Juni I885 (cand. med. Sören HANSEN), Holstenburg, 13- I6. Juni i 889 und 8. Juli I895 (W. LundBECK), Karsiliak naer Navertalik, 22. Mai I885 (T. EberLeIN), Ritenbenk, 27. Aug. I890 (W. Lundbeck); Island: Hekla-Havn, April r892 (DEICHManN).

Weitere Verbreitung: Arktisches Lappland (I903, TRÄGARDH), Norwegen (THOR., Strand).

\section{Trombidimm sucillnm. (L. КОСН)}

Textfig. 99-ror.

1879 Rhyncholophus sucidus, L. Koсn, l. c. p. 124, tab. 6, fig. 1, 1a.

1883 Trombilium armatum, KuAMEse, "Vega"-Exp., p. 239.

1) THOR kann sich nur auf diese Abbildung stützen, denn in der Diagnose wird die Crista nicht genau beschrieben.

2) Auch das Epistom dürfte von BERLESE unrichtig abgebildet sein, denn Exemplare aus Schweden, die im Bau der Taster eane vermittelnde Stellung zwisclien der Varietät und der Hauptform darstellen, haben ein ausgerunietes Epistom. 
1897 Trombidium armatum, Kram., Oudemans u. Konnike, l. c. p. 239.

1900 Ottonia spinifera, Sig. Tron, Furste Undersogelse af Norges Trombididae, Christiania Vid. Selsk. Forh., 1!900, No. 2, p. 9, tab. 1, fig. 3-6.

1900 Ottonia plunca (Kocr 1837) Sig. Thor, ibidem, p. 11, tab. 1, fig. 11.

1901 Trombidium sucidum (L. КосH) Trägi̊nd, l. c. p. 60.

1902 " $"$ l. c. p. 4, tab. 1, fig. $1-3$

Diese in arktischen Gebieten weit verbreitete Art ist mit T. pusillum (Herm.) BERL. am nächsten verwandt, unterscheidet sich aber von ihr leicht durch den Bau der Taster, welche sowohl an der Außen- wie an der Innenseite des vorletzten Gliedes mit einer kräftigen zahnförmigen Borste bewaffnet sind, durch die Mandibeln, welche nicht gezälınt sind, und durch die Tasterglieder des I. Beinpaares, die nur wenig verdickt sind.

Wie ich schon (l. c.) hervorgehoben habe, ist sie mit der aus Norwegen beschriebenen Ottonia spinifera SIG. Thor identisch. Sig. THOR hebt hervor, daß seine Art mit $T$. armatum Kramer große Uebereinstimmung zeigt. Letztere soll aber nur 2 Paar Genitalsaugscheiben haben, während 0 . spinifera 3 hat. Ich weiß nicht, ob es die Typen Kramer's sind, die ich untersucht habe; unter den Sammlungen der

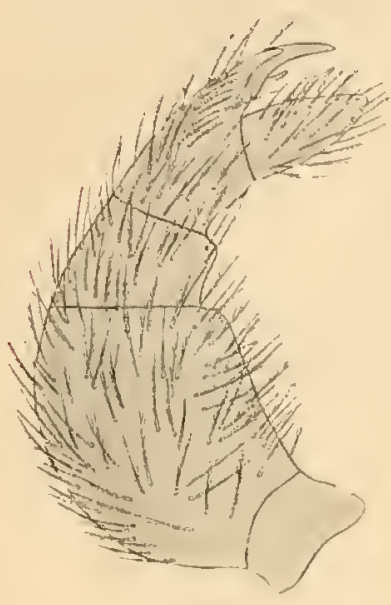

Fig. 99a.

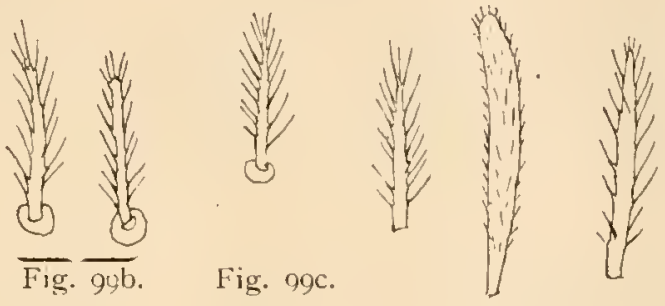

Fig. $99 \mathrm{~d}$.

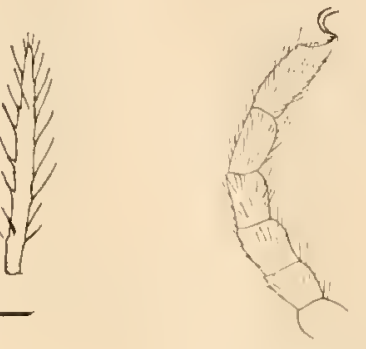

Fig. IOI.

Fig. 99a. Tromlidium sucidum L. КосH. Taster. Vergr. 232,5: 1.

Fig. 99b. " " " Kürperhaare der Typen Koch's. Vergr.620:1.

Fig. 99c. " " " $\quad$ eines Exemplares aus Grönland.

Fig. 99d. " " " von T. armatum Kram. Vergr. $620: 1$.

Fig. 100. " " " " " Das I. Bein. Vergr. 107: J. Fig. Jo0.

Fig. IOI. ., " $, \quad, \quad$, Das 2. Bein. Vergr. I07: I.

„Vega"-Expedition befand sich aber eine Glastube, etikettiert „No. I063, Lawrence-ön I2 Augusti I879“, und in dieser befanden sich 2 unbestimmte Acariden-Arten, T. sucidum und Rhayidia getida THOR. Da unter anderen Fundorten für 7 ' armatum auch St. Lawrence-Bay von KRAMER erwähnt wird, spricht dies für die Annahme, daß KRAMER T. sucidum als T. armatum beschrieben hat.

Seine Beschreibung der Taster paßt sehr gut auf T. sucidum: „.... 4. Glied läuft vorn in eine scharfe zahnartige Spitze aus, neben welcher innen und außen ebenfalls eine solche Spitze bemerkt wird; am Außenrande schließt sich an letztere eine Reihe von 4-5 schmalen Zahnfortsätzen an, welche nur bei einer Ansicht von oben her bequem gesehen werden können". Mit diesen .Zahnfortsätzen" meint er wohl die kräftigen Borsten, die auf der Rückseite des vorletzten Gliedes sitzen; auf seiner Abbildung sind sie zu grob gezeichnet. Die Exemplare aus Lawrence-Bay haben drei Genitalsaugscheiben, nicht zwei ${ }^{1}$ ), wie KRAMER unrichtigerweise angiebt. In einer Hinsicht weichen diese Exemplare von den mir aus Sibirien bekinnten ab: sie tragen zwischen den gewöhnlichen dünneren gefiederten Körperhaaren etwas längere und dickere, schwach keulenförmige Haare. 
Sie stimmen in dieser Hinsicht mit der von Sig. THOR beschriebenen Ottonia planca (C. L. Koch) überein, die sich nur durch diesen Charakter von O. spinifera unterscheidet.

Da aber nach BerLese dieses Merkmal nur ein weiblicher Geschlechtscharakter ist, liann es hier kaum den Wert eines Artcharakters haben und ich rechne die Exemplare aus Lawrence-Bay daher zu T. sucidum und führe auch Ottonir planca als Synonym unter T. sucidun auf, trotzdem die Weibchen von T. sucidum, die ich aus Lappland besitze, keine Kolbenhaare tragen.

In Bezug auf die Crista verweise ich auf Thor.'s Fig. 3, Pl. I. Die Vorderbeine sind verhältnismäßig kürzer als bei T. pusillum (Textfig. IOO, 101). Da außerdem die Taster des T. sucidum und ebenso die zahnförmigen Borsten des vorletzten Gliedes kürzer als bei der náhe verwandten T. pusillum sind, so stehen diese Arten zu einander in einem ganz analogen Verhältnis wie T. bicolor und seine Varietät, obgleich der Unterschied zwischen den ersteren größer ist als bei letzteren.

In ¡beiden Fällen weist die nördliche Form eine Verkürzung der Beine, der Taster und der zahnförmigen Borsten auf.

Fundort: Arktisches Sibirien: Jinretlen, Pitlekaj, St. Lawrence-Bay, St. Lawrence-Insel, Port Clarence („Vega"-Expedition) Matotschkin. Besimanja, Gi̊stcap u. a. (L. KосH); Westgrönland: Nekamiut, I8. Juli I 889 (W. Lundbeck), Ipiutat „unter Steinen“, 5. September I889 (W. Lunobeck), „unter Steinen“ bei Sermiliak, I6. Juni 1885 (S. Hansen), Holstenburg, 16. Juni i 890.

Weitere Verbreitung: Arktisches Lappland, Norwegen.

Bestimmungstabelle der Subfamilie Erythraeince.

Taster viergliedrig

Taster fünfgliedrig
Gatt. Smaris LATR. p. 54 Gatt. Erythraeus LATR. p. 54

\section{Smaris expalpis (HeRu.) KocH ${ }^{1}$ )}

1879 Smuris plana, L. KocH, 1. c. p. 127, tal). 6, fig. 6.

Fundort: Sihirien (L. Koch).

Weitere Verbreitung: Ganz Europa.

Bestimmungstabelle der Gattung Erythraeus LATr.

I. Das I. und 4. Beinpaar viel länger als der Körper; 4 Augen _ . . . . . . . . . . 4.

I Das I. und 4. Beinpaar von ungefähr derselben Länge wie der Körper; 2 Augen . . . . 2. f Körperhaare gefiedert . . . . . . . . . . . . . . 6r. E. vertex p. 57

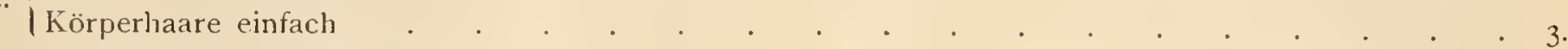

3. Die Tasterklaue ungezähnt

59. E. miniretus p. 55 I Die Tasterklaue mit einem Zahn versehen . . . . . . . . 60. E. unidentritus p. 56 4. Körperliaare einfach, lang . . . . . . . . . . . . 65. E. regalis p. 6I

4. | Körperhaare dicht gefiedert, kurz

5. Das 3. Tastergied auf der Innenseite nur mit Haarborstenbesetzt $\quad 63$. L. plulangioiles var. gracilipes p. 59 I Das 3. Tasterglied mit 2-4 ungewandelten, gezähnten Borsten besetzt . 62. F. phalangioidcs p. 58

1) In Bezug auf die Synonymik dieser Art verweise ich auf SIG. THOR: Forste undersugelse af Norges Rhyncholophidae. Christiania Vid. Selsk. Forhandl., 1900, No. 3, p. 3. 


\section{Erythraeus miniatus (HERM.)}

Textfig. I02-106.

1872 Trombidium hyperloreum, THоneLL, Arachniden fr. Grönland, Öfv. Kongl. Svenska Vet. Akad. Handl., No. 2, p. 162.

1879 Rhyncholophus albicomus, L. Koci, Arachniden fr. Sibirien i Novaja Semlja, Kongl. Svenska Vet. Akad. Handl., Bd. XYI, p. 125, tab. 6, fig. 3.

1901 Rhyncholophus hyperboreus (Thов.), TRäGÅRDH, Vorl. Mitteilung, p. 60.

Wie ich in der vorläufigen Mitteilung hervorhob, ist THORELL's T. hyperboreum keineswegs eine Trombidizm-Art, sondern gehört zur Gattung Erythraens. Ein Vergleich mit dem wohlkonservierten Materiale von E. miniatus (HERM.), das ich aus Grönland bekommen habe, und worunter sich auch eine Nymphe befand, hat gezeigt, daß Thorell's Art auf eine Nymphe dieser Art gegründet ist. Es genügt, um dies außer Zweifel zu stellen, auf die Textfigg. 103 und Io4 hinzuweisen, die den Taster des THorkLL'schen Typenexemplares (Textfig. 103) und denjenigen eines Fxemplars aus Grönland (Textfig. I04) darstellen.

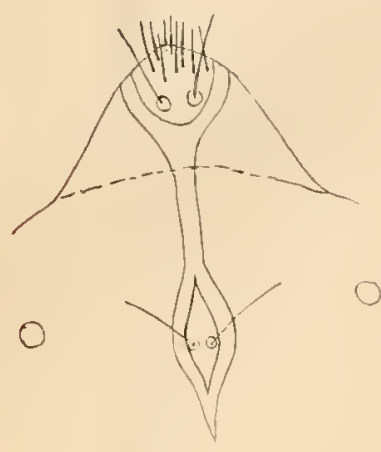

Fig. 102.

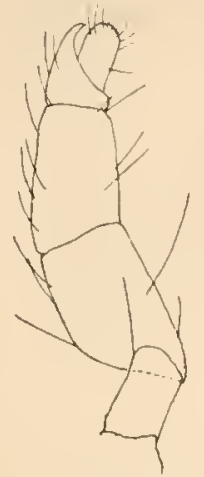

Fig. 103.

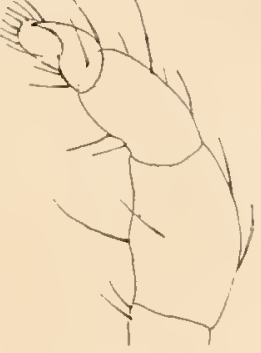

Fig. 104.

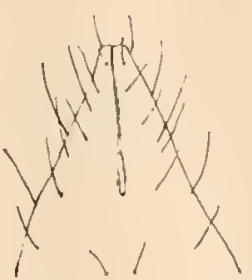

Fig. 105.

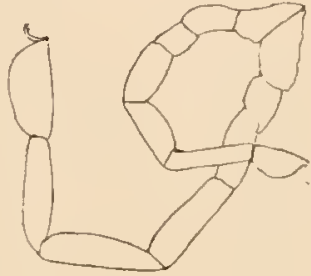

Fig. 106

Fig. 102. E. miniatus (HERM.). Crista metopica eines Exemplares aus Grönland Vergr. $248: 1$.

Fig. 103. " $" \quad$ Taster (nach ThORELL's Typen). Vergr. $2 \nmid 8:$ I.

Fig. I0.4. " , ,. Taster eines Exemplares aus Grönland. Vergr. 248: I.

Fig. 105. E. mimiatus (HERM.). Rostrum, von unten gesehen. Vergr. I50:I.

Fig. 106. " " $"$ Das 3. und 4. Bein (nach THORELL's Typen). Vergr. 75: I.

Weiterhin ist der von L. Koch aus Sibirien beschriebene E. albicomus offenbar mit E. miniatus identisch. Schon die Beschaffenheit der Körperhaare, die von KocH, als ,weiß und seidenglänzend“ bezeichnet werden, lenkte meine Aufmerksamkeit darauf ${ }^{1}$ ). Wenn man genau die Längenverhältnisse der Beinglieder beachtet, die auf KocH's Abbildungen zuverlässig dargestellt zu sein pflegen, so stimmen sie ganz genau zu denjenigen von $E$. miniatus. So ist das I. Beinpaar ein wenig länger als der Körper, das ${ }^{*} 4$. ungefähr so lang wie derselbe und die Tarsen des I. Beinpaares sind ungefähr doppelt so lang wie diejenigen der übrigren Beinpaare, die sämtlich kurz sind. Wegen dieser großen Uebereinstimmung, und da sonst nichts in der KocH'schen Diagnose gegen eine Identifizierung spricht, führe ich unbedenklich E. albicomus als Synonym zu L. miniatus auf. Ich gebe schließlich einige Messungen der Beinglieder der grönländischen Exemplare.

\begin{tabular}{|c|c|c|c|c|c|c|c|c|c|c|c|c|c|c|c|}
\hline & \multirow{2}{*}{$\begin{array}{c}\text { Körper- } \\
\text { länge }\end{array}$} & \multirow{2}{*}{$\begin{array}{c}\text { Totallänge } \\
\text { des } 1 \text {. Bein- } \\
\text { paares }\end{array}$} & \multicolumn{6}{|c|}{ I. Beinpaar } & \multirow{2}{*}{$\begin{array}{c}\text { Höhe } \\
\text { der } \\
\text { Tarse }\end{array}$} & \multicolumn{5}{|c|}{ 4. Beinpaar } & \multirow[b]{2}{*}{6.} \\
\hline & & & 1. & 2. & 3. & 4. & 5. & 6. & & 1. & 2. & 3. & 4. & 5. & \\
\hline No. 1 & 0,72 & $0,7 \mathrm{I}$ & 0,06 & 0,09 & 0,14 & 0,15 & 0,16 & 0, I I & 0,054 & - & 0,07 & 0,1 & 0,13 & 0,17 & 0,06 \\
\hline, 2 & 0,85 & 0,83 & 0,07 & $0, \mathrm{I} I$ & 0,17 & 0,18 & 0,18 & 0,13 & 0,054 & - & - & - & - & - & - \\
\hline, 3 & 0,9 & $0,7 \mathrm{I}$ & 0,07 & 0,09 & 0,12 & 0,15 & 0,15 & 0,13 & 0,054 & $\mathrm{O}, \mathrm{C} 7$ & 0,09 & 0,14 & 0,16 & 0,17 & 0,08 \\
\hline
\end{tabular}

Wenn man das Verhältnis zwischen der Körperlänge (exkl. Rostrum) und der Länge des I. Beinpaares bei den grönländischen Exemplaren mit demjenigen bei BERLESES Figur vergleiclıt, so ergiebt sich,

I) Das einzige Typenexemplar war in der Sammlung nicht vorhanden. 
daß das I. Beinpaar bei ersteren verkürzt ist. Bei Berlese's Figur ist dieses Verhältnis nämlich durch I,3: I ausgedrückt.

Fundorte: Sibirien (L. Kосн), Grönland: Quanersoit (ThorelL), Nekamiut, i8. Juli i889 (W. LUNDBECK).

Weitere Verbreitung: Frankreich, Italien.

60. Evythraeus midentritus nov. spec.

Fig. I07-IIO.

Diese Art steht E. minirtus ${ }^{1}$ ) (HERM.) sehr nahe, unterscheidet sich jedoch deutlich durch den Bau der Taster, indem die Schneide der Klaue des 4. Gliedes einen stumpfen Zahn hat (Fig. IOS).

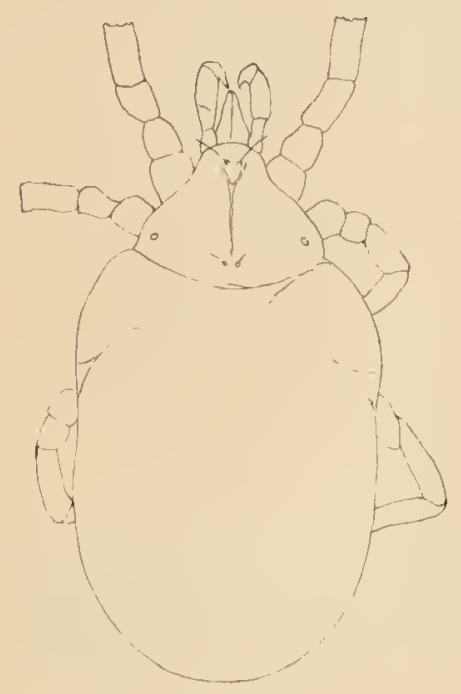

Fig. 107.

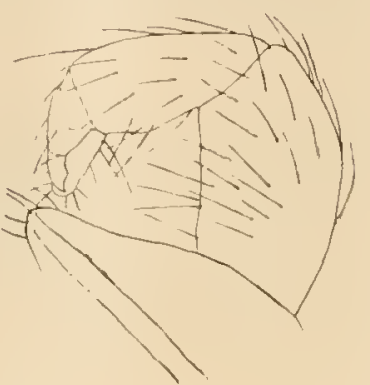

Fig. 108 .

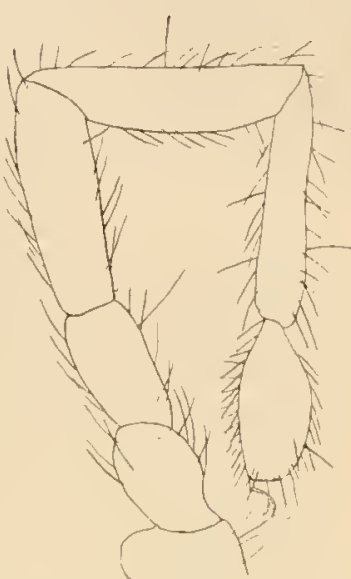

Fig. 109.

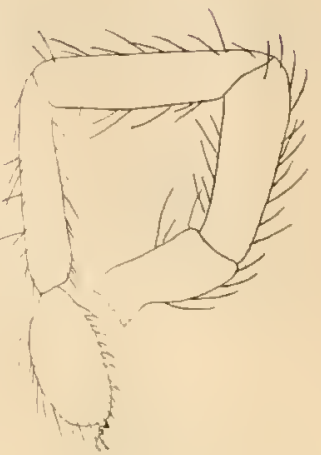

Fig. 110.

Fig. 107. Erythaces unidentutus n. sp. Dorsalansicht. Vergr. 22,5: I.

Fig. 108. " " " "Taster. Vergr. 228 : 1.

Fig. I09. . " $", \quad "$ Das 1. Bein. Vergr. 112,5:1.

Fig. 110. " " " "Das 2. Bein. Vergr. 112,5:1

Die Behaarung ist dieselbe wie bei $E$. miniatus, d. h. die Haare sind einfach und weißlich schinmernd. Man könnte daher meinen, daß L. Koch's E. albicomus ebenso gut mit E. unidentrutus identisch sein könnte. E. albicomus hat aber verhältnismäßig längere Beine, und die Tarsen des I. Beinpaares sind doppelt so lang wie diejenigen der übrigen Beinpaare, während sie bei F. midentatus von annähernd derselben Länge sind. Der Körper ist mehr plump und breit als bei $E$. miniatus. Die längenverhältnisse der Beine sind aus folgender Tabelle ersichtlich.

\begin{tabular}{|c|c|c|c|c|c|c|c|c|c|}
\hline & $\begin{array}{c}\text { Länge der } \\
\text { Körper }\end{array}$ & I. & $\begin{array}{l}\text { Läng } \\
2 .\end{array}$ & $\begin{array}{l}\text { e der } \\
\text { des } 1 . \\
3 .\end{array}$ & $\begin{array}{c}\text { Beingl } \\
\text { Paares } \\
4 .\end{array}$ & $\begin{array}{l}\text { der } \\
5 .\end{array}$ & 6. & $\begin{array}{l}\text { Hölue } \\
\text { der } \\
\text { Tarse }\end{array}$ & $\begin{array}{l}\text { Total- } \\
\text { länged. } \\
\text { Beines }\end{array}$ \\
\hline No. I & 1,44 & 0,108 & 0,126 & 0,18 & 0,25 & 0,18 & 0,16 & 0,07 & 1,00 \\
\hline . 2 & - & 0,09 & 0,12 & 0,216 & 0,24 & 0,20 & 0,14 & 0,06 & $\mathrm{I}, \mathrm{Ol}$ \\
\hline
\end{tabular}

Man sieht, daß das I. Beinpaar bedeutend kürzer als der Körper ist. Betreffs der relativen Länge der Glieder stimmt die Art mit E. miniatus ziemlich gut überein, abgesehen davon, daß das 4. Glied länger als das 5. ist, während diese bei E. miniatus von derselben Länge sind.

Die Taster unterscheiden sich, wie erwähnt, durch den Zahn auf der Kilaue des 4. Gliedes, aber auch durch ihre mehr plumpe Gestalt und durch die dichtere Behaarung.

I) Ich vermutete zuerst, daß Fitteria norregien Sig. THoR entweder mit $E$. miniatus oder E. unidentatus identisch sei. Das ist aber keineswegs der Fall, dem sie ist mit E. miniatus var. mbripes TrT. identisch, welche Art ich von der Westkiste von Schweden besitze; diese Form hat noch klirzere Beine als die obigen. 
Trotzdem die Formen voneinander gut getrennt erscheinen, kann ich mich doch nicht der Vermutung erwehren, daß sie möglicherweise $q$ und $\delta$ derselben Art darstellen. Von E. unidentrutus liegen mir nämlich nur Weibchen vor, während anderseits die wenigen Exemplare von E. miniatus, die ich besitze, Männchen sind. Da mein Material aber sehr spärlich ist, kann dies ja auf einem Zufall beruhen, und es bedarf weiterer Untersuchungen, um die Frage zu lösen. Es wäre jedenfalls sehr interessant, wenn meine Hypothese sich bewähren würde, denn man kennt bei dén Erythracarinen bis jetzt nichts von einem so ausgesprochenen Geschlechtsdimorphismus.

Fun dor te: Westgrönland: 23. Juli i889, Tasiusal: (W. LundBeck), 25. September I889, Ipiutat, unter Steinen (W. LUNDBECK); Ostgrönland (RYDER's Expedition).

\section{Erythrueus vertex (KRAMER)}

\section{Textfig. II I-II5.}

? 1879 Rhyncholophus tonsus, L. Kосн 1. c. p. 126, tab. 6, fig. 4.

1886 " vertex, Krauer, Arch. f. Naturg., Bd. LII, tab. 12, fig. 23-26.

1900 Ritteria vertex, Kram., Sig. Thor. Forste undersogelse af Norges Rhyncholophidae. Christiania Vid.-Selskabs Forhandl., No. 3, p. 8, tab. 2, fig. 34 .

Meine Exemplare aus Grönland stimmen mit denjenigen, die ich aus Norwegen besitze, und die dem E. vertex KRAu. So nahe stehen, so überein, daß es sicher dieselbe norwegische Form ist, die THOR mit diesem Namen bezeichnet hat. Die norwegische und grönländische Form stimmt nicht ganz mit KRAMER's Beschreibung überein. Die Diagnose und Abbildung von R. tonsus paßt in Bezug auf Körperform, Länge der Beinglieder, Behaarung und Bau der Taster und der Crista metopica auf E. vertex, so daß diese Art mit E. vertex identisch sein dürfte.

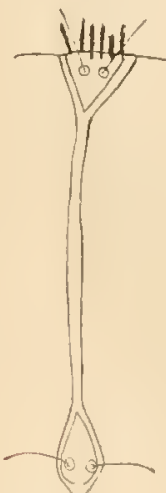

Fig. 111 .

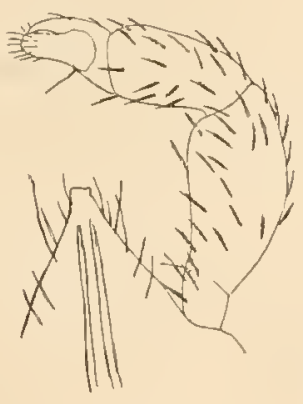

Fig. I12.

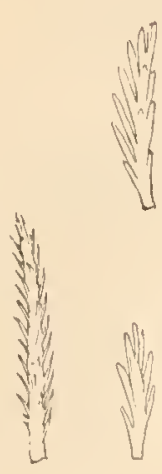

Fig. I 13 .

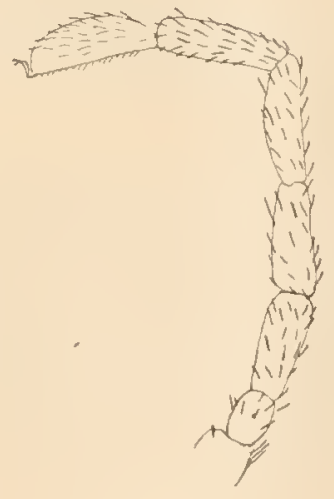

Fig. II 4 .

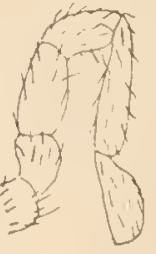

Fig. II 5 .

Fig. II1. Erythraeus vertex KRAM. Crista metpica. Vergr. I20: I.

Fig. I12. " " ", Taster. Vergr. I20:1.

Fig. 113. " " "

Fig. I14. " " $\quad " \quad$ Das I. Bein. Vergr. $48:$ I.

Fig. 115. " " , , Das 2. Bein. Vergr. 60:1.

Die Taster haben nämlich das 3. Glied verhältnismäßig kürzer und dicker als bei dieser, und das 5. Glied überragt nicht die Klaue des 4. Bei Kramer's Form erreicht das 3. Glied $3 / 4$ des 2. (bei unserer Form nur $2 / 3$, und das 5. Glied ist viel länger als die Klaue des 4. Bei der italienischen Form ${ }^{1}$ ) ist das 3. Glied sogar länger als das 2. Es erhellt daraus, daß bei den nördlichen Formen eine allmähliche Reduktion des 3. Gliedes gegenüber dem 2. stattgefunden hat, die bei der grönländischen Form lutminiert. In Bezug auf Crista, Körperhaare und Beine der grönländischen Form verweise ich auf die beigefụ̈ten Figuren. Fundorte: ?Sibirien: Selivanin (L. Koch); Grönland: Tasiusak, 23. Juli 1889 (W. Lundbeck), „Flua, fra Lundholm", i 890.

Weitere Verbreitung: Norwegen, Deutschland, Italien.

I) Berlese, Acari, Meyr. Scorpionesque in Italia reperta: Prostigmata, Tab. CL. 


\section{Erythroeus groentandicus n. sp.}

Textfig. I 16 u. I 17 .

? 1872 Rhyncholophus (?) inc, spec., TнокецL, l. c. p. 163.

Diese Art, welche auf eine Larvenform gegründet ist, wird sich wohl künftighin als mit einer der größeren grönländischen Enythraeus-Arten identisch zeigen. Gegenwärtig habe ich aber keinen sicheren Ausgangspunkt für die Beurteilung ihrer Zugehörigkeit zu der einen oder der anderen von diesen Arten, obwohl mir E. phalangioides var. gracilipes sehr verdächtig scheint, und ich bin daher genötigt, vorläufig für die Larvenform eine neue Art aufzustellen. Die Länge beträgt ungefähr I mm. Die Larve unterscheidet sich deutlich von den 2 bis jetzt beschriebenen europäischen Erythrueus-Larven, E. phalangioides und E. quisquiliarum, von

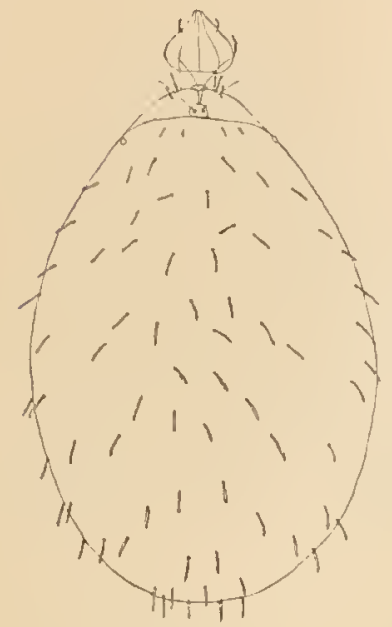

Fig. I16.

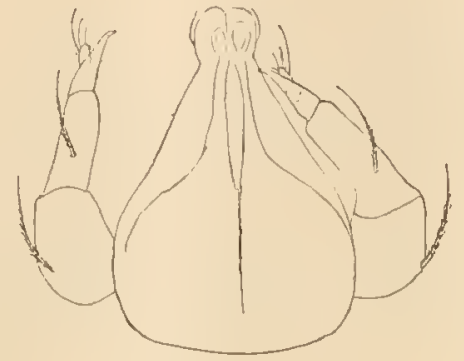

Fig. 117.

Fig. 116. Enythraens groenlandicus n. sp. Dorsalansicht. Vergr. $45:$ I.

Fig. I17. Erythraeus yroenlandieus n. sp. Taster und Mandibeln. Vergr. $232,5: 1$. ersterer durch die Abwesenheit einer dorsalen Platte, von letzterer durch den abweichenden Bau der Crista metopica, die so schwach entwickelt ist, dåß sie kaum sichtbar ist. Durch diesen Charakter nähert sie sich dem von Oudemans ${ }^{1}$ ) beschriebenen $E$. lomani, welcher vollständig der Crista entbehrt. Der Körper hat einen eiförmigen Umriß. Rostrum und Pseudocapitulum sind nach hinten sehr erweitert und durch eine enge, halsförmige Partie mit dem Körper verbunden. Am Vorderrand des Cephalothorax, welcher mit dem Abdomen vollkommen verschmolzen ist, sitzen 2 nach vorn gerichtete, gefiederte, stumpfe Borsten

und ein wenig hinter und außen von ihnen 2 etwas kürzere. Auch durch dieses Merkmal nähert sich unsere Art dem E. lomani Oudms. Die Crista ist sehr schwach chitinisiert und sehr kurz; sie erweitert sich nach vorn Y-förmig und umfaßt eine kleine hervorgewölbte Partie, worauf 2 Tasthaare sitzen, erweitert sich ebenfalls nach hinten und bildet einen Ring, welcher die Insertionspunkte zweier etwas größerer Tasthaare umgiebt.

Die Augen sind sehr klein und sitzen weit voneinander entfernt an den Seiten des Körpers an der Grenze zwischen dem I. und 2. Achtel der Körperlänge. Der Körper ist ziemlich spärlich mit groben, gefiederten Haaren besetzt, die zwar unregelmäßig, aber ziemlich genau symmetrisch sitzen. Nur am Vorderteil des Körpers zwischen den Augen ist eine deutliche Querreihe von 4 Borsten zu unterscheiden. Die Taster (Textfig. II7) tragen auf der Oberseite des I. und 2. Gliedes je eine grobe, gefiederte Borste. Das 4. Glied, das mit langen Haaren besetzt ist, erreicht nicht die Länge der Klaue des 3. Gliedes.

Fundorte: Grönland, 5. Juli I8go, Egedesminde (W. LundBecK), ?Quanersoit (ThoreLL).

\section{3. : Evythraeus phalrengioirles (DE GEER)}

1897 Rhyncholophus phalangioides, DE GEer, Krımer, Grönländische Milben, Bibliotheca zoologica, Heft 20, Lief. 3, p. 78.

Ich führe diese Art auf KRAMER's Autorität hin für Grönland auf, obgleich ich vermute, daß er mit diesem Namen eine ungewöhnlich langbeinige Form der var. gracilipes bezeichnet hat.

Fundort: Grönland: am Ufer der Itiodliarsukfjordes (KRAMER).

Weitere Verbreitung: Ganz Europa.

I) Notes on Acari, 5. Serie. Tijdschr. voor Entomologie, Bd. XLV, p. I4I, tab. 12, fig. 3I-38. 


\section{Elythrcens phalangioides var. gracilipes (KRAM.)}

Textfig. I $18 \mathrm{a}-\mathrm{k}$ u. I19-I24.

1897 Rhyncholophus gracilipes, Kramer, 1. c. p. 77.

1902

intermedius, Träg̊̊iLH, Lapplïndische Trombididen und Oribatiden, Bih.t. Kongl. Sv. Vet.-Akad. Handl., Bd. XXVIII, Afd. 4, No. 5, p. 4, tab. 1, fig. 4.

Es stimmen die zahlreichen Exemplare, die ich aus Grönland besitze, mit dem von KRAMER aus Grönland beschriebenen E. grucilipes vollständig überein (vergl. No. 8 und 9 mit Io in der Tabelle). Der Unterschied zwischen dieser Art und meinem aus Lappland beschriebenen $\boldsymbol{E}$. intermedius zeigte sich bei einer Untersuchung über die Variation der als Artcharaktere angewendeten Merkmale nicht bedeutend genug, um die Aufstellung des Letzteren als eine besondere Art zu rechtfertigen (vergl. No. II, I2 und I3). Bei der Untersuchung über die Variation der grönländischen Form habe ich auch Material aus Norwegen heran. gezogen, und da die dabei gewonnenen Resultate für die Beurteilung der Stellung der grönländischen Form sehr wichtig, ja sehr notwendig sind, teile ich sie hier mit.

\begin{tabular}{|c|c|c|c|c|c|c|c|c|c|c|c|}
\hline No. & Lokalität & $\begin{array}{c}\text { Bau der } \\
\text { Körperhaare }\end{array}$ & $\begin{array}{l}\text { Zahl der } \\
\text { auf den } \\
\text { 4. Glied }\end{array}$ & $\begin{array}{l}\text { Zähne } \\
\text { Tastern } \\
\text { 3. Glied }\end{array}$ & $\begin{array}{r}\text { F } \\
\text { Glie } \\
\text { I. }\end{array}$ & $\begin{array}{l}\text { Relat } \\
\text { eder }\end{array}$ & $\begin{array}{l}\text { ive } 1 \\
\text { des }\end{array}$ & 4. Be & $\begin{array}{l}\text { e der } \\
\text { einpaz }\end{array}$ & ares & \\
\hline 1. & Norwegen & $\begin{array}{l}\text { Fig. a, grob, } \\
\text { gefiedert }\end{array}$ & 3 & 2 & I & 2 & 4,2 & $4, I$ & 7,6 & 2,1 & E. phalangioides \\
\hline 2. & $"$ & Fig. b & $2-3$ & 2 & I & 2,3 & 4 & 4,1 & 7,6 & 2 & \\
\hline 3. & $"$ & $\begin{array}{c}\text { Fig. c, einfach, } \\
\text { schwach ge- } \\
\text { fiedert }\end{array}$ & 2 & $1-2$ & 0,8 & 2 & 4 & 4 & 6,6 & 1,5 & E. regalis \\
\hline 4. & " & Fig. d, einfach & 4 & $4-5$ & I & $\mathrm{I}, 6$ & 2,6 & 2,8 & 4,6 & 1,6 & \\
\hline 5. & $"$ & $\begin{array}{l}\text { Fig. e, grob, } \\
\text { gefiedert }\end{array}$ & 5 & 2 & 0,83 & 1,7 & 2,6 & 2,6 & 5 & 1,6 & E. phalangioides \\
\hline 6. & $"$ & Fig. $\mathrm{f}$ & $4-5$ & $4-5$ & I & I, 8 & 2,8 & 2,9 & 5,3 & I, 8 & E. phalangioides nach KRAMER. \\
\hline 7. & Grönland & Fig. g, grob & - & - & 1 & 1,7 & 3,5 & 3,5 & 7 & 2,3 & E. phalongioides var. gracilipes \\
\hline 8. &, & grob $=$ No. 7 & 3 & 1) & 0,83 & $\mathrm{I}, 8$ & 2,8 & 2,8 & $5 \cdot 3$ & I, 3 & $" \quad " \quad, \quad$, \\
\hline 9. & $"$ & grob $=$ No. 7 & $3-4$ & 1) & 0,83 & $\mathrm{I}, 6$ & 2,6 & 2,6 & 4,2 & 1,6 & " $\quad, \quad$, \\
\hline IO. & $"$ & ziemlich grob & + & 1) & 1 & $\mathrm{I}, 5$ & 2,2 & 2,7 & 5 & 1,3 & E. gracilipes nach KRAMER. \\
\hline II. & Lappland & Fig. $h$ & 5 & 2 & I & 1,8 & $3, \mathrm{I}$ & 3.5 & 6,16 & $\mathrm{I}, 7$ & E. intermedius nach TRÄGARDH. \\
\hline I 2. & Norwegen & Fig. $k$, einfach & $4-5$ & 2 & I & 2 & 3,6 & 4 & 6,3 & 2 & E. regalis \\
\hline 13. & Grönland & ziemlich grob & $3-4$ & 1) & I & 1,8 & 2,8 & 3,1 & 5,8 & $\mathrm{i}, 4$ & E. phalangioides var. gracilipes \\
\hline
\end{tabular}

SIG. THOR giebt bekanntlich an, daß sowohl $E$. regalis wie $E$. phalangioides (= opilionidcs) in Norwegen vorkommen. Die von ihm als $E$. opilionides bezeichnete Art soll sich von dem von BERLESE beschriebenen durch verschiedene. Form und Borstenbesatz, sowie das Vorhandensein von nur 3 Zähnen am 4. Gliede der Palpen unterscheiden. E. regalis und E. phalangioides, die 2 Arten, auf welche BERLESE die von den Autoren beschriebenen, zu der Untergattung Apectoloplus gehörenden Erythraeus-Arten zurückführt, unterscheiden sich nach BERLESE voneinander folgendermaßen: $E$. regalis hat am 4. Tasterglied 3-5 zahnförmige Borsten, am 3. Glied 2; E. phalangioides hat am 3. und 4. Glied eine Reihe von groben Borsten („Serie“ Berlese, an seiner Figur sind am 4. Glied 6, am 3. Glied 3 zu sehen). Bei E. regalis ragt das 5. Glied kaum über die Klaue des 4. hervor. Bei E. phralanginides ist das 5. Glied "tarso longius" (BERLESE). Bei $E$. regalis sind die Körperhaare „longe foliiformes, utrinque serrulatae“ und nicht gleichförmig über die Oberseite des Körpers verbreitet, sondern in der Mitte spärlicher vorhanden. Bei E. phalangioides sind die Körperhaare kürzer und dicker (s. BERLESE, Fig. 3, 4, Taf. CLII) und gleichförmig über die Oberseite des Körpers verbreitet. Die Haare der Beine sind bei E. regalis „subsimplices, vel vix lateraliter serrulati". Bei E. phalangioides sollen sie "plumiformes" sein.

1) Nur Haarborsten, keine Zähne vorhanden. 
Schließlich ist aus BerLeSE's Figuren zu ersehen, daß bei E. phalangioides das 5. Glied des 4. Beinpaares verhältnismäßig viel länger ist als bei $E$. regalis.

Es ist möglich, daß die beiden italienischen Formen durch die oben erwähnten Merkmale leicht zu unterscheiden sind, bei den norwegischen und grönländischen Formen aber vermischen sich diese Charaktere meistens so miteinander, daß nur ein einziges Merkmal beim Unterscheiden der Formen gebraucht werden kann, nämlich der Bau der Körperhaare. Denn wenn man auch zugeben muß, ¿daß auch zwischen den verschiedenen Formen von diesen Uebergänge existieren (Textfig. II $8 \mathrm{~g}, \mathrm{~h}$ ), die vielleicht durch Untersuchung eines noch größeren Materiales, als es mir zu Verfügung stand, vermehrt werden können, so verteilt sich jedoch die norwegische Form deutlich auf zwei Gruppen: die eine ist durch Körperhaare von dem in Textfig. IIse, $\mathrm{f}$ abgebildeten Typus, d. h. durch kurze, dicke, mit 4-5 Längsreihen von blattförmigen Härchen versehene Borsten charakterisiert, und diese Gruppe stimmt in dieser Hinsicht mit E. phalangioides überein; die andere Gruppe hat Haare von dem in Textfig. $118 \mathrm{c}, \mathrm{d}, \mathrm{k}$ abgebildeten Typus, d. h. von schlankerer und längerer Gestalt, die nur mit sehr kleinen Härchen besetzt sind. Diese Gruppe hat also typische regalis-Haare.
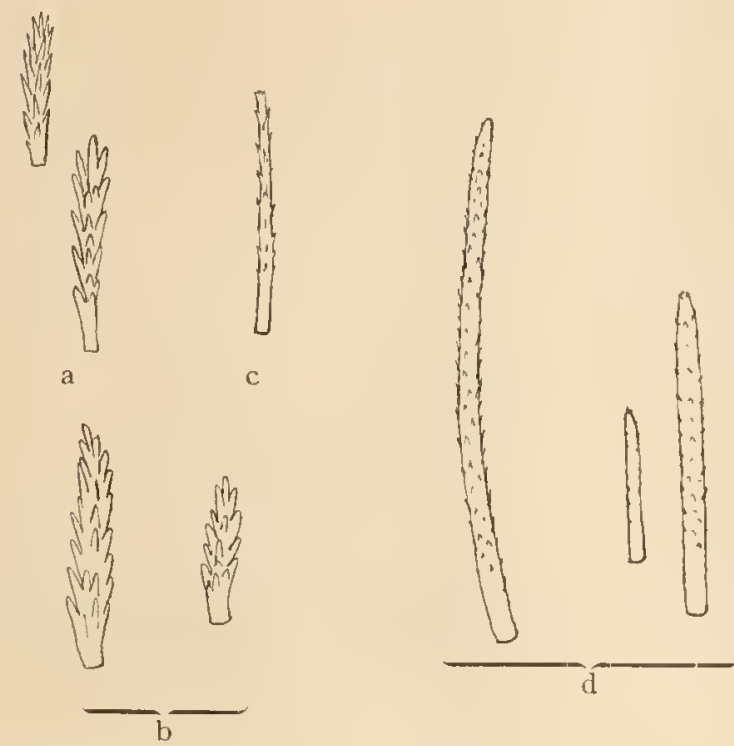
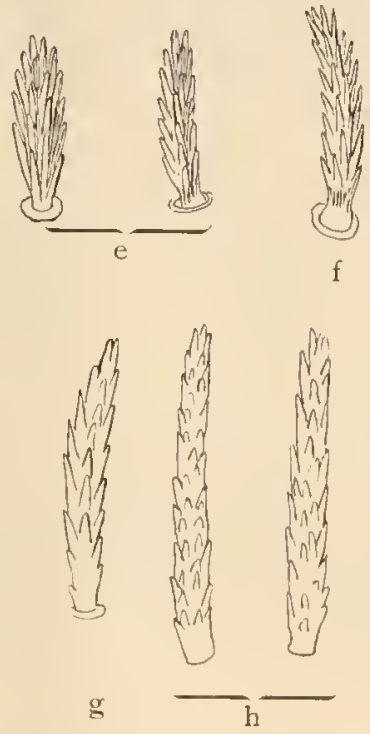

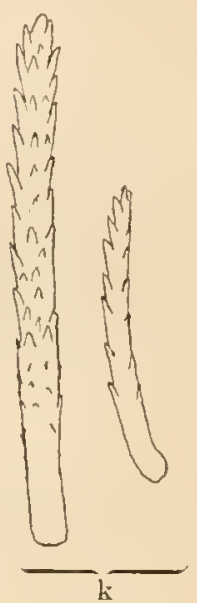

Fig. 118a-k. Körperhaare von Erythraeus phalangioides var. gracilipes: g, b, von E. phalangioides: a, b, e und f, von E. regalis: $\mathrm{d}$ und $\mathrm{k}$ und $E$. signatus: $\mathrm{i}$.

Die anderen Merkmale, wie die relative Länge der Glieder des 4. Beinpaares und die Zahl der auf dem 3. und 4. Tastergliede vorhandenen zahnförmigen Borsten, können nicht benutzt werden, um die beiden Arten auseinanderzuhalten, denn wenn auch ein Vergleich zwischen den Nummern I und 2 der Tabelle einerseits und No. 3 andererseits, die alle nicht völlig erwachsene Tiere sind, uns zeigt, daß bei den mit phalangioides-Haaren versehenen jüngeren Individuen das 5. und 6. Glied des 4. Beinpaares relativ länger (obgleich sehr unbedentend) ist, so ist doch die Zahl der Tasterborsten annähernd dieselbe, bei beiden Formen, und betreffs der Haare der Beine sind diese bei No. 3, welche den regalis-Typus darstellt, sehr kräftig gefiedert, während sie bei No. I und 2 sehr schwach gefiedert sind, also gerade umgekehrt, wie Bertese es angiebt. Die Verteilung der Haare auf dem Rücken ist bei allen 3 dieselbe. Bei erwachsenen Tierchen dagegen ist auch dieser Unterschied nicht mehr vorhanden. So hat z. B. No. I2, die Haare von dem regalis-Typus (Textfig. Ii8k), das 5. und 6. Glied des 4. Beinpaares länger als No. 8 und 9, welche Haare von einem Typus (Textfig. II $8 \mathrm{~g}$ ), der phalangioides sehr nahe kommt, haben, und die Zahl der Tasterborsten des 4. Gliedes ist bei No. I2 größer als bei No. 8 und 9. 
Das einzige Merlimal, das ein Unterscheiden von zwei Formen erlaubt, ist somit die Beschaffenheit der Körperhaare. Wenn wir dieses Merkmal anwenden, finden wir, wie oben gesagt, daß in Norwegen zwei ausgeprägte Formen existieren, die eine mit Haaren von dem in Textfig. I I $\mathrm{a}$, b, e, f dargestellten Typus (phalangioides), die andere mit Haaren von dem in Textfig. I $18 \mathrm{c}, \mathrm{d}$, k abgebildeten (regalis), und daß die grönländische Form (Textfig. II $8 \mathrm{~g}$ ), mit welcher die lappländische (Textfig. II $8 \mathrm{~h}$ ) am meisten übereinstimmt, im Bau der Haare insofern eine gewissermaßen vermittelnde Stellung einnimmt, als diese ziemlich reich gefiedert,

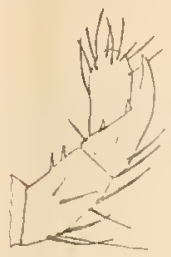

Fig. II

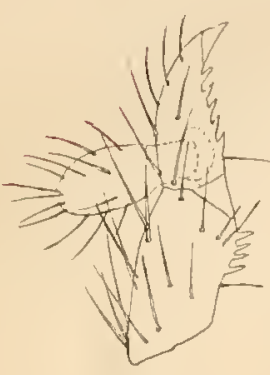

Fig. 120.

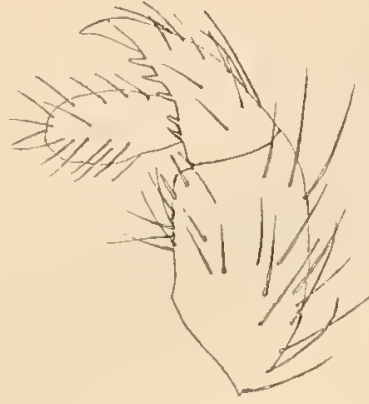

Fig. I2I.

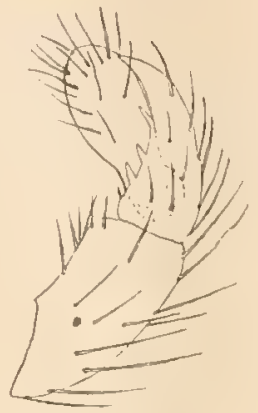

Fig. I22.

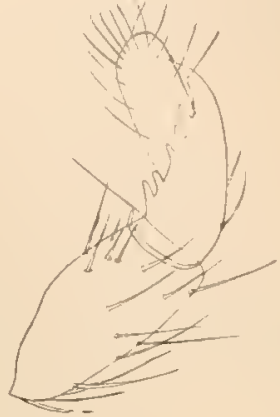

Fig. 123.

Fig. II9. Endglieder des Tasters von einer Nymphe von R. phalanyioides (No. 2).

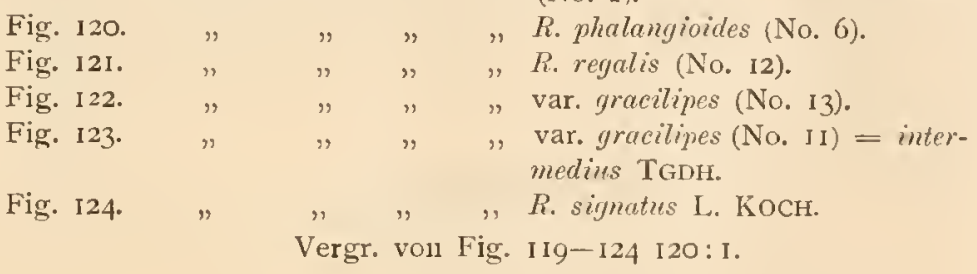

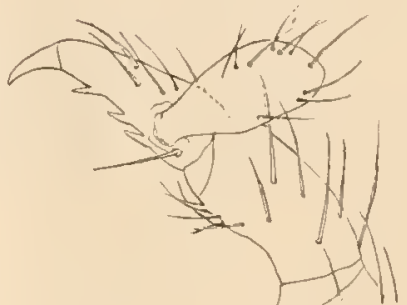

Fig. 124 .

wie bei phalangioides, gleichzeitig aber länger und allseitig rund sind, wie bei regalis. Die Uebereinstimmung mit dem phalangioides-Typus erscheint mir aber am größten und ich führe daher die grönländische und lappländische Form als eine Varietät von E. phalangioides auf. Weitere Untersuchungen müssen angestellt werden, um die Frage zu lösen, ob E. regalis und E. phalangioides 2 "scharf getrennte Arten sind, und es somit nur auf einer eventuellen Reduktion der Tasterborsten und der Beine bei ihren nördlichen Formen beruht, daß sich die Grenze zwischen ihnen verwischt, oder ob es auch in anderen Gebieten Uebergänge giebt und sie also nur Varietäten von derselben Art sind. Es ist hervorzuheben, daß bei der grönländischen Form (Textfig. I22) die Degeneration der Taster am weitesten vorgeschritten ist, indem am dritten Glied nur Haarborsten vorhanden sind. Bei der lappländischen Form (Textfig. 123) sind noch ein Paar kräftiger Borsten vorhanden.

Fundort: Grönland: Asakak am Umanakfjord (Kraıer), Kvanfjord (W. Lundbeck), Orpiksuit (W. Lundbeck), Kekkertarsuksuk, Ipiutat (W. Lundbeck), Egedesminde (Levinsen), Jacobshavn (Dr. Pfaff).

W eitere Verbreitung: Lappland.

65. Erythrous regalis (C. L. KOCH)

1879 Rhyncholophus signatus, L. KocH, Arachniden aus Sibirien und Novaja Semlja, K. Vet. Akad. Handl., Bd. XirI, 1). 124 , tab. 6 , fig. 2 .

?1879 Rhyncholophus imperialis (C. L. Kocн), L. Косн, ebenda, p. 125.

Rhyncholophus signatus L. KocH ist eine auf Nymphen vermutlich der mit dem Namen $R$. imperialis bezeichneten Acaride, die an demselben Orte, Krasnojarsk in Sibirien, gefunden wurde, gegründete Art. 
Die Körperhaare (Fig. IISi) stimmen vollständig mit denjenigen der Nymphe von $R$. regalis (Fig. II8d น. k) aus Norwegen überein, und ich führe daher $R$. signatus als Synonym zu $R$. regalis auf (vgl. auch die Taster Textfig. 12 und I24).

Fundort: Sibirien, Krasnojarsk (L. KосH).

Weitere Verbreitung: Ganz Europa.

\section{Erythraeus elongatus (BANKs)}

1899 Rhyncholophus elongatus, Banks, Reports upon the Insects, Spiders, Mites, and Myriapods collected by Dr. L. Stejneger and Mr. G. E. H. Barret-Hamilton on the Commander Islands. Extr. from the Fur Seals and Fur-Seal Islands of the North Pacific Ocean, Part IV, Arachnida, p. 348, fig. 3, pl. A.

Wie überhaupt die von Banks beschriebenen Acariden, ist auch diese Art so schlecht beschrieben, daß es unmöglich ist, über sie ins klare zu kommen. Zufolge der ungewöhnlichen Kürze der Beine kann es kaum eine Erythraeus-Art sein, sondern sie gehört wohl der Gattung Trombidium an. (Auch wenn es eine Trombidium-Art wäre, so würde sie sich durch die ungewöhnlich kurzen Beine auszeichnen.) Möglicherweise ist es eine nicht geschlechtsreife Form. Es dient absolut zu nichts, die Diagnose wiederzugeben, denn sie enthält meistens Merkmale, die entweder nichts besagen oder sowohl auf die Gattung Erythracus als Trombidium passen.

Ein einziges Merkmal möchte ich jedoch hervorheben, daß das letzte Glied des I. Beinpaares etwas verdickt und kürzer als das vorletzte Glied ist. Die Länge des Tieres beträgt I,8 mm.

Fundort: Bering-Insel (Banks).

\section{Familie Hydrachnidae.}

\section{Lebertia fabricii (THORELL)}

Textfig. I25, I26.

1780 Acarus aquaticus, Fabricius, l. c. p. 222.

1872 Hygrobates fabricii, THoneLL, l. c. p. 163.

1872 Trombidium(?) inc. spec. ThoreLL, l. c. p. 163.

1900 Lebertia vigintimaculata, Tнов, Nyt Mag. Naturv., Bd. XXXVIII, Fasc. 3, p. 272, tab. 10, fig. 1 -2.

1901 "fabricii (Thorelt), Trägånd, l. c. p. 62.

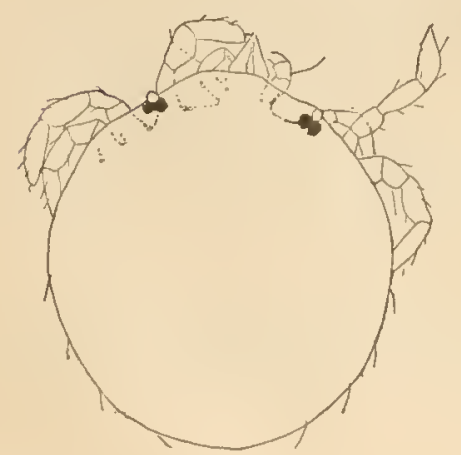

Fig. 125 .

Fig. 125. Lebertice fabrieii (THORELL).

Fig. 126.

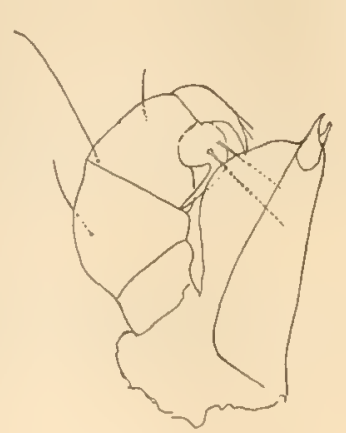

Fig. 126 .

Dorsalansicht der Larve. Vergr. IOO: I.

Mandibel und Taster derselben. Vergr. 4r3,3:1.

Das einzige vorhandene Typenexemplar THORELL's stimmt vollständig mit THOR's $L$. vigintimuculata überein. THORELL erwähnt in derselben Publikation eine Trumbidium-Larve, die auf Chironomus frigidus ZETT. schmarotzte, und von welcher er 6 Exemplare auf dem Thorax und dem Hals der Mücke fand. Diese Larven zeichneten sich unter anderem durch große, schwarze Augen aus. Daß diese Larven nicht der Gattung Trombilium angehören (und ebensowenig Erythraeus), geht schon aus diesem Merkmal hervor. Es wäre aber gewiß nicht leicht gewesen, sich über sie auszusprechen,

hätten sich nicht unter den Kopenhagener Sammlungen aus Grönland einige Mücken befunden, die am Halse und an der Unterseite des Thorax solche kleine Larven mit großen, schwarzen Augen tragen. Es 
paßt Thorell's Diagnose sehr gut auf sie, sie gehören aber nicht der Gattung Trombidium an, sondern sind Hydrachnidenlarven, und da THORELL's Larven an demselben Fundort wie seine Lebertia fabricii (bei Quanersoit) vorkommen, so stelle ich sie unbedenklich zu dieser Art. Die Art liegt außerdem in einem Exemplare aus Heklahavn vor.

Fundort: Grönland: Quanersoit, Island: Heklahavn (1892, Deıchmans).

Weitere Verbreitung: Norwegen (THor.).

\section{Familie Halacaridae.}

\section{Rhomboynathus notops (Gosse)}

1855 Pachygnathus notops, Gosse, Annals and Magazine of Nat. Hist., Ser. 2, Vol. XVI, p. 307, tab. 8, fig. 1 -4.

1897 Rhombognathus notops, P. Kramer, Bibliotheca Zoologica, Vol. XX, p. 83.

Fund ort: Westgrönland, Sermidlet-Fjord, $7 \mathrm{I}^{0} \mathrm{n}$. Br. (Kramer).

\section{Agaue hirsuta TRT.}

Textfig, I27 u. I28.

1889 Agaue hirsuta, Trougssart, Naturaliste, Vol. XI, p. 181.

Das einzig vorhandene Exemplar übertrifft weit die Exemplare aus dem Mittelmeer an Länge, indem es 1,08 $\mathrm{mm}$ mißt. Sonst stimmt es gut zu der Diągnose von $A$. hirsuta.

F un d ort: Grönland (ohne nähere Angabe).

Weitere Verbreitung: Mittelmeer (Frankreich).

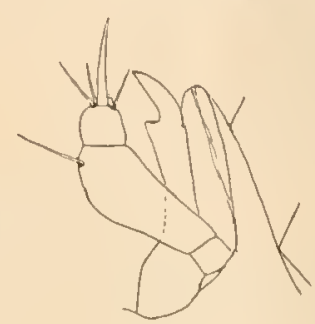

Fig. I27.

Fig. 127. Agaue hirsuta TRT. Mandibel und Taster. Vergr. 120:1.

Fig. 128. Agaue hirsute TRT. Das erste Bein. Vergr. I00: 1 .

\section{Halacurus borenlis TRT.}

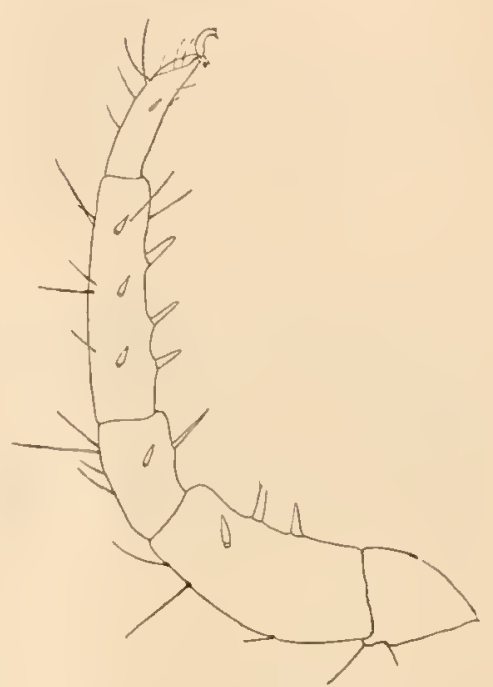

Fig. 128.

1894 Halacarus borealis, T'rovessart, Mém. Soc. Cherbourg, Vol. XXIX, p. 191, fig. 1.

Fundort: Atlantischer Ocean (Island).

\section{Halacarus (Copidognuthus) reticulatus TRT.}

1894 Halacarus reticulatus, Trouessart, Mém. Soc. Cherbourg, Vol. XXIX, p. 197, fig. 3a-c.

Fundort: Atlantischer Ocean (Island).

\section{Halacams (C.) poncheti TRT.}

1894 Halacarus poucheti, Trounssant, Mém. Soc. Cherbourg, Tol. XXIX, p. 193, fig. 2a-c.

Fundort: Atlantischer Ocean (Island, Labrador).

\section{Halacarus (C.) sp. LoHм.}

1893 Halacarus sp., Lohmans, Ergebnisse der Plankton-Expedition, Bd. II, G a $\beta$, p. 79, tab. 10, fig. 4-6.

Eine Larve, die $H$. fabricii nahe steht.

Fundort: Nordsee, Grönland, Sermidlet-Fjord, 7 I $^{0}$ n. Br. (P. Kramer).

Familie Ixodidae.

\section{Txorles mutus (CAMBRIDGE)}

?1852 Ixodes uriae, White, in: StTherland, Journ. Voyage in Baffins-Bay etc.

1879 Hyalomma puta, O. P. CAmbridge, An account of the collections nade in Kerguelen Land during the transit of Venus-Expedition, Arachnida, Philosophical Transactions, 1879, p. 222, tab. 13, fig. 4. 
Ixodes boreulis, Krraner u. Neumanx, 1. c. p. 518, tab. 42.

" putus (Cambr.), G. Neunanx, Révision de la famille des Ixodidés, Extr. Soc. Zoologique, T. XII, p. 125.

", borealis, K. u. N. Banks, Reports etc., p. 349.

Diese Art scheint losmopolitisch zu sein. Da ich Exemplare besitze, die auf Uria brünichi gefunden sind, dürfte sie mit White's 1. uriue identisch sein. NeuManN führt 1. putus und I. borealis als Synonyme auf.

Fundorte: Bering-Insel („Vega“-Expedition, Banks); Toporkoff-Insel; Grönland: auf Uria brïnichi, Ritenbenk, Juli I86I (OlRIK); Ikerasak, Umanak, I867 (OlRIK); auf Larus tridactylus und auf Larus gluucus, Sermiliarsuk (W. LundBEck).

Weitere Verbreitung: Miquelon, Britisch Columbia, Alaska, Cap Horn.

75. Ixodes fimbriatus KR. U. NeUm.

1883 Ixodes fimbriatus, Kramen u. Neumann, 1. c. p. 518, tab. 43.

Trotzdem Kramer und Neunann angeben, daß ein $\subsetneq$ q vorliegt, vermutet Banks jedoch, daß die Art nur das Männchen von Ixortes borealis ist.

Fundort: Ein $q$ auf der Bering-Insel („Vega"-Expedition).

\section{Familie Sarcoptidae.}

Da diese Familie neuerdings im Tierreich vorzüglich bearbeitet worden ist und sämtliche Arten mit Ausnahme von zweien daselbst beschrieben sind, halte ich es für unnötig, Bestimmungstabellen zu geben. Betreffs der Analginen sind alle Arten als arktische mit aufgenommen, die nach der Zusammenstellung im Tierreich auf arktischen Vögeln gefunden sind.

\section{Subfamilie Analginae.}

\section{Freyana anatina (C. L. $\mathrm{KoCH})$}

1844 Dermaleichus anatinus, C. L. Kocн, Deutschlands Crnstaceen, Myriapoden und Arachniden, Fasc. 38, fig. 23. Auf Mergus serrator und Anas acuta.

7\%. Hoveyan caput-medusue TRT,

1886 F. (Michaelichus) caput-medusae, Truuessalit, Bull. Soc. Angers, Vol. XVI, p. 100. Auf Sula bassanu.

\section{Pterolichus (Eupterolichus) charadrii (CAN.)}

1878 Dermaleichus charadrii, Canestrini, Atti Ist. Veneto, Ser. 5, Tol. V, p. 48.

Auf Charadrius hiaticula.

Fundort: Auf C. hiaticula, Taitip ata, Grönland, 27. Juni I890 (W. Lundbeck).

\section{Pterolichus (E.) totani (CAN.)}

1878 Dermaleichus totani, Canestrini, Atti Ist. Veneto, Ser. 5, Vol. V, p. 60.

Auf Totrmus totanus.

80. Pterolichus (E.) forficiger MÉGn. u. TRT.

1884 Pterolichus forficiger, Mégnix u. Truuensant, Joum. de Nicrographie, Vol. VIII, p. 380, fig. 48 a, b. A uf Urinator glacialis.

\section{Pterolichus (W.) mmmenii CAN.}

1878 Dermalcichus mumenii, Canestrini. Atti Ist. Veneto, Ser. 5, Vol. V, p. 61. Auf Numenius phoeopus. 
32. Pterolichus (E.) buchholzi (CAN.) var. fuscigero MÉGN. u. TRT.

1884 Pterol. Uuchholzi var. fascigeru, Megsix u. Trouessant, Journ. de Micrographie, Vol. VIII, p. 428.

Auf Arenarin interpres.

S3. Pterolichns (E.) colmmbi (CAN.) var major MÉGN. u. TRT.

1884 Pterol. columbi var. major. Mégnix u. Trovesmart, Journ. de Micrographie, Vol. ViII, p. 429.

Auf Urinator septentrionalis.

\section{Pterolichns (Psendalloptes) bimucronatus TRT.}

1884 Pterolichus bimucronatus, Trouessari, Journ. de Micrographie, Vol. VIII, p. 53‥

Auf Lagopus-Arten.

Fundort: Auf Lagopus alpinus, Taitip ata, Grönland, 27. Juni 189o (W. Lundbeck).

\section{S5. Thecarthra thech (MEGN. U. TRT.)}

1884 Pterolichus theca, MEgnin u. Trouessart, Journ. de Micrographie, Vol. Vill, p. 434.

Auf Stercorarius parasiticus.

\section{Pteronyssus puffini (Веснн.)}

1869 Dermaleichus puffini, Bocнноцz, Bemerkungen über die Arten der Gattung Dermaleichus Kócн, Dresden, p. 37, tab. 4, fig. $23,24$.

Fundorte: Auf Sterme macrura, 30. Juni I\$90, Manermiut, und auf Xema sabini, Kristianshabn, Grönland (W. LundBECK).

\section{Analyes longispinosus TYRR.}

1882 Anulges longispinosus, 'Trreei, Ottava Club Transactions, Vol. III, p. 45, tab. 1, fig. 1, 2.

Fund ort: Auf Plectrophanes nivalis, Grönland (W. Lundbeck).

\section{Alloptes phacthontis (GM.)}

1788 Acarus phaethontis, Greuin, Systema naturae, Ed. XIII, Vol. V, p. 2930, No. 53.

Auf Fratercula arctica.

\section{Alloptes crossipes ( $\mathrm{CAN}$.)}

1878 Dermaleichus crassipies Canestrini, Atti Ist. Veneto, Ser. 5, Vol. V, p. 68. Auf Tringa alpina.

\section{Alloptes crassipes (CAN.) var. commla TRT.;}

1885 Alloptes crussipes conurus Trovessart, Bull. Soc. Angers, Vol. XIV, p. 68. A uf Tringa alpina.

\section{Alloptes crassipes (CAN.) var. mimor TRT.}

1885 Alloptes bisetretus minor, Trouessakt, Bull. Soc. Angers, Vol. XIV, p. Gis. Auf Alce torda, Uria grylle und Fratercula aretica.

Fundort: Auf Uria grylle, Grönland.

\subsection{Alloptes bisetutus (HALLER)}

1881 Pterocolus hisetatus, Haller, Zeitschr. wiss. Zoologie, Bd. XXXYI, p. 377, tab. 25, fig. 1, 2. Auf Sterna hirme, Stercorarins parasiticus, Tringa alpina.

Fundort: Auf Tringa maritima, Grönland (W. Lundbeck). 


\section{Subfamilie Tyroglyphinae.}

\section{Tyroglyphus lundbecli ${ }^{1}$ ) nov. spec.}

\section{Textfig. I 29 u. I3O.}

Diese Art, von der nur Hypopi vorhanden sind, steht der neuerdings von Oudemans beschriebenen T. fucorum ${ }^{2}$ ) am nächsten, unterscheidet sich aber deutlich durch die fein punktierte Chitindecke und die Abwesenheit von blattähnlichen Haaren auf den Beinen.

Hy popus. Die Länge beträgt ungefähr $0,25 \mathrm{~mm}$.

Die Farbe ist braun.

Die Chitindecke ist sehr fein punktiert. Die Form ist oval, die größte Breite ist unmittelbar hinter der Grenze zwischen Abdomen und Cephalothorax. Cephalothorax triangulär, ziemlich schmal,

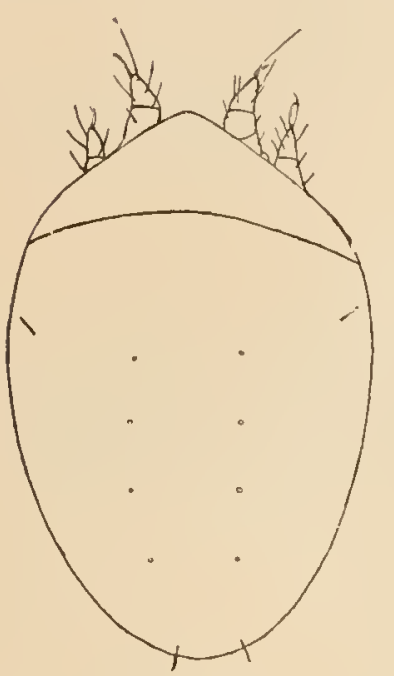

Fig. I 29.

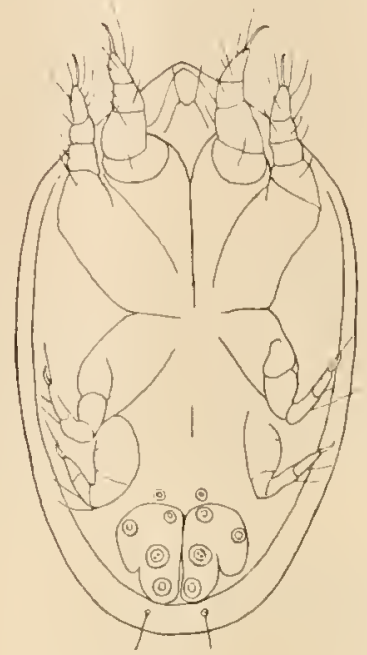

Fig. 130.
Fig. 129. Tyroglyplus lumblechi TRÄGiRDH nov. sp. Dorsalansicht. Vergr. 232,5: I.

Fig. 130. Tryoulyphus lundbecki TRÄG.iRDH nov. sp. Ventralansicht. Vergr. 232,5:1.

etwas mehr als $1 / 6$ von der Totallänge. Die Grenzlinie zwischen Abdomen und Cephalothorax ist nach vorn konvex. Keine Haare vorhanden. Auf dem Abdomen habe ich 2 Reihen von je 4 sehr kleinen Haaren, 2 Schulterhaare und am Hinterrande 2 etwas größere Haare gefunden. Auf der ventralen Seite sind zufolge der schwachen Chitinisierung der Epimeren keine so ausgeprägten Schilder vorhanden wie bei $T$. fucorum. Nur die Epimeren der 4 Vorderbeine treten genügend hervor, um ihre Grenze deutlich sichtbar zu machen.

Die Saugscheibenplatte ist dagegen stärker chitinisiert und tritt deutlich hervor. Vor der Platte sind ganz wie bei $T$. fucorum 2 Saugscheiben vorhanden. Die Platte selbst trägt 4 Paar Saugscheiben, deren Placierung Textfig. I30 zeigt. Zwei von ihnen, die mittleren in der medialen Reihe, scheinen in tiefe Höhlen überzugehen, die gegen die Rückenfläche emporsteigen, und ihre ventrale Mündung besteht aus je 2 kleineren Löchern.

Das Fühlerorgan oder Mentum ist mit 2 Borsten versehen, die kaum über den Vorderrand des Cephalothorax hervorragen. Auf dem Rostrum sind keine Haare vorhanden.

Die Beine der vorłeren und der hinteren Paare ähneln einander, soweit ich habe finden können ${ }^{3}$ ).

Das I. Paar träg̨ auf dem letzten Glied lange Fühlerhaare.

Fundort: Auf Bombus sp. zusammen mit einer Purusitus-Art Holstenburg, Westgrönland.

\section{Tyroglyphus siro (L.)}

? 1780 Acrus siro var. farinue, Fabricios, Fauna groenlandica.

Wie ich in der geschichtiichen Einleitung hervorhob, kann die von FABricıus in Mehl gefundene A. siro var. farinue ebensogut $T$. siro wie Aleurolins farime (DE GEER) sein, denn beide kommen gleich oft sowohl in Mehl als in Käse vor. Da keine Diagnose gegeben wird, ist es einfach unmöglich zu entscheiden, welche

I) Es ist mir eine angenehme PHicht, diese Art nach dem Herrn Dr. W. LuNDBECK in $K$ openhagen zu benennen, welchem die Ehre gebührt, sehr reiche Sammlungen von grönändischen Acariden zusammengebracht zu haben.

2) Notes on Acari, 6. Serie, Tijdschr. v. Entomologie, Bd. XLVX, p. 18, tab. 3, fig. 38-40.

3) Die hinteren sind ungemein schwer deutlich zu sehen. 
von den beiden Arten Fabricius gemeint hat. Da aber T. siro seitdem auf Grönland gefunden ist, führe ich die Fabricius'sche Art als Synonym unter dieser auf.

Fundorte: Grönland (Fabricius), 2. September I890, Ritenbenk auf Käse: „Zwei Jahre alt im Lande" (IV. LUNDBECK).

Weitere Verbreitung: Kosmopolitisch.

95. Histiostoma digitifer' nov. spec.

Textfig. I3I, I32, I33.

Diese Art wurde in einer großen Menge von Exemplaren auf einer Fliege gefunden. Nur Hypopi sind vorhanden. Diese zeigen eine beträchtliche Uebereinstimmung mit dem Hypopus der von BERLESE ${ }^{1}$ ) beschriebenen und abgebildeten Histiostoma (= Anoctus) muscarum (L.) und die unbedeutenden Verschiedenheiten, die zwischen beiden existieren, hätten mich möglicherweise sonst nicht veranlaßst, die grönländische Form als eine besondere Art zu rechnen, wenn nicht, wie Oudenans $\left.{ }^{2}\right)$ hervorhebt, die Hypopi von Anoetus nach den bisherigen schlechten Besclireibungen und Abbildungen kaum zu unterscheiden wären, was wohl darauf beruht, daß sie sich oft nur durch sehr unbedeutende und leicht zu übersehende Merkmale voneinander unterscheiden.

Unter solchen Umständen thut man gewiß am besten, wenn man unbedeutende Verschiedenheiten nicht unberücksichtigt läßt, sondern die betreffenden Formen so genau wie möglich beschreibt und abbildet. Aus diesen Gründen führe ich die grönländische Form als eine

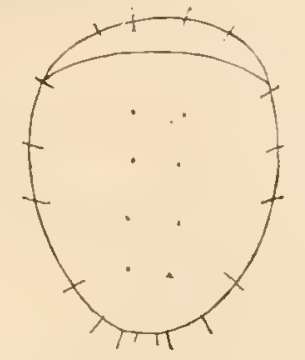

Fig. 131 .

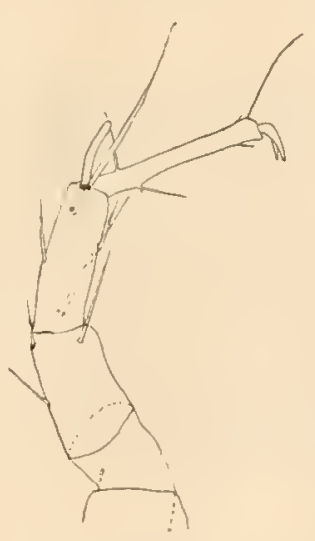

Fig. 133.

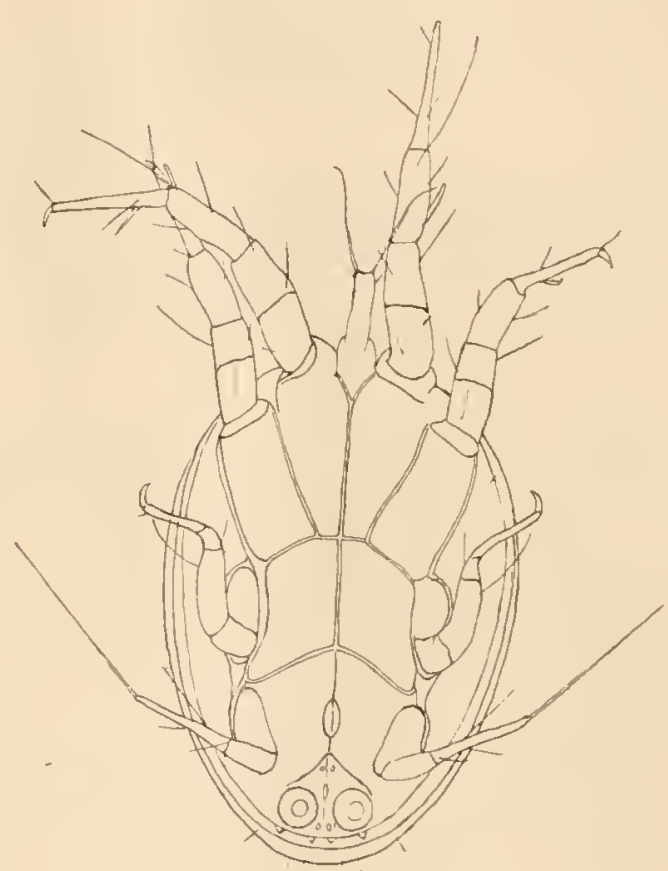

Fig. 132.

Fig. 131. Histiostoma digitifera TRAGARDH nov. spec. Dorsalansicht. Vergr. 150:1. Fig. 132. " " " " " " Ventralansicht. Vergr. 248: 1. Fig. 133. " " " $\quad " \quad$ " $\quad$ Das Bein. Vergr. 496:1. besondere Art auf.

Die Länge beträgt (exkl. Mentum) ungefähr $0,20 \mathrm{~mm}$. Die Chitindecke ohne besondere Skulptur. Die Form ist eiförmig. Cephalothorax sehr schmal, erreicht kaum $1 / 6$ der gesamten Körperlänge. Nahe am Vorderrand des Cephalothorax sitzen 4 lileine Haare. Auf der Rückseite des Abdonens sind nahe am Seiten- und Hinterrand im ganzen 7 Paar kleiner Haare vorhanden. Ich glaube auch in der IIitte des Rückens eine Reilıe von 3-4 Paar sehr kleiner Haare beobachtet zu haben. Das Mentum ist an der Spitze ein wenig ausgeschnitten und mit 2 Borsten versehen, die das Mentum ein wenig (kaum 1/5) an Länge

1) Acari Myriopodi etc. Ordo cryptostigmata.

2) Siehe Fußnote 2, p. 66. 
übertreffen und an der Spitze nach außen gebogen sind. Etwas mehr proximalwärts sitzen 2 sehr kleine Borsten.

Die Epimeren sind stärker chitinisiert als bei A. muscarum. Keine Saugscheiben an den Epimeren vorhanden. Die Beine sind im allgemeinen nach dem Typus von A. muscarum (L.) BerL. gebaut. Im einzelnen existieren jedoch mehrere Unterschiede.

Während bei $A$. muscarum die Tarsen der 2 ersten Beinpaare die Tibien um die Hälfte an Länge übertreffen, sind sie bei $H$. digitifera nur wenig länger als die Tibien. An den distalen Enden der Tibien des I. Beinpaares ist eine Fühlborste vorhanden, welche die Länge der Tarsen fast erreicht. Weiterhin sind sie mit einem Paar fingerähnlicher Borsten versehen, die wenigstens an BERLEsE's Figur ${ }^{1}$ ) nicht zu sehen sind.

Weitere Merkmale bietet das 4. Beinpaar, dessen in lange Borsten umgewandelte Tarsen gegen $2 / 5$ der gesamten Körperlänge erreichen, während sie bei $A$. muscarum $2 / 3$ dieser Länge erreichen. Auf der Saugscheibenplatte, die nach vorn in ein Dreieck ausläuft, sind drei P a a ${ }^{2}$ ) Saugscheiben vorhanden, von denen das mittlere die übrigen weit an Größe übertrifft.

Fundort: Auf einer Fliege I6. Juli rgoo, Orpiksuit, Westgrönland (W. LundBEck).

\section{Glyciphayus domesticus (DE GEER)}

1897 Glyciphagus domesticus (De Geer), Michael, l. c. p. 357.

Fundorte: Cap Flora, Northbrook-lnsel, Franz Joseph-Archipel.

Weitere Verbreitung: Kosmopolitisch.

\section{Ueber die Variation der arktischen Oribatiden.}

In den Fällen, wo es gelungen ist, bei den arktischen Insekten eine bestimmte Variation zu konstatieren, besteht diese in Melanismen (Lepidoptera und Coleoptera) oder in stärkerer Haarbekleidung (Bombus). Man hat auch durch Experimente festgestellt, daß durch Einwirkung von Kälte und Feuchtigkeit auf Schmetterlingspuppen melanistische Varietäten hervorgebracht werden.

Man hat auch gefunden, daß von den Hymenopteren es vorzugsweise kleine Formen (exkl. Bombus) sind, die in das arktische Gebiet vordringen.

Ueber die anderen Insektengruppen liegen, soweit ich weiß, keine Beobachtungen über Variation in den arktischen Gebieten vor. Meiner Meinung nach wird man aber ohne Zweifcl durch sorgfältige Untersuchungen auch bei diesen Gruppen Variationen in gewissen Richtungen konstatieren können.

Es erscheint dagegen weniger wahrscheinlich, daß so niedrige Formen, wie die Oribatiden, eine ausgeprägte Variation, die man auf die specifisch arktischen Verhältnisse zurückführen könnte, zeigen werden. Die Oribatiden sind freilich herbivor und somit von einer gewissen Vegetation abhängig, sie sind aber keine Feinschmecker, sondern ernähren sich von verwelktem Laub, Flechten, Moos, Algen und allerlei vegetabilischen Detritus, und man hat noch nie konstatiert, daß eine bestimmte Art an ein besonderes Gewächs gebunden wäre. Sie sind dagegen gegen Schwankungen in der Feuchtigkeit der Luft und gegen hohe Temperatur sehr empfindlich. Infolgedessen sind sie in trockenen und warmen Gebieten, wie z. B. im Sudan, äußerst spärlich vertreten. Diese Bedingungen, eine gewisse Feuchtigkeit der Luft und

1) Solche Borsten sind allerdings an anderen Acams-Arten. wie A. spiniferus Mich. und A. neglectus Oudemans, vorhanden und sind somit möglicherweise Genuscharaklere.

2) Ich habe mich nicht mit absoluter Sicherheit von der Saugscheibennatur des hintersten Paares überzeugen kïnnen, denn es erscheint nur als ein Paar einfacher Löcher. 
nicht zu hohe Temperatur, sind aber sowohl in arktischen wie paläarktischen Gebieten erfüllt, und man könnte von diesem Gesichtspunkte aus keine bestimmte Variation bei den arktischen Formen erwarten. Ich hätte auch nie an die Möglichkeit gedacht, eine solche dartun zu können, wenn ich nicht ein so typisches Beispiel von leiner ausgeprägten Variation gefunden hätte, wie Notasyis bipilis und ihre arktische Varietät sphaerica. Diese Varietät unterscheidet sich von der Hauptform einerseits durch ihre Größenzunahme, andererseits durch Reduktion der Cephalothorakallamellenspitzen und der Lamellenborsten.

Dieser äußerst typische Fall veranlaßte mich, zu untersuchen, ob nicht möglicherweise auch andere arktische Formen in derselben Richtung variierten, und ich stellte eine Tabelle über die Längenverhältnisse zusammen.

\begin{tabular}{|c|c|c|c|c|c|}
\hline & Europa & $\begin{array}{l}\text { Arktisches } \\
\text { Lappland }\end{array}$ & Artitis & $\begin{array}{c}+ \text { oder - } \\
\text { Proz. }\end{array}$ & \\
\hline Oribata setosa & 0,54 & - & 0,60 & $+11,1$ & Oribata notata \\
\hline " cuspidata & 0,35 & $0,4^{2}$ & 0,39 & $+11,4-20$ & " cuspidata var. birulai \\
\hline$" \quad$ lucens & - & $0,5^{8}$ & $0,63-0,65$ & +12 & " lucens \\
\hline Notaspis lipilis & 0,65 & 0,80 & $0,75-0,80$ & +23 & Notaspis lipilis var. spliaerica \\
\hline "exilis & 0,37 & $0,4^{6}$ & - & $+24,3$ & " exilis var. crassipes \\
\hline$" \quad$ conferiae & $0,47-0,52$ & - & 0,64 & $+23,0$ & $" \quad$ confervae \\
\hline Liacarus globifer & 0.64 & - . & 0,45 & $-29,6$ & Liccarus glotsifer \\
\hline Seutorertex lineatus & 0,68 & - & 0,68 & \pm 0 & Scutocertex lineatus \\
\hline$" \quad, \quad \quad$ & 0,68 & - & 0,76 & $\overline{+} 11,7$ & $" \quad$ " var. nigrofemonata \\
\hline ", maculatus & 0,54 & - & 0,46 & $-I_{4}, 8$ & " marulatus var. yroenlandica \\
\hline Hermannia retieulata. & 0,85 & - & 0.85 & \pm 0 & Hermannia reticulata \\
\hline$"$ seabra & $\mathbf{0}, 87$ & - & 0,87 & \pm 0 & " seabra \\
\hline Nothrus horridus & 0,80 & $0,85-0,90$ & 0,95 & $+18,7$ & Nothrus horridus var. borealis \\
\hline
\end{tabular}

Aus dieser geht folgende interessante Tatsache hervor: daß von I3 arktischen Formen, die mit ihren zu derselben Art gehörenden paläarktischen Formen verglichen werden können, 8 (also mehr als die Hälfte) eine Vergrößerung aufweisen, nämlich 0 . notuta, 0 . cuspidate var. birulai, O. lucens, N. bipilis var. spherica, $N$. exilis var. crassipes, $N$. confervae, Scutovertex linentus var. nigrofemoratu und N. lorridus var. borcalis. 3, Scutovertex lineatus, Hermumia reticulatı und $H$. scubra, sind von derselben Länge in arktischen wie in paläarktischen Gebieten, und 2, Liacarus globifer und Scutovertex maculntus var. groenlandicu, sind in den arktischen Gebieten kleiner als ihre resp. paläarktischen Formen. In dem Falle, wo die arktischen Formen größer sind, untersteigt die Längenzunahme nicht I I Proz. der Körperlänge (der resp. paläarktischen Formen).

Eine solche Größenzunahme von 61,5 Proz. der untersuchten Formen kann offenbar nicht auf einem Zufall beruhen, sondern muß das Resultat von einem oder mehreren in derselben Richtung wirkenden Faktoren sein. Meiner Meinung nach bängt sie mit dem Umstand zusammen, daß die Oribatiden gerade in den arktischen Gebieten zufolge des großen Moos- und Flechtenreichtums, der Feuchtigkeit und der Abwesenheit einer Menge von Feinden, wie Pseudoscorpionen, Ameisen und Käfern, die das arktische Klima nicht vertragen können, außerordentlich günstige Lebensbedingungen haben.

In diesem Zusammenhang muß erwähnt werden, daß ich schon in meinem Aufsatz über die litoralen Arten der Gattung Bdella darauf hinwies, daß die Größenzunahme dieser Arten den nicht-litoralen gegenüber wohl auf die günstigeren Lebensverhältnisse zurückzuführen war ${ }^{1}$. Aber diejenigen Arten, die keine Größenzunahme aufzuweisen haben? Spricht nicht das Vorhandensein von solchen vegen meine Hypothese? Nein, durchaus nicht; es bestätigt vielmehr die Hypothese, denr diese Arten sind sämtlich

1) Bdella vulgaris var. littoralis MovıEz, die an den Küsten von Frankreich vorkommt, weist im Verhäjtnis mit der nicht. litoralen Hauptform rach Moniez auch eıne Größenzunahme auf. R. MoNiez, Acariens et Insects marins des côtes du Boulonnais. Revue biologique du Nord de la France, 1889,90, Fasc. 2, p. 198. 
Küstenbewohner, die in Algen, in Brackwasser u. a. am Ufer leben, und sie dürften sich demnach in den arktischen Gebieten nicht unter günstigeren Lebensbedingungen als an den Küsten von England, Schweden und Finnland befinden. Vielnehr sind wohl die Existenzbedingungen ungefähr gleich an den Küsten ${ }^{1}$, wenigstens in Bezug auf die Abwesenheit einer Menge von Feinden oder möglicherweise in den arktischen Gebjeten ungünstiger. 2 Formen, die Küstenbewohner sind, haben ja auch eine Größenabnahme erlitten.

Wenden wir uns darauf zı dem anderen Charakter, durch den Notaspis bipilis var. sphaerica sich von der Hauptform unterschejdet, nämlich die Verkürzung der Cephalothorakallamellenspitzen, Lamellar- und Interlamellarborsten, so stellt es sich bei näherer Untersuchung heraus, daß auch dieser Fall nicht einzig und allein dasteht. Denn Uribata notata (welche $O$. setosa so nahe steht, daß MichaEL sie für Synonyme hält) unterscheidet sich von $O$. setosı durch Verkürzung der Lamellenspitzen; ebenso unterscheidet sich O. cuspidata var. birului von der Hauptform durch kürzere Lamellen und Tectopediaborsten. Möglicherweise gehört hierher auch Notnspis exulis var. crassipes, deren Cephalothorakallamellen ohne Spitzen sind, während die Hauptformen Spitzen haben.

In keinem von diesen Fällen ist die Variation so ausgeprägt wie bei N. bipilis var. sphaerica, und man wird vielleicht einwenden, daß die vorhandenen Fälle gar nicht genügen, um den Satz aufzustellen, daß die arktischen Oribatiden sich von den paläarktischen durch Reduktion der defensorischen Organe auszeichnen. Aber es muß betont werden, daß diese Fälle zugleich die einzigen sind, in welchen eine solche Variation hätte stattfinden oder jedenfalls konstatiert werden können, denn die übrigen arktischen Arten gehören entweder Gattungen wie Nothrus, Hermunia u. a. an, welche dergleichen defensorischer Organe entbehren, oder sind nicht in Europa durch so äußerst nahe verwandte Formen repräsentiert, daß man einen Vergleich hätte anstellen kömnen. Außerdem gewinnen diese Fälle sehr an Bedeutung dadurch, daß bei den Trombidiiden, wie $\mathrm{jch} \mathrm{jm}$ folgenden zeigen werde, ganz analoge Erscheinungen auftreten.

Die Reduktion der defensiven Organe, die jch bei den erwähnten Oribatiden lionstatiert habe, ist wohl eine Folge desselben Verhältnisses, das zum Teil die zunehmende Größe so vieler arktischer Arten beeinflußt hat, nämlich die durch die Abwesenheit von Feinden ${ }^{2}$ ) in den arktischen Gebieten ungemein vereinfachten Existenzbedingungen der Acariden. Die Oribatiden, welche gar keine Organe offensiver Natur besitzen. sind im Gegenteil reichlich mit defensiven Organen ausgerüstet. Zu diesen gehören vor allem die Flügelanhänge des Abdomens (bei der Gattung Oribata), die sog. Tectopedia, und Cephalothorakallamellen mit ihren Spitzen und Borsten. Betreffs der Lamellenspitzen ist bei Oribata setosa in England von Michael und bei Notuspis exilis in Holland von Oudemans eine Variation konstatiert worden.

In den arktischen Gebieten, wo auf der Basis dieser Variation keine Auswahl der besser geschützten, d. h. mit spitzeren Lamellen und anderem versehenen Individuen von seiten der Pseudoscorpione und anderen Feinden lat stattfinden können, hat sie in Varietäten mit stumpferen und kürzeren Lamellenspitzen und Borsten resultiert.

Unter denselben Gesichtspunkt wie diese Reduktion fällt vermutlich die Thatsache, daß Hermanmin scalra und Nothrus horridus, welche in Fngland und Schweden immer mit Schmutz, Algen u. dgl. völlig bedeckt sind, in den arktischen Gebiete dieses Schutzes enthehren ${ }^{2}$ ).

1) Die htoralen Bdella-Arten weisen keine Großenzunahme gegen den Norden hin auf.

2) Es ist natürlich schwer testzustellen, welche Feinde die Oribatiden haben. MrchaEL giebt Chelifer an. Das allgemeint Vorkommen von Pseudoscorpionen unter Flechten auf den äußeren Schären, wo kaum anderes Freßbares als Oribatiden und andere Acariden vorkommen, spricht für die Richtigkeit seiner Angabe.

3) Zufolge der kurzen Beine dieser Arten ist es wohl nicht anzunehmen, daß sie sich selbst mit diesem Schutz versehen, sondern es hängt mit ihrer ungemein langsamen Bewegungsweise zusammen (und Ausscheidung eines Sekretes?). Von anderen langheinigen Formen, wie Damaeus-Nymphen, ist es aber beliannt, daß sie absichtlich fremde Parlilielchen und abgestreifte Nymphenhäute sich auf den Rücken festkleben. Der von mir in "Lappländische Trombidiiden etc." beschriebene $D$. farinosus unterscheidet sich von der selır ralıe stehenden südlicheren Art D. rerticilippes durch die Abwesenheit dieses Schutzes. 
Schlleßlich ist in diesem Zusammenhang hervorzuheben, daß 2 Arten, Scutovertex linertus und S. maculatus, in den arktischen Gebieten in Varietäten auftreten, die sich durch Reduktion der Skulptur des Abdomens und Cephalothorax auszeichnen.

\section{Ueber die Variation der arktischen Trombidiidae.}

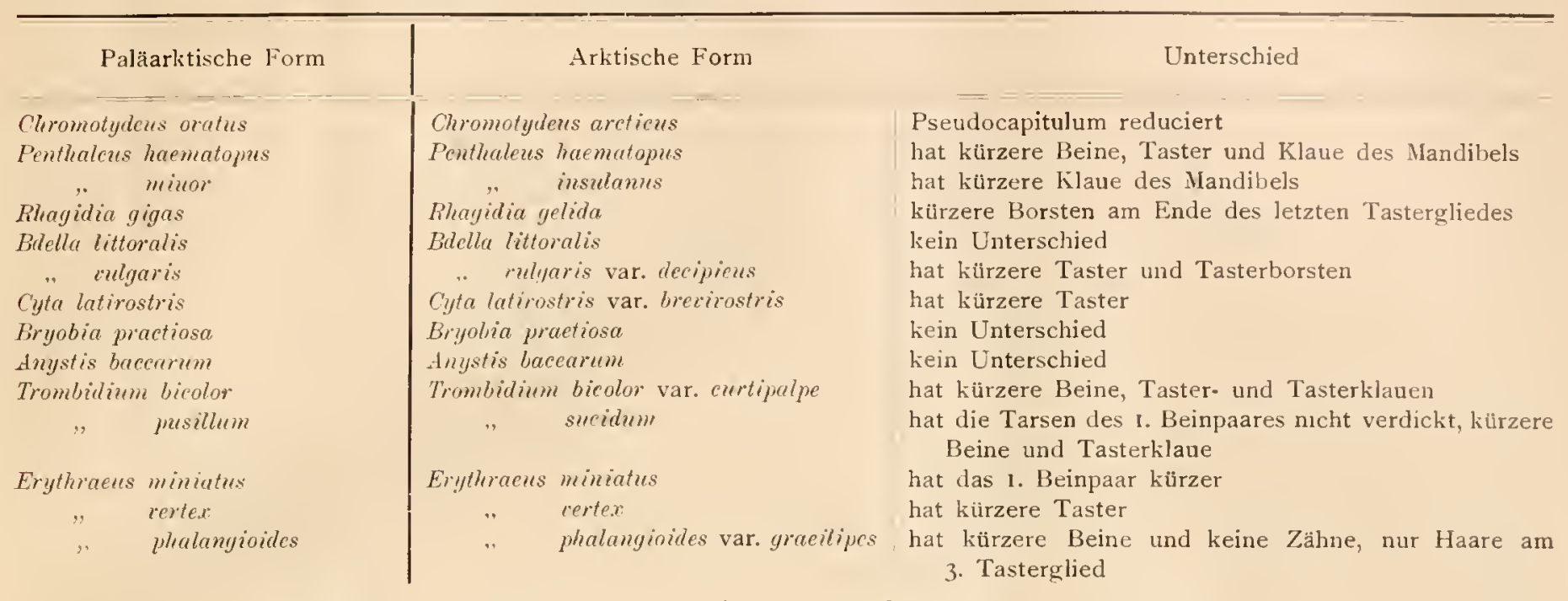

Die bei den Oribatiden konstatierte Variation veranlaßte mich, zu untersuchen, ob es nicht gelingen würde, auch bei den Trombididen eine gewisse Variation zu konstatieren. Leider habe ich bei dieser Untersuchung oft nicht Material von den zu vergleichenden paläarktischen Formen gehabt, sondern mußte nach BERLESE's Abbildungen urteilen. In Bezugauf die Längenverhältnisse der Taster- und Beinglieder dürften diese aber zuver]ässig sein, wenn auch einzehne Abbildungen betreffs der Details etwas zu wünschen übrig lassen.

In der obigen Tabelle ist das Resultat dieser Untersuchung kurz zusammengefaßt. Nähere Angaben findet man unter den resp. Arten in der systematischen Abteilung.

Aus der Tabelle geht hervor, daß von I3 arktischen Formen, die mit paläarktischen entweder identischen oder als Hauptformen zu bezeichnenden Arten verglichen werden könnten, II sich durch Verkürzung von Beinen, Tastern und Mandibeln oder Tasterborsten und Mandibelklauen von ren resp. paläarktischen Formen unterscheiden.

Von den 3 Arten, bei denen kein Unterschied zwischen den arktischen und paläarktischen Formen konstatiert werden könnte, ist eine, Bdella littoralis, eine litorale Form, was an Bedeutung gewinnt, wenn wir diese Thatsache mit dem bei den Oribatiden gemachten Befunde zusammenstellen, daß die litoralen Formen keine bestimmte Variation aufweisen. Die 2 übrigen sind sehr weit verbreitete Formen, die eine, Actintda vitis, dürfte kosmopolitisch sein, und da solche Arten ihre weite Verbreitung ihrer großen Anpassungsfähigkeit an die verschiedensten Verhältnisse verdanken, ist bekanntlich ihre Variation sehr gering.

Der oben bei den Trombidiiden konstatierten Variation schreibe ich zum Teil dieselben Ursachen zu, die die Reduktion der defensiven Organe bei den Oribatiden bewirkt haben, d. h. die in den arktischen Gegenden so ungemein vereinfachten Lebensverhälnisse, die an die Trombidiiden nicht so große Forderungen an Schnelligkeit und Schärfe und Größe der offensiven Waffen stellen. Es ist für diese Hypothese von Wichtigheit, daß nach TrouessarT die antarktische Form von Rhagidir gigus sich auch durch Verkürzung des I. Beinpaares auszeichnet.

\section{Bemerkungen ïber die geographische Verbreitung der arktischen Acariden.}

Es ist eine wenig dankbare Aufgabe, auf unserem jetzigen Standpunkt der Kenntnis der arktischen Acariden sichere Schlüsse über ihre Verbreitung zu ziehen, und man muß mit großer Vorsichtigkeit die 
Fakta handhaben. Denn wenn auch auf einer verhältnismäßig großen Anzahl von Lokahiäten Acariden in dem arktischen Gebiete gesammelt worden sind, so muß doch betont werden. daß diese Einsammlungen fast nie von einem speciellen Acaridologen gemacht sind. Zufolgedessen kann man sich nicht auf die Vollständiglieit der gemachten Sammlungen verlassen, die nicht mit Hilfe der Methode ${ }^{1}$, , Moos, Flechten u. dgl. zu sieben, vorgenommen sind, der einzigen Methode, die sichere Resultate leisten kann, da die Tiere zufolge ihrer Kleinheit und ihrer verborgenen Lebensweise sich der Aufmerksamkeit völlig entziehen.

Schließlich ist auch hervorzuheben, daß wir der einzigen festen Basis für tiergeographische Spekulationen, einer genauen Kenntnis der großen subarktischen und borealen Gebiete wie Skandinavien, Rußland, Sibirien und Noramerika, entbehren. Trotzdem glaube ich jedoch, aus folgender Zusammenstellung der Fundorte der arktischen Acariden einige kleine Resultate und Gesichtspunkte gewonnen zu haben, die verdienen hier besprochen zu werden, wenigstens um zu weiteren Forschungen anzuregen.

Der Gesamtzahl der bis jezt aus den arktischen Gegenden bekannten Acariden ist nach der hier mitgeteilten Revision 96 Arten $\left.{ }^{2}\right)$. Diese verteilen sich auf die verschiedenen Familien in folgender Weise: Oribatidne 24, Purasitidae I8, Trombidiudae 24, Hydrachnidae I, Halacuridae 6, Ixodidae $2{ }^{2}$ ), Sarcoptidae 2 I Arten. Von diesen Zahlen dürften diejenigen der Oribatidae, Parasitidae, Trombidiidae, Ixodidae und Hydrachnidae eine an. nähernd gute Vorstellung von der wahren Zahl der arktischen zu diesen Familien gehörenden Arten geben Dagegen ist die Anzahl der arktischen Halacariden und Sarcoptiden gewiß in Wirklichkeit viel größer.

Tabelle über die Verbreitung der arktischen Oribatiden-Arten.

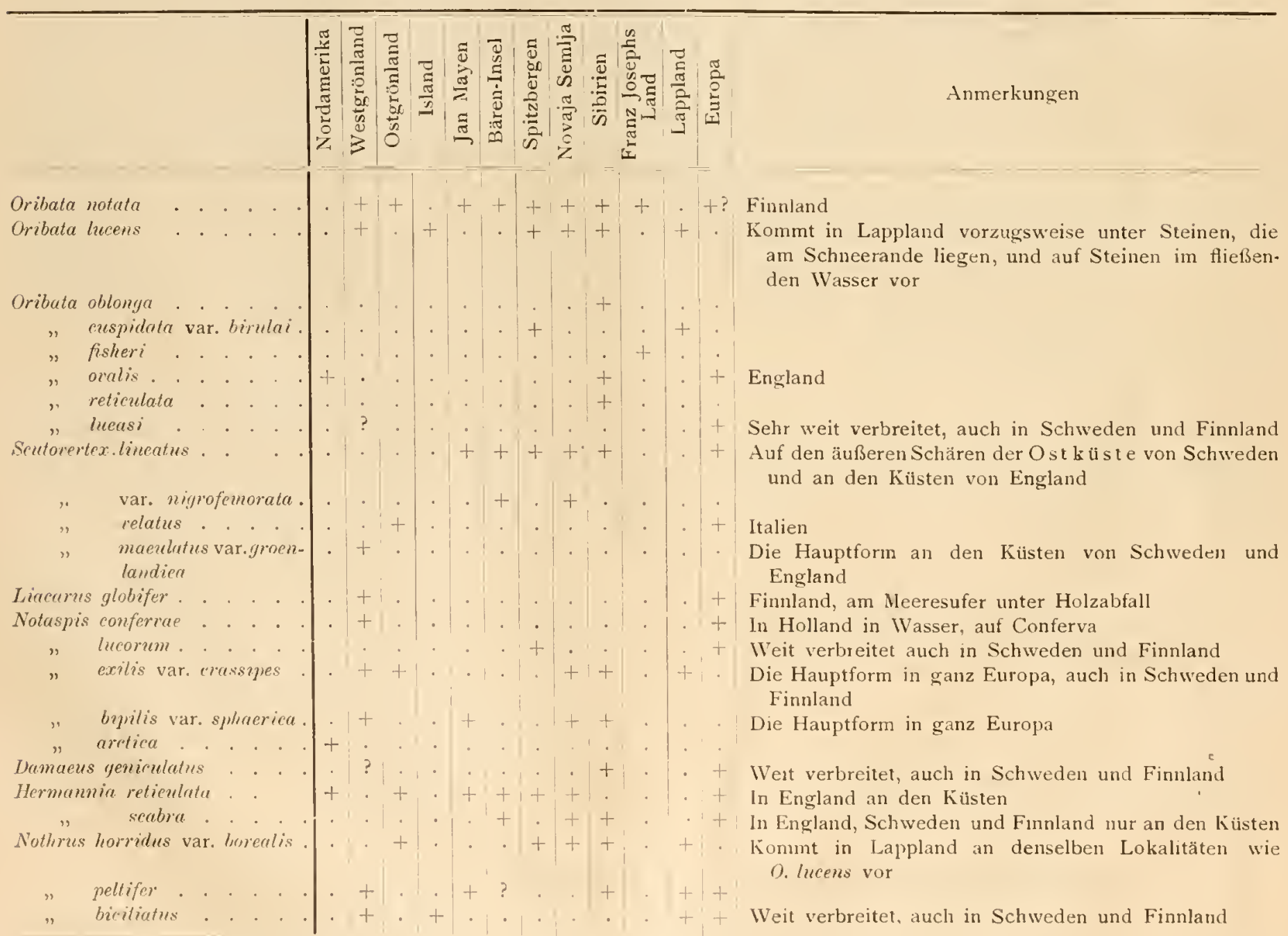

I) Nur bei den Sammlungen, die Dr. J. ARwıssox während Nathorst's Expedition auf Jan Mayen und Ostgrönland machte, ist die Siebungsmethode mit Gewissenhaftigkeit angewendet worden.

2) Unter Hinzurechnung des im system. Teil vergessenen Ixodes sulcatus 97 Arten. Siehe Fußnote p. 7.5 . 
Bemerkenswert ist, daß nur eine einzige Hydrachniden-Art in die arktischen Gegenden einzudringen vermocht hat. Es dürfte dies sowohl auf dem für ihre Entwickelung zu kurzen Sommer wie auf der Abwesenheit geeigneter Wirtstiere für die Larven beruhen.

Ueber die Verbreitung der Ixodiden, Halacariden und Sarcoptiden sind keine Tabellen gegeben, da nichts von Interesse aus solchen zu holen wäre.

Die Oribatiden. Diese können nach ihrem Vorkommen in 4 verschiedene Gruppen eingeteilt werden. Zu der I. Gruppe gehören: Oribata oblonga, O. fisheri und O. reticulata und Notaspis arctica die einzigen, die nur in arktischen Gebieten gefunden sind, und von welchen wir keine deutlich nahe verwandten paläarktischen Formen kennen. Es muß hervorgehoben werden, daß diese an der Nordküste von Sibirien (resp. Nordamerika), also auf einem ungeheuren, in Bezug auf ihre Acaridenfauna röllig (d. h. mit Ausnahme der Nordküste) undurchforschten Gebiete gefunden sind. Wir sind daher gar nicht berechtigt, diese Arten als endemisch arktische Formen anzusehen, denn die Ausbreitung der anderen arktischen Acariden lehrt uns, daß solche überhaupt nicht existieren. Wir können vielmehr mit ziemlich großer Sicherheit erwarten, daß sie weiter nach Süden zu finden sein werden. Zu der 2. Gruppe rechne ich Scutovertex lineatus, S. maculatus var. groenlandica, Liacarus globifer, Hermannia reticulata und H. scabra. Diese sind dadurch gekennzeichnet, daß sie in den arktischen Gebieten eine sehr weite Verbreitung haben, auch auf vereinzelt liegenden Inseln leben und in den paläarktischen Gebieten an den Küsten und auf kleinen Schären vorkommen (siehe die Anmerkung in der Tabelle). So sind Scutovertex lineatus und S. maculatus an 3 verschiedenen Orten auf Schären an der Ostküste von Schweden und außerdem an der Küste von Cornwall in England gefunden. Liacarus globifer ist unter Holzabfall am Meeresufer in Finnland gefunden, Hermannia reticulata kommt an den Küsten von England vor, und $H$. scabra ist sowohl an den Küsten von England wie von Schweden und Finnland gesammelt worden.

Die interessanteste von diesen Formen ist Scutovertex lineatus, welche in den arktischen Gebieten so weit verbreitet ist und überall so ungemein häufig vorkommt, daß man diese Gebiete unziveifelhaft als ihr Verbreitungscentrum ansehen muß. Inwieweit dies auch für die anderen Formen gilt, ist unmöglich zu entscheiden, da sie meistens vereinzelt gefunden sind. Hermannia scabra dürfte jedoch eine ausgesprochen nördliche Form sein, da sie an der Westküste von Schweden in ungeheurer Menge vorkommt.

Dieses Vorkommen von Formen, von denen eine sicherlich ein arktisches Verbreitungscentrum hat, die übrigen wenigstens bis jetzt mehr aus arktischen als aus paläarktischen Gebieten bekannt sind, könnte, da es sich um litorale Arten handelt (d. h. genaue Angaben über die Fundorte liegen nur aus dem palä. arktischen Gebiete vor), nur als eine verbreitungsbiologische Erscheinung aufgefaßt werden. Und das Vorkommen von Bdella littoralis überall an den Küsten und auf den kleinsten Schären der arktischen und paläarktischen Gebiete spricht deutlich für die Annahme, daß diese Art durch das Wasser oder mittels im Wasser treibender Gegenstände verbreitet wird. Für die Annahme, daß auch die Oribatiden durch das Wasser verbreitet werden können, spricht auch das Resultat eines Experimentes, das ich im Sommer I903 in Lappland mit 2 Oribatiden, Oribata lucens und Nothrus horridus var. borealis, ausführte. Diese Arten, diejenigen, welche auf den Hochgebirgen am höchsten in die Schneeregion vordringen und täglich während der Schneeschmelze im Sommer fließendem Wasser ausgesetzt sind, wurden in mit Wasser gefüllten Glastuben aufbewahrt, und es zeigte sich, daß sie, in dieser Weise von Luftzufuhr und Wasser abgesperrt, während 8 Tage gut aushielten. Eine solche Ausdauer muß natürlich eine Verbreitung mit Hilfe des IVassers sehr erleichtern.

Es giebt aber eine Thatsache, welche betveist, daß die Acariden auch andere Verbreitungsmittel haben, nämlich der Fund von Oribatiden auf Vögeln. So ist Oribata Tucens und Nothrus horvidus var. borertis in Grönland auf Lagopus alpinus und Nothrus biciliatus auf Harclda glucialis gefunden worden. Aus diesen Funden 
dürfte man berechtigt sein zu schließen, daß ziemlich oft Oribatiden auf Vögel gehen, und die Möglichkeit ist somit vorhanden, daß sie mittels Vögel große Strecken transportiert werden.

Diesen Gedanken hat WAHLGREN ${ }^{1}$ ) zum ersten Mal ausgesprochen, um die große Verbreitung der Collembolen zu erklären; er stützt sich auf den Fund einiger Collembolen-Arten im Moose von Nestern des Larus glaucus und Larus eburneus.

Wenn das Vorkommen der oben besprochenen Oribatiden auf den Schären sich wenigstens zum Teil in der obigen Weise erklären läßt, so bin ich doch geneigt, für eine der Arten, Scutovertex lineatus, eine andere Hypothese in Anspruch zu nehmen, nämlich daß sje eine arktische Reliktenform ist.

Die Aehnlichkeit in der Zusammensetzung der Fauna und der Flora auf den Schären und in arktischen (und alpinen) Gegenden ist schon von anderen Autoren, wie LEvANDER ${ }^{2}$ ), hervorgehoben worden. LEVANDER bespricht die Fauna der Kleingewässer der Inselfelsen und lenkt die Aufmerksamkeit darauf hin, daß in diesen sich konstant Hydroporus griseostriatus ${ }^{3}$ ) und Coriza carinata vorfinden, Arten, welche sonst nur in den alpinen Gewässern Lapplands und in denjenigen von Mitteleuropa angetroffen sind. LEvaNDER betont, daß dies darauf hinweist, daß die Existenzbedingungen der Wasserorganismen in den stehenden Gewässern auf den Schären der Ostsee und in denen auf den Alpen Centraleuropas und Lapplands sehr ähnlich sind.

Die Verbreitung der Acariden berechtigt uns, den Schluß zu ziehen, daß auch die Existenzbedingungen für die litorale Landfauna sehr ähnlich sind.

Wie sind aber die Acariden und Inseliten auf die Schären gelangt? LEvANDER spricht darüber keine bestimmte Vermutung aus ${ }^{3}$ ). Die Besiedelung läßt sich auf verschiedene WVeise erklären. Entweder ist sie eine spätere Folge der durch die gleichen Existenzbedingungen hervorgerufenen Konvergenz, oder die Tiere sind Reliktenformen, die bei der allmählichen Abschmelzung der Eisdecke und Erhöhung des Landes nach der Eiszeit die kleinen Felseninseln nach und nach entsprechend dem allmählichen Vorrücken der arktischen Fauna und Flora nach Norden in Besitz nahmen. Sie sind nachher bei der allmählich noch zunehmenden Erhöhung des Landes und folgliche Verschiebung der Küste nach Osten immer mehr nach Osten auf die äußersten Schären verbreitet worden.

In dem ersteren Falle muß man ein unbegrenztes Verbreitungsvermögen der Tiere annehmen; in letzterem Falle ist eine solche Annahme nicht notwendig.

Die beiden Erklärungsversuche schließen einander natürlich nicht aus, sondern die Besiedelung kann auch auf beiden Wegen vor sich gegangen sein. In letzterem Falle könnte man aber erwarten, daß die Reliktenformen auch in den alpinen Gegenden z. B. von Lappland gefunden werden würden. Meine Bemühıngen in dieser Hinsicht haben auch im letzten Sommer den Erfolg gehabt, daß ich in den Hochgebirgen von Lappland eine Scutovertex-Form fand, welche dem S. lineutus so sehr nahe steht, daß sie von diesem abzuleiten ist. Dieser Fund beweist natürlich nicht, daß S. lineatus auf den Schären eine Reliktenform ist, er macht es aber viel wahrscheinlicher, als wenn sich herausgestellt hätte, daß keine der auf den Schären gefundenen in arktischen Gegenden heimischen Acariden in dem alpinen Lappland vorkommt.

$\mathrm{Zu}$ der 3. Gruppe rechne ich Oribata lucasi, Scutovertex velatus, Notaspis lucorum, N. confervae, Damaeus gcniculatus, Nothrus pettifer und Nothrus bicitutus, welche weit verbreitete Arten zu sein scheinen und weit nach Süden vorkommen (O. lucusi ist z. B. in Algier gefunden).

1) Beitr. z. Kenntn. d. Collembolafauna a. d. äußeren Schären, Ent. Tidskrift 1899, p. 192.

2) Z. Kenntn. d. Lebens in den stehenden Kleingewässern auf den Schäreninseln, Acta Soc. Fauna Flora fennica, Bd. XVIII, No. 6, 1900 .

3 Daß Il. griseostrialus auch an den Küsten von Schweden in allen permanenten Wasseransanımlungen auf den Schären eine konstante Erscheinung ist, habe ich Gelegenheit gehabt zu konstatieren.

4) In einem anderen Zusammenliang äußert er jedoch (p. 36): „Das konstante Vorkommen gewisser Insektenarten ... erblärt sich durch die allgemeine Verbreitung im fortpflanzungsteifen Stadium." 
Zur 4. Gruppe sind folgende Formen zu stellen: Oribata notata, O. lucens, O. cuspidata var. bimlai, Scutovertex lineatus var. nigrofemorata, Notaspis exilis var. crassipes, N. bipilis var. sphuerica und Nothrus horridus var. borealis. Diese sind weit in arktischen Gebieten verbreitete Formen, welche aber, mit Ausnahme von drei, Notata, S. lineatus var. nigrofemorata und $N$. bipilis var. sphaerica, im arktischen Lappland wiedergefunden sind. Sie stehen (mit Ausnahme von O. lucens) paläarktischen Formen sehr nahe und sind als arktische Varietäten von diesen, die durch die arlitischen Existenzbedingungen hervorgerufen worden sind (siehe S. 70 über die Variation), anzusehen.

Tabelle über die Verbreitung derarktischen Trombidiiden-Arten.

\begin{tabular}{|c|c|c|c|c|c|c|c|c|c|c|c|c|c|c|c|}
\hline & & 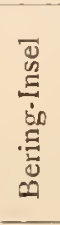 & 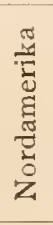 & 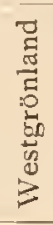 & 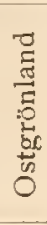 & $\begin{array}{l}\vec{E} \\
\frac{\vec{J}}{n}\end{array}$ & 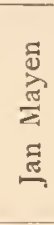 & 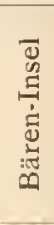 & 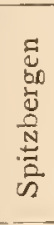 & 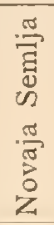 & $\frac{\overline{\vec{v}}}{\overrightarrow{\bar{v}}}$ & 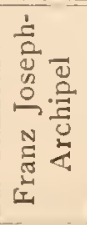 & 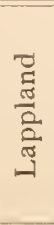 & 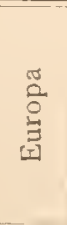 & \\
\hline Chromotydens areticus. . . . . . & . & . & & & & & . & + & . & . & . & . & + & . & \\
\hline Penthalcus haematopus . . . . . & . & . & . & t & + & . & . & . & . & . & & . & & + & \\
\hline " insulamus. . . . . . & . . & . & . & . & + & . & + & + & . & + & + & . & . & . & \\
\hline Rhagidia gelida. . . , . . . . . & . . & . & & + & & + & + & + & + & + & + & + & + & . & \\
\hline Bdclla littoralis . . . . . . . . & . & + & + & + & + & + & + & + & + & + & + & & & + & \\
\hline " capillata var. pallipes . . . . . & . . & . & . & . & & . & . & . & . & + & + & & & . & \\
\hline "vulgaris var. dccipiens . . ., . & . . & + & . & + & . & . & + & . & + & + & + & & + & & \\
\hline "groenlandica . . . . . . & . . & . & . & + & . & . & . & . & . & . & . & . & . & & \\
\hline longirostris . . . . . . & . . & + & . & . & . & . & . & . & . & . & . & . & + & + & \\
\hline Cyta latirostris var. urevirostris . . . . & . . & . & & . & + & . & + & t & . & + & + & . & . & . & \\
\hline Bryobia matiosa . . . . . . . . . & . . & . & . & . & + & . & . & + & . & + & + & . & + & + & \\
\hline Anystis baccurum . . . . . & . . & . & . & + & . & . & . & . & . & . & + & . & . & + & \\
\hline Eirythracarus harmsworthi . . . . . & . . & . & . & . & . & . & . & . & . & . & ? & + & . & ? & Norwegen? \\
\hline 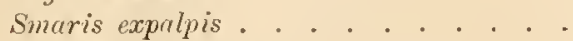 & . . & . & . & . & . & . & . & . & . & . & + & & . & + & \\
\hline Trombidinum bicolor var. curtipalpe . . . & . . & . & . & + & + & . & . & . & . & . & + & 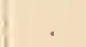 & + & & \\
\hline 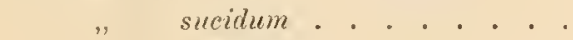 & . & . & + & + & . & . & . & . & . & . & t & . & t & . & \\
\hline Erythraens miniatus . . . . . . . . & . & . & . & + & + & . & . & . & . & . & + & . & & $\dot{.}$ & \\
\hline " unidentatus . . . . . . . & . & . & . & + & . & . & . & . & . & . & . & . & . & . & \\
\hline rerter . . . . . . & . & . & . & + & & . & . & . & . & . & + & . & . & + & \\
\hline elongatus . . . . . . . . & & + & . & . & . & . & . & . & . & . & & . & & & \\
\hline phalangioides. . . . . . &. & . & . & + & & . & . & . & . & . & . & . & . & . & \\
\hline phalangiondes var. gracilipes. & . . & 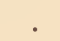 & . & + & + & & . & . & & . & . & . & + & . & \\
\hline regalis . . . . . . . & 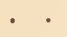 & • & . & . & & . & - & . & & & + & & & + & \\
\hline
\end{tabular}

Die Trombidiiden. Aus der beigefügten Tabelle geht hervor, daß keine endemischen Arten der Trombidiiden ${ }^{1}$ ) in den arktischen Gebieten vorkommen. 3 Arten, Erythraeus harmsworthi, Enythraens unidentatus und Bdella groenlandica, sind freilich noch nicht in subarktischen Gebieten gefunden; erstere ist aber wahrscheinlich mit einer in Norwegen gefundenen, nicht beschriebenen Art identisch und die andere wird sich vermutlich als $q$ von $E$. miniatus entpuppen. B. groenlandica, welche im arktischen Gebiet nur auf Grönland vorkommt, dürfte vom nördlichen Amerika eingewandert sein, und kommt vermutlich weiter nach Süden in der neuen Welt vor. Sie ist, wie schon hervorgehoben ist, mit der aus Südfeuerland beschriebenen B. symmetrica am nächsten verwandt.

Weiterhin ist hervorzuheben, daß gerade die Art, welche eine litorale Lebensweise führt, nämlich Bdella littoralis, sich der größten Verbreitung erfreut, was mit dem bei den Oribatiden gemachten Befunde übereinstimmt.

Eine sehr auffallende Erscheinung ist, daß sowohl die Gattung Trombidium wie Erythrceus auf den isoliert liegenden Inseln, wie der Bären-Insel, Jan Mayen u. a., vollkommen fehlen und nur auf Grönland und in Sibirien vorkommen. Es kann dies wohl kaum darauf beruhen, daß gerade diese Gattungen das schlechteste 
Verbreitungsvermögen besitzen sollen, sondern hängt gewiß mit dem Umstand zusammen, daß sie für ihre Entwickelung Insekten, vor allem Fliegen, als Wirtstiere brauchen, und da diese auf den isolierten Inseln nur sehr spärlich vorkommen, können die Trombidiinen und Erythräinen dort nicht die notwendigen Daseinsbedingungen finden.

Tabelle über die Verbreitung der arktischen Parasitiden-Arten.

\begin{tabular}{|c|c|c|c|c|c|c|c|c|c|c|c|c|c|c|}
\hline & 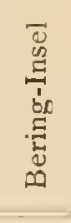 & $\begin{array}{l}\frac{\pi}{\pi} \\
\frac{\pi}{\pi} \\
\frac{\pi}{4}\end{array}$ & 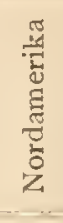 & 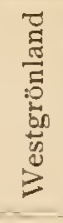 & 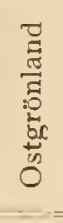 & 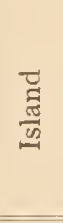 & 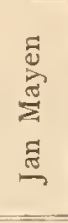 & 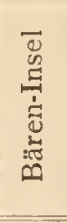 & 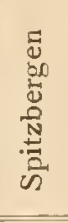 & 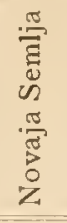 & 苞 & 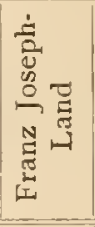 & 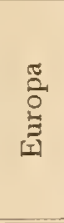 & \\
\hline 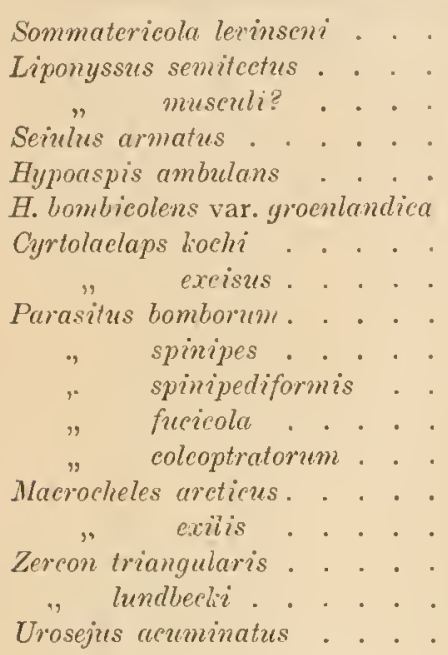 & $\begin{array}{l} \\
\vdots \\
\vdots \\
\dot{t} \\
\dot{0}\end{array}$ & + & i. & $\begin{array}{l}+ \\
+ \\
+ \\
+ \\
+ \\
+ \\
+\end{array}$ & $\begin{array}{l}+ \\
\dot{ } \\
+ \\
+\end{array}$ & $\begin{array}{l}+ \\
: \\
: \\
: \\
:\end{array}$ & $\begin{array}{l}. \\
. \\
. \\
.\end{array}$ & $\dot{0}$ & i. & $\begin{array}{l}+ \\
+ \\
\dot{ } \\
+ \\
+ \\
\dot{+} \\
\dot{ } \\
\dot{ }\end{array}$ & $\begin{array}{l}+ \\
+ \\
. \\
+ \\
+ \\
+ \\
+ \\
. \\
+ \\
. \\
+ \\
+ \\
\dot{.} \\
.\end{array}$ & . & $\begin{array}{l}+ \\
+ \\
+ \\
? \\
+ \\
\dot{+} \\
\dot{+} \\
+ \\
+\end{array}$ & Norwegen \\
\hline
\end{tabular}

Die Parasitiden. Aus der beigefügten Tabelle ist ersichtlich, daß die große Mehrzahl der Parasitiden, wie die Erythräinen und Trombidiinen, nur auf Grönland und in Sibirien vorkommen. Was die A bwesenheit von Liponyssus semitectus und L. musculi, Hypoaspis bombicolens var. groenlandica u. a. auf den Inseln betrifft, so beruht dies auf demselben Umstand wie die Abwesenheit der Erythräinen und Trombidiinen, nämlich auf dem Nichtvorhandensein ihrer resp. Wirtstiere. Betreffs der übrigen muß man wohl annehmen, daß sie ein geringeres Verbreitungsvermögen als die Trombidiiden und Oribatiden haben.

\section{Ueber Cirkumpolarität und Bipolarität.}

Infolge der ungenügenden Kenntnis der Acaridenfauna des arktischen Amerika ist es noch unmöglich, uns ein befriedigendes Bild von der Verbreitung der arktischen Acaridenfauna zu verschaffen. So viel wissen wir jedoch schon, daß es mehrere Arten giebt, welche cirkumpolar sind, nämlich Bdella littoralis, B. vulgaris var. decipiens, Trombidium sucidum und vermutlich auch Oribata ovalis und Hermamia reticulata. Weitere Untersuchungen werden gewiß die Zahl der cirkumpolaren Acariden bedeutend steigern.

Von der antarktischen Acaridenfauna wissen wir so gut wie gar nichts. Aus Kerguelen wurden von CAMBridge $^{1}$ ) 2 Acariden beschrieben, Timynophlora serrata und Poecilopllysis kerguelensis. Erstere ist eine Bryobia-Art, letztere eine Rhagilia-Art. Sie gehören also weit verbreiteten Gattungen an. Ob die Bryobia-Art wie ich früher vermutete ${ }^{2}$ ) und wie L. $\mathrm{KoCH}^{3}$ ) annahm, mit der arktischen Bryobia-Art, welche sich seitdem als mit der paläarktischen identisch erwiesen hat, zusammenfällt, müssen künftige Untersuchungen klarlegen.

Außerdem ist von MıCHAEL ${ }^{4}$ ) aus Süd-Georgien eine Oribatide, Oribata antarctica, beschrieben.

I) Proc. Zool. Soc. London, 1876.

2) 1900, p. 20.

3) 1. c. p. 134 .

4) Mitteil. Mus. Hamburg, Vol. XII, p. 7I, Textfig. 
Wenn wir hinzufügen, daß E. RacovitzA 1) für Kerguelen „3 oder 4 Arten kleiner Acariden“ angiebt, so haben wir alles, was bis jetzt von der antarktischen Acaridenfauna bekannt ist, erwähnt.

In einer neuerdings erschienenen Arbeit ${ }^{2}$ ) hat Trouessart aus der Antarktis diese 4 Acariden beschrieben: Smaridia scopula, Rhagidia (Nömeria) giges subsp. gerluchei, Chromotydeus (Penthatens) villosus und Parasitus (Gamasus) Racovitzai. Da meine Vermutung, daß $R$. gelida nur eine Form von $R$. gigas sei, sich durch Untersuchung des Materiales letzterer Art, daß ich aus Aegypten besitze, als richtig erwiesen hat, ist somit der Arktis und der Antarktis eine Art gemeinsam. Sehr auffallend ist die angebliche Abwesenheit der Bdella-Arten in der Antarktis.

Da nach Neumann Ixodes putus und I. Worealis identisch sind, sind also zwei Acariden der Arktis und der Antarktis gemeinsam.

\section{Litteraturverzeichnis.}

(Hier ist uur die Litteratur der arktischen Acariden aufgenommen.)

1770 Fabricios, O., Fauna groenlandica.

1786 Монв, N., Forsog til en Islandsk Naturhistorie, Kjobenhavn.

1824 Gliemand, TH., Geographische Beschreibung von Island, Altona.

1852 Suthertand, P. S., Journal of a voyage in Baffin's-Bay and Barrow Straits in the years, 1850-1851, London.

1871 Tновеці, 'T., Om Arachnider från Spetsbergen och Beeren-Eiland. Öfvers. Kongl. Svenska Vet.-Akad. Handl., No. 6. 1872 Derselbe, Om naigra Arachnider från Gröuland, Ebenda, No. 6.

1877/79 M'Lachlax, R., Report on the Insecta (including Arachnida) collected by Capt. Feilden and Mr. HaRT between the Parallels of $78^{\circ}$ and $83^{\circ}$ Latitude, during the recent Arctic Expedition. Journal of Linnean Society, Vol. XIV.

1878 Koch, L., Arachniden aus Sibirien und Novaja Semlja. Kongl. Svenska Vet.-Akad. Handl., Bd. XVI.

1882 vол Woнцемuтн, Die österreichische Polarstation Jan Mayen. Beobachtungsergebnisse, Bd. III.

1883 Kramer, P., und Neunann, C., Acariden während der "Vega"-Expedition eingesammelt. "Vega"-Exp. Vetensk. Jakttagelser, Bd. III, Stockholm.

1894 Trodtssart, E., Note sur une grande espèce de Bdelle maritime originaire d'Island. Journal de l'Anatomie et de la Physiologie, T. XXX.

1894 Trouessart, E., Note sur les Acariens recueillis au Spitzberg pendant le voyage de la Manche. Nouvelles Archives des Missions scientifiques et littéraires, T. V.

1895 Trodessart, E., Revision des Acariens arctiques. Soc. Nat. des Sciences nat. et math. de Cherbourg, T. XXIX.

1897 Oddemans, A. C., und Koenike, F., Acari collected during the Willem Barents-Expedition of 1881 and 1882. Tijdschrift, vorr Entomologie, Bd. XL.

1897 Mrсhaed, A. D., Report on the Acari by collected Mr. Fisher, Naturalist of the Jackson-Halmswonth Expedition at Cape Flora, Northbrook Island, Franz Joseph-Archipelago, in 1896. Journal of the Linn. Society, Vol. XXVI, No. 168.

1897 Kramer, P., Grönländische Milben. Bibliotheca Zoologica, Heft 20, Lief. 3.

1899 Banks, N., Report upon the Insects, Spiders, Mites and Myriapods collected by Dr. L. Strejnegger and Mr. G. E. H. Barrett-Hamiton on the Commander Islands. Extr. from the Fur Seals and Fur Seal Islands of the north Pacific Ocean, Pt. IV.

1900 TrägÅRDh, J., Die Acariden der Bären-Insel. Kongl. Svenska Vet.-Akad. Handl., Bihang, Bd. XIVI, Afd. 4, No. 7.

1900 Banks, N., Papers from the Harriman Alaska Expedition, XI. Entomological Results (5), Proceed. Washington Acad. of Science, Vol. II.

1901 TrägånDr, J., Revision der von Thorell aus Grönland, Spitzbergen und der Bären-Insel und von L. KocH aus Sibirien und Novaja Semlja beschriebenen Acariden. Vorl. Mitteilung. Zool. Anzeiger, Bd. XYV, No. 660.

1902 Derselbe, Zur Kenntnis der litoralen Arten der Gattung Bdella Latr. Kongl. Srenska Vet.-Akad. Handl., Bihang, Bd. XxviI, Afd. 4, No. 9.

1902 Derselbe, Beiträge zur Kenntnis der schwedischen Acaridenfauna, I. Lappländische Trombididen und Oribatiden. Ebenda, Bd. XXYIII, Afd. 4, No. 5.

1902 Kulczynsk1, V., Zoologische Ergebnisse der russischen Expeditionen nach Spitzbergeu. Anu. du Mrnsée de l'Acad. Impériale des Sciences de St. Pétersbourg, T. VII, No. 3.

I) Die erste Südpolarnacht von F. A. Cook, p. 369.

2) Resultats d. Voyage d. S. Y Belgica $1897-1899$ Rapports scientifiques. Acariens. 


\section{Inhaltsverzeichnis.}

Einleitung . . . . . . . . . . . . . . . . . . . . . . . . . . . . .

Historisches . . . . . . . . . . . . . . . . . . . . . 6

Systematischer Teil . . . . . . . . . . . . . . . . . . . . . . . . II

Oribatidae . . . . . . . . . . . . . . . . . . . I I

Parasitidae . . . . . . . . . . . . . . . . . . . 28

Trombididae . . . . . . . . . . . . . . . . . . . . . . . . . $4 \mathrm{I}$

Hydrachnidae . . . . . . . . . . . . . . . . . . . . 62

Halacaridae . . . . . . . . . . . . . . . . . . . . . . . 63

Ixodidae . . . . . . . . . . . . . . . . . . . . . . . . . . . 63

Sarcoptidae . . . . . . . . . . . . . . . . . . . . . 64

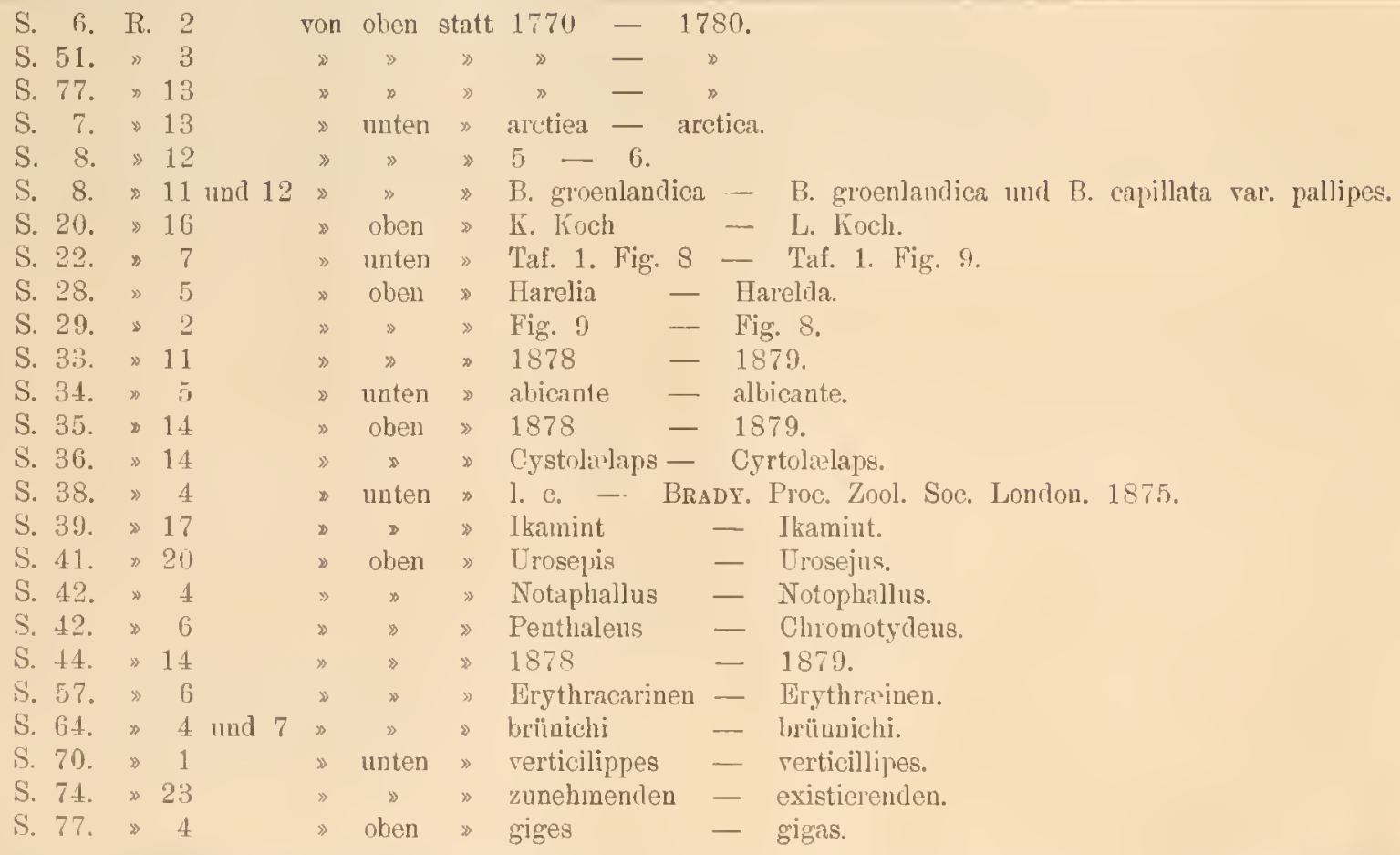


Tafel I. 


\section{Tafel I.}

Fig. I. Sommatericola levinseni n. g. n. sp. f.

"2. Sejulus armatus (L. KocH).

"3. Sommatericola levinseni ठ.

"4. Scutovertex lineatus var. nigrofemorata. Die Leisten auf dem Rücken sind in Punkte aufgelöst.

"5. Scutovertex lineatus var. nigrofemorata. Ein Teil der Leisten ist reduziert.

"6. Scutovertex lineatus var. nigrofemorata. Nur 2-3 Leisten sind jederseits noch vorhanden.

"7. Scutovertex maculatus var. groenlandica.

8. Rückenschild von Sommatericola levinseni.

" 9. Notaspis confervae (Schrank) OUdms. 

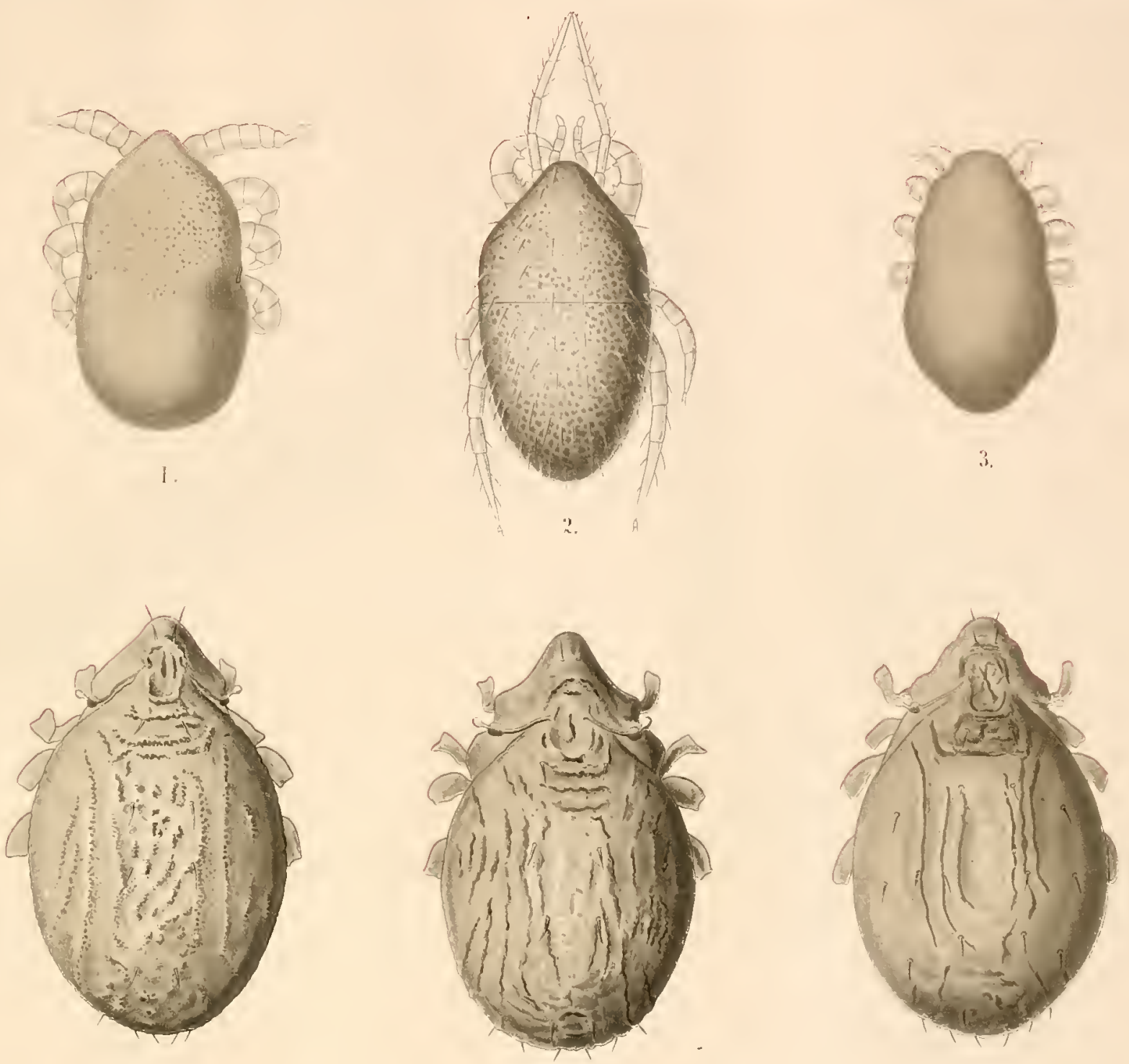

$$
5
$$
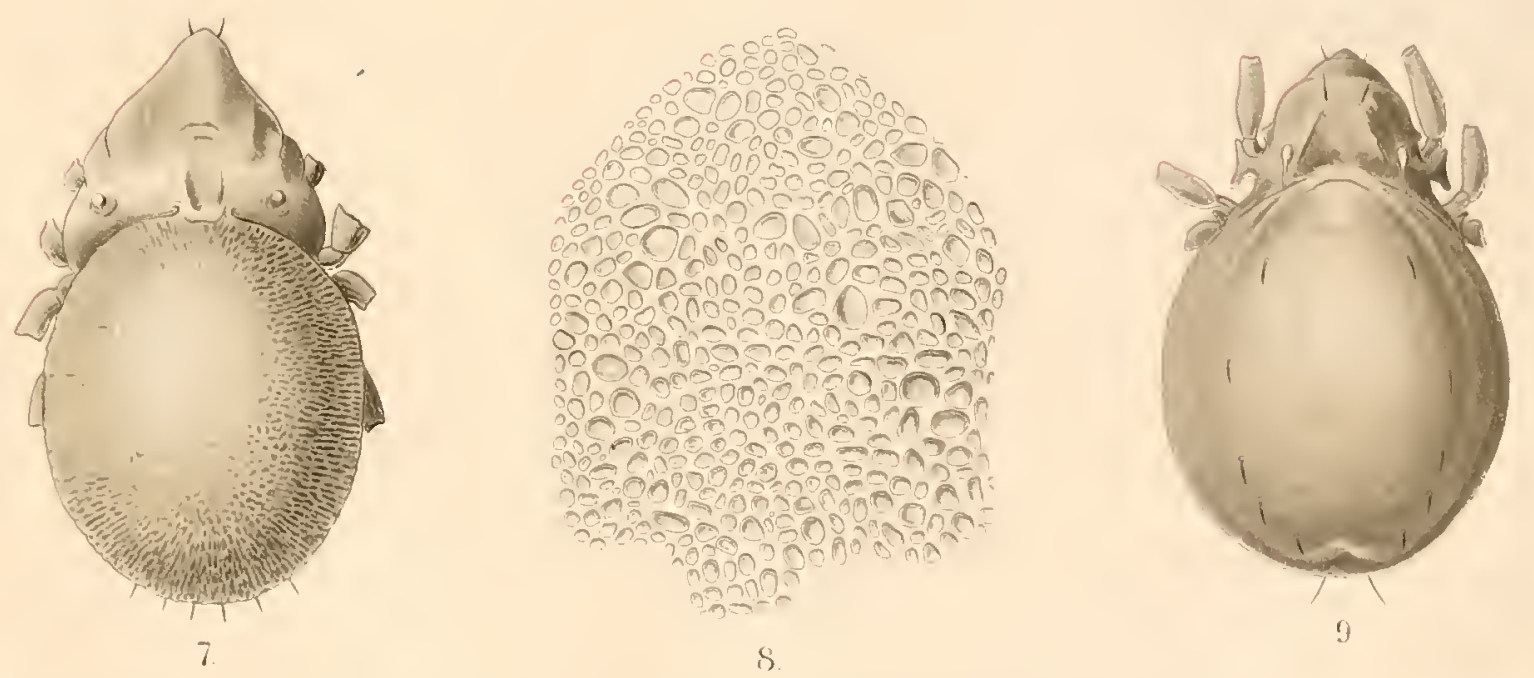








\section{dic} cer

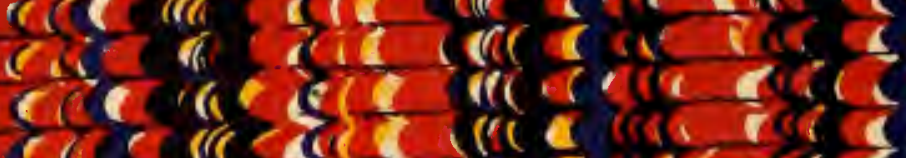

$$
\begin{aligned}
& 5 \text {. }
\end{aligned}
$$
is $\cos$ है

acsa 
